\title{
Where to Belong and Why? \\ Sri Lankan immigrants' perceptions of Australian, New Zealand and Sri Lankan citizenship
}

\author{
By \\ Kahandawa Pathirannehelage Pavithra Udari Jayawardena
}

\begin{abstract}
A thesis
submitted to Victoria University of Wellington in fulfilment of the requirements for the degree of

Doctor of Philosophy
\end{abstract}

Victoria University of Wellington

2021 


\section{Dedication}

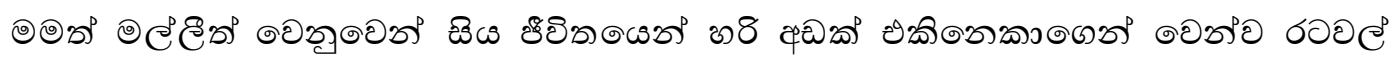

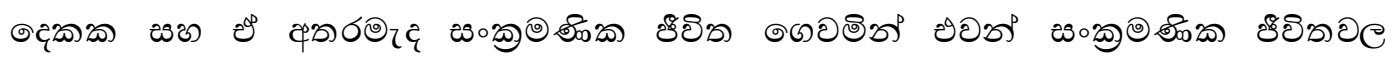

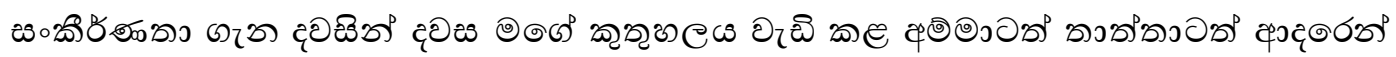

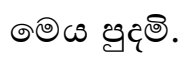

I dedicate this thesis to my parents who, to ensure a better life for my brother and me, spent half of their lives apart from one another in two different countries and in the process kindled my interest in exploring the complexities of migrants' lives. 


\begin{abstract}
Migration from developing to developed countries has led to the naturalisation of millions of immigrants in their new destinations. Meanwhile, the trend of relaxing dual citizenship policies by many states has offered immigrants the option of retaining their home country citizenship as well as obtaining citizenship in their new country. Thus, legally, immigrants whose home and adoptive country both allow dual citizenship, can continue to be citizens in both countries at the same time, although such multiple attachments challenge the traditional meaning of belonging of a citizen: that one citizen can belong to one country only. In this thesis, I analyse the meaning immigrants ascribe to citizenship when they are legal members of two states. In particular, I am interested in understanding the factors that lead emigrants/immigrants to see their home and host country citizenship in terms of the material benefits they provide, and those that lead them to see citizenship as an expression of loyalty and belonging. I do this by exploring the similarities and differences in the way Sri Lankan immigrants give meaning to their adoptive (Australian or New Zealand) citizenship as opposed to their home (Sri Lankan) citizenship.
\end{abstract}

To explore Sri Lankan immigrants' views, this study employs a qualitative methodology. I collected data through forty-nine semi-structured interviews with first-generation Sri Lankan immigrants in Melbourne, Sydney, Auckland and Wellington, and used thematic analysis to interpret my data. I found that my participants give different meanings to their Sri Lankan, Australian, and New Zealand citizenship. In terms of the adoptive country citizenship, participants' instrumental and patriotic views were intertwined. My findings show that Sri Lankan immigrants' loyalty and sense of belonging to Australian or New Zealand society has developed on top of their positive thoughts about achieving socioeconomic or political migratory expectations. In contrast, participants viewed the patriotic spirit and the instrumentalist value of home country citizenship separately, and the strength of their feeling about loy alty and belonging was not affected by the 
material aspects of citizenship. Based on these findings, I highlight the need to understand immigrants' perceptions of citizenship differently than those of native citizens. I argue that assumptions, such as only good immigrants can belong and be loyal to the host society in isolation to their materialistic interests of citizenship, are highly misleading and result in ineffective policy decisions.

The findings also show that home country factors that affect the way my participants see citizenship vary across ethnic lines. While the way Sinhalese participants perceive their Sri Lankan and Australian or New Zealand citizenship are more affected by socio-economic factors, Tamil participants' views are mostly influenced by political factors, due to the ethnic suppression they faced in Sri Lanka. Thus, I conclude that migration scholarship should acknowledge heterogeneity within immigrant communities and migrants' unique, individual, experiences, and subjective realities. 


\section{Acknowledgements}

During the journey of completing this doctoral thesis, I have incurred many intellectual and personal debts. I am immensely grateful to all those who supported me; for their suggestions, guidance, tolerance and above all their constant confidence in me.

This thesis would not have been possible without the support and guidance by my primary supervisor, Associate Professor Kate McMillan. I thank you for guiding me to improve my intellectual capabilities as well as helping me to be on the right track despite all the personal challenges I faced. I also thank Dr. Ayca Arkilic, not only for being a very attentive secondary supervisor, but also for being a sincere friend.

There are always numerous ups and downs, in both academic and personal lives, along one's doctoral journey. My fellow PhD students in Victoria University of Wellington played an essential role in helping me face some of those challenges; thus they deserve a special mention here: Chiara - thanks for the true friendship; Samuele - thanks for your advice; Meera - thanks for the emotional support throughout; Kaitlin - thanks for your caring; Chris - thanks for believing in me, reminding me of my priorities, and helping me to find my true potential; and Luna (Ge Lei) - thanks for making you and me a team. I also thank all the administrative support received from Victoria University of Wellington in completing this thesis as well as Dr. Caroline Bennette for copy editing the thesis. I cannot forget my support team, outside the university, who played an important role in my doctoral journey. Manori akka, Steve, Sachi, Lahiru, Kasun, Bimali, Shamini, Anoja Aunty and Chanaka Uncle; you all helped me to complete this thesis in numerous ways you couldn't possibly know. Thanks for being my Wellington family and making me feel comfortable.

Sincere gratitude also goes to Senior Professor Nayani Melegoda, who is my longterm mentor. Thank you for always being my rock, through thick and thin. From 
writing several academic recommendation letters for me, to listening to my reflections about life, I appreciate each and everything you have done for me. I also thank Dr. Maneesha Wanasignhe-Pasqual for all the academic, administrative, and personal support offered to me. I am also very grateful for all my colleagues at the Department of International Relations, University of Colombo, Sri Lanka, for stimulating my intellectual curiosity. Waradas deserves a special mention. Wara, this thesis would not be possible without your constant encouragement. Also, thank you Professor Jayadeva Uyangoda for your generous input, specifically during the first stages of this research.

I would like to sincerely acknowledge the NCAS (National Centre for Advanced Studies in Humanities and Social Sciences, Sri Lanka) scholarship that made this research possible. I thank the University of Colombo for granting me paid leave throughout my PhD period. Because of these generous grants, I could focus on my research work with a relaxed mind.

A special thanks is deserved by all my fieldwork participants who let me explore their migrant lives. Thank you for sharing your life stories, your thoughts and experiences with me. I appreciate the trust you all placed in me. Thank you to Pavithra, Isuri, Wasana, Chamani and Maduhari for being lifetime friends. You might not know that you were a part of this thesis, but you were. Thank you for encouraging me to get over my lows. Thank you also to Pathum Fernando, for helping me to be stable during the last three years. Completion of this thesis would have been delayed without you.

Last but not least, my family deserves huge appreciation. The completion of any doctoral thesis needs years of patience and focus. My husband provided me with much practical support, enabling me to focus on my research. Supun, you had to make many changes in your life, as well as taking some bold career-related decisions because of my doctoral studies and, for that, I am forever grateful to you. As always, I appreciate your flexibility, openness, and understanding. I thank my darling daughter Sukhi, who was two years old when I started the $\mathrm{PhD}$ and had to adapt to a variety of changes because of my studies. Thank you for being the happy 
child you always are and for understanding that your mother is doing something serious, called a PhD! I thank Thercie Hettiarachchi, my mother-in-law, as well as all the other family members of my husband's family, for unconditionally taking care of Sukhi whenever necessary. Without this practical help, the completion of this thesis would be far away.

The primary motivation for this research was from my father, Sarath Jayawardena (Thaththa). Being a Sri Lankan immigrant himself for nearly 30 years (living in Italy), he was the individual who constantly stimulated my curiosity about the way Sri Lankan immigrants negotiate their sense of belonging as citizens between host and home countries. Thaththa, you never failed to impress and surprise me about immigrants' thoughts. Thank you for being the silent motivator for this entire project. I also thank my only brother Ishanka Jayawardena (Malli), for everything you did and said to keep me stable throughout the last three years. A very special thanks is to my wonder woman, the strongest and the kindest woman I have ever known, my mother, Ramani Wickramasinghe (Amma). If I am to name only one individual who has given me energy throughout the last three years, undoubtedly it is you. Thank you for always standing with me Amma. The most fortunate thing that ever happened to me was being born as your daughter.

Much love to you all. Thank you. 


\section{Table of contents}

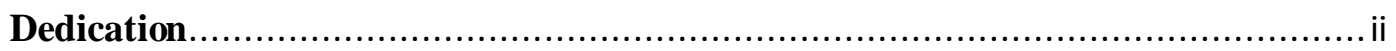

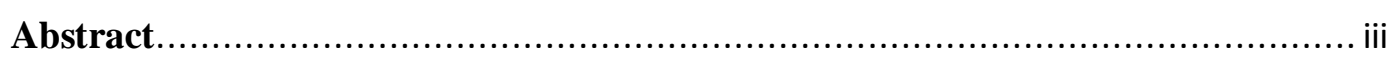

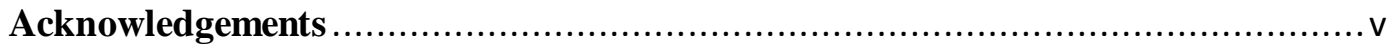

Table of contents ............................................................................

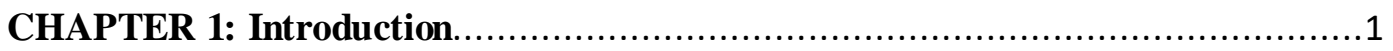

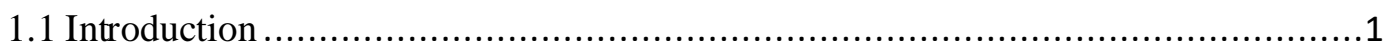

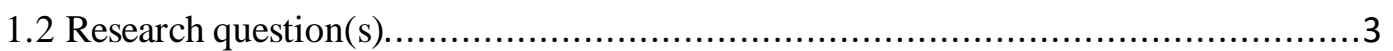

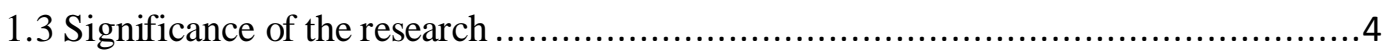

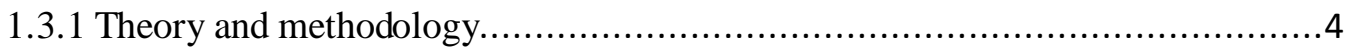

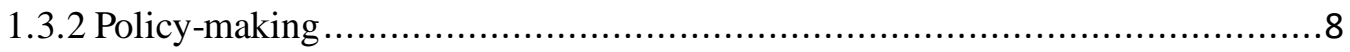

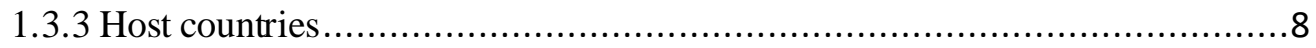

1.3.4 Home countries............................................................. 10

1.4 Limitations and clarifications ................................................................ 11

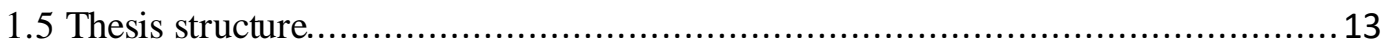

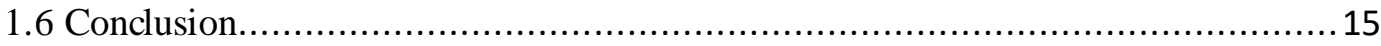

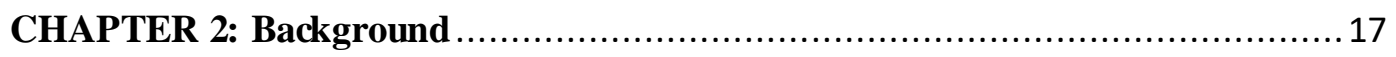

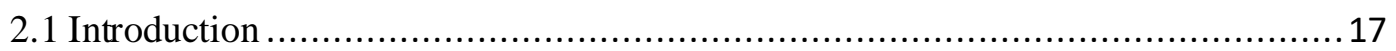

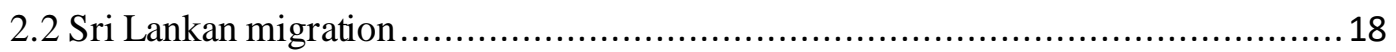

2.2.1 Sri Lanka's citizenship policy for Sri Lankan emigrants..........................23

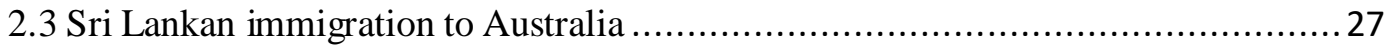

2.3.1 Australian immigration and citizenship policies for immigrants....................28

2.4 Sri Lankan immigration to New Zealand...................................................... 33

2.4.1 New Zealand immigration and citizenship policies for immigrants..................33

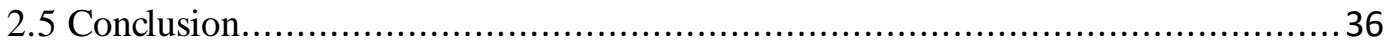

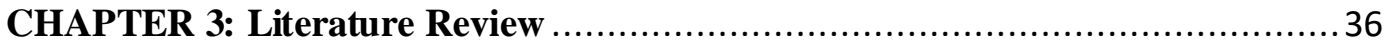

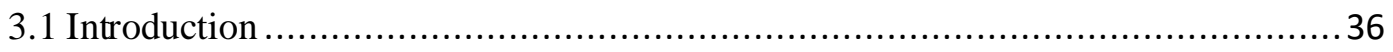

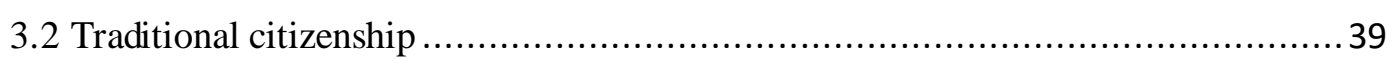

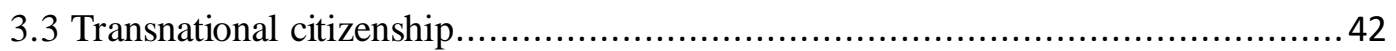

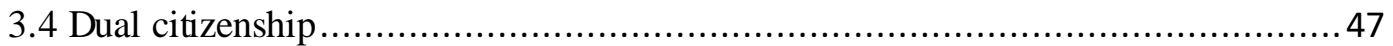

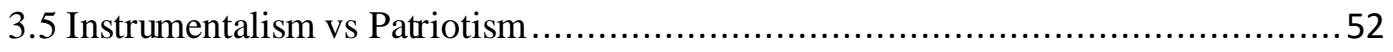

3.6 Explaining instrumental and patriotic perceptions.....................................5 57

3.6.1 The socio-economic determinants model ............................................58 
3.6.2 The non socio-economic determinants model

3.6.3 Mixing both socio-economic and non socio-economic determinants..............67

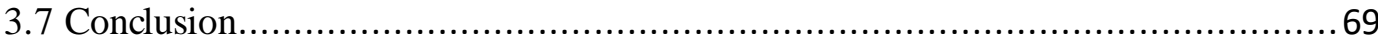

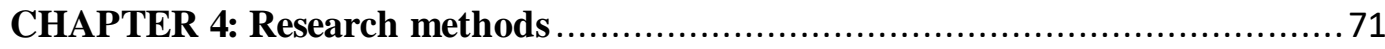

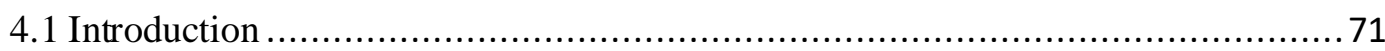

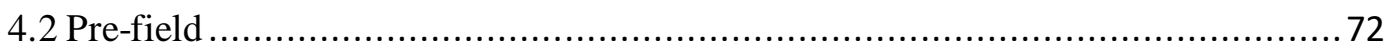

4.2.1 Semi-structured questions........................................................ 74

4.2.2 Sampling and participant recruitment ................................................ 75

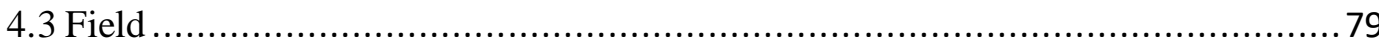

4.3.1 Interviewing, protocols, choices and lengths......................................... 81

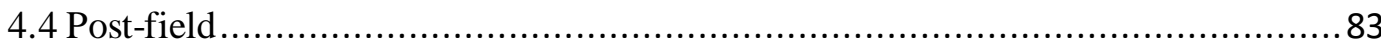

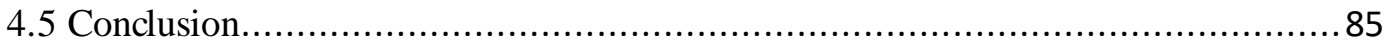

CHAPTER 5: Sri Lankan immigrants' instrumental perceptions about the host

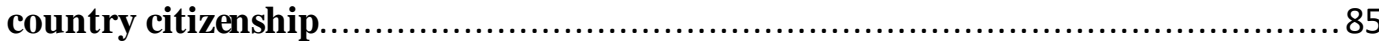

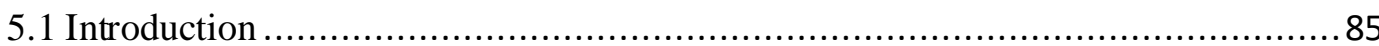

5.2 Instrumental perceptions based on socio-economic reasons........................ 87

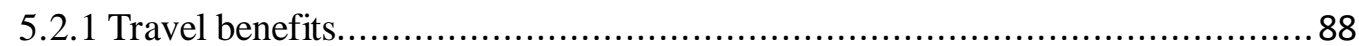

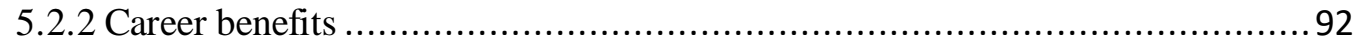

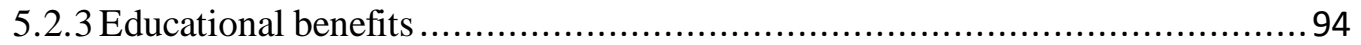

5.3 Instrumental perceptions based on political factors ......................................97

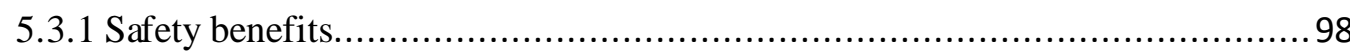

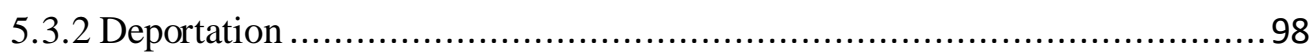

5.3.3 Protection from consular services while abroad....................................99

5.3.5 Protection from racism and anti-immigrant sentiment in the host society.... 103

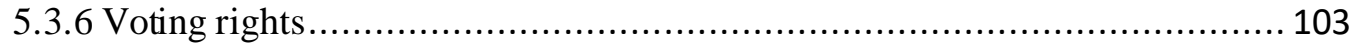

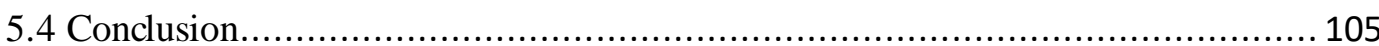

CHAPTER 6: Sri Lankan immigrants' patriotic perceptions about the adoptive

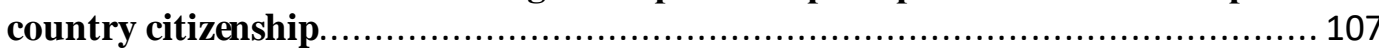

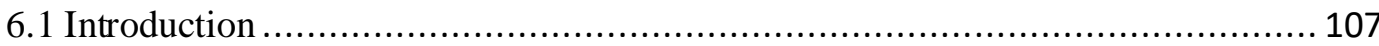

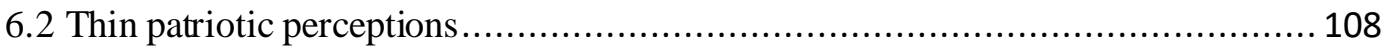

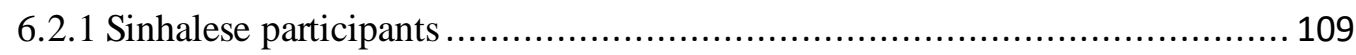

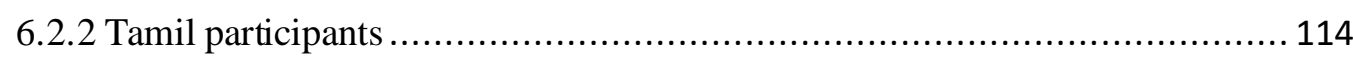

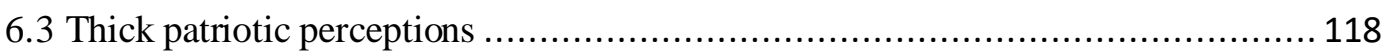

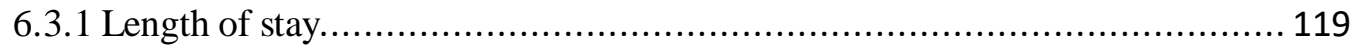

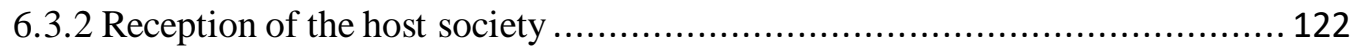

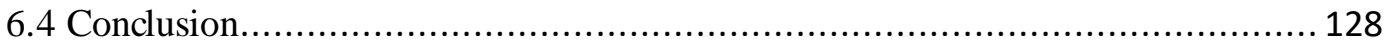


CHAPTER 7: Sri Lankan immigrants' instrumental and patriotic perceptions about

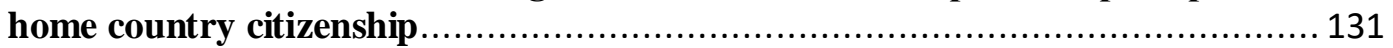

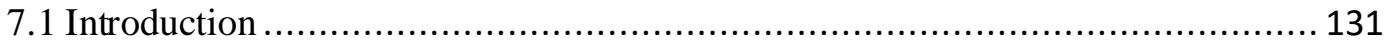

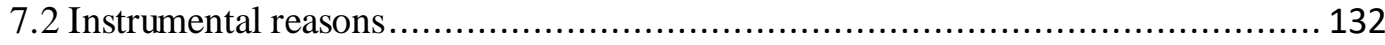

7.2.1 Direct instrumental reasons .............................................................. 133

7.2.2 Indirect instrumental reasons ......................................................... 134

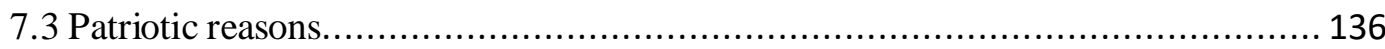

7.3.1 Sinhalese participants .......................................................... 137

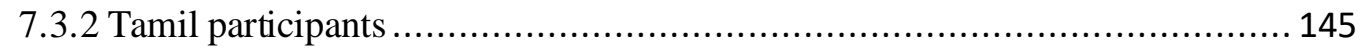

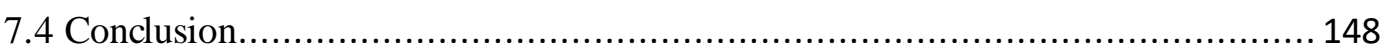

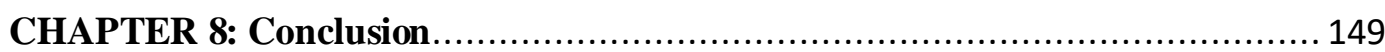

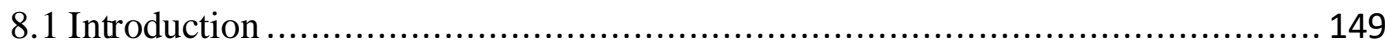

8.2 The limitations of the reversibility hypothesis......................................... 151

8.3 Participants' instrumental perceptions towards the host country citizenship have a causal effect on their patriotic perceptions................................................ 153

8.4 Participants' instrumental and patriotic views towards home country citizenship are

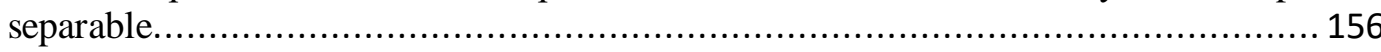

8.5 Potential avanues for future research...................................................... 160

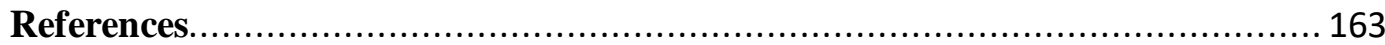

Appendix A: List of participants........................................................ 193

Appendix B: Participant information sheet............................................... 200

Appendix C: Participant consent form ..................................................... 202

Appendix D: Sample interview questions............................................... 203 


\section{CHAPTER 1: Introduction}

\subsection{Introduction}

Migration from developing to developed countries has led to the naturalisation of millions of immigrants in their new destinations. Meanwhile, the trend of relaxing dual citizenship policies by many states has offered immigrants the option of retaining their home country citizenship as well gaining citizenship in their new country of residence. Thus, legally, immigrants whose home and adoptive country both allow dual citizen ship, can continue to be citizens in both countries at the same time. Such multiple attachments, however, challenge the traditional meaning of belonging of a citizen: that one citizen can belong to only one country. In this thesis, I analyse the meaning immigrants ascribe to citizenship when they are legal members of two states. In particular, I am interested in understanding the factors that lead emigrants/immigrants to see their home and host country citizenship in terms of the material benefits they provide, and those that lead them to see citizenship as an expression of loyalty and belonging. I do this by exploring the similarities and differences in the way Sri Lankan immigrants give meaning to their adoptive (Australian or New Zealand) citizenship as opposed to their home (Sri Lankan) citizenship.

Immigrants' belonging and loyalty to a society as citizens is challenging at both theoretical and policy levels. On the one hand, the concept of citizenship has been widely explored, but is still not adequately understood in the context of migration. Citizenship is traditionally understood within nation-state borders where one citizen belongs to one state. However, with the increase of migration, theories such as transnational citizen ship suggest that understandings of citizenship based on nationstate has failed to recognise the complex relationships created when people have multiple belongings with two or more states. In brief, we still lack academic knowledge about how immigrants' meanings of citizenship affect their different attachments with host and home countries. 
Immigrants' sense of belonging and loyalty to a society as naturalised and dual citizens remains a heated political topic in both host and home countries. Some scholars argue that many citizenship policies are failing because they focus only on native citizens' interests, perceptions, and feelings (Fleras \& Spoonley, 1999), thereby neglecting immigrants' experiences and views (Leitner \& Ehrkamp, 2006). In this thesis, I study immigrants' perceptions of their adoptive and home country citizenship in order to address these academic and policy gaps.

Perceptions are the driving forces behind any person's actions, decisions, or behaviours (Bartley \& Spoonley, 2008); therefore, exploring perceptions increases the ability to understand and predict immigrants' actions, decisions, and behaviours in relation to host and home country citizenship. Through exploring immigrants' perceptions, this thesis contributes much-needed empirical data to the academic literature on immigrants' experiences of, and attitudes towards, adoptive and home country citizenship.

This study highlights the importance of considering migrants' perceptions of citizenship in answering questions such as: Do immigrants seek to naturalise as an expression of loyalty and belonging to that state, commonly described as a patriotic orientation towards citizenship? Or are citizenship decisions primarily motivated by the benefits immigrants see as accruing from citizenship, commonly described as instrumental motivations? Further, is there any relationship between patriotic and instrumental perceptions of citizenship: are they opposing or complementary?

The cases in this study are Sri Lankan immigrants living in New Zealand and Australia. Specifically, I investigate Sri Lankan immigrants' perceptions of their host country citizenship (Australia and New Zealand) and their home country citizenship (Sri Lanka). It employs a qualitative methodology, using data collected through forty-nine semi-structured interviews with Sri Lankan immigrants in Melbourne, Sydney, Auckland, and Wellington. In assessing participants' citizenship perceptions, I employ a distinction between instrumental and patriotic understandings; the most frequently employed dichotomy in the citizenship literature. "Instrumental" here refers to viewing citizenship in terms of its civic and 
legal nature, whereas "patriotic" refers to the emotional and ethnocultural bond towards it (Betts \& Birrell, 2007; Fozdar \& Spittles, 2010).

My study suggests that participants view their adoptive and home country citizenship differently. On the one hand, in viewing the adoptive country citizenship (Australian or New Zealand), participants' instrumental and patriotic perceptions are inseparable. Sri Lankan immigrants in this study, tended to develop a patriotic attitude towards their adoptive country firstly as a form of gratitude (a thin form of patriotism), since they have positive instrumental perceptions of the socioeconomic and political rights and benefits they receive from the state. Once they develop this thin patriotism, then under the right conditions, such as continuing to receive better socio-economic and political benefits, living in the host society for a longer period, and experiencing a positive reception from the host society, participants tend to progress into an incremental version of thicker patriotism. Hence, due to the fact that instrumental perceptions play a critical role throughout this process, I argue that participants' instrumental and patriotic perceptions towards their adoptive country citizenship are inseparable.

On the other hand, this study reports that participants' instrumental and patriotic perceptions of their home country (Sri Lankan) citizenship are separable. In this regards, participants' patriotism came from their belonging to the people, the land, and the culture of Sri Lanka, and are thus not instrumental in the same way as perceptions of citizenship of their adoptive country are. In fact, a majority of the participants hold negative perceptions about the in strumental benefits of Sri Lankan citizenship.

In this chapter, I first detail the research question(s) that guided this research, and then explain the significance of the research in two broad areas; firstly, theory and methodology, and secondly, policy-making. Next, I identify limitations and clarifications of this study. Finally, I present the structure of the chapters of the thesis.

\subsection{Research question(s)}


This research explores how immigrants view their adoptive and home country citizenship. Do they view these equally or differently? What factors affect their views? Using the case of Sri Lankan immigrants in Australia and New Zealand, I tailor the research question more specifically as: how do Sri Lankan immigrants view their Australian and/or New Zealand citizenship (adoptive) and Sri Lankan citizenship (home)? Do they view these equally or differently? What socioeconomic, political, and otherfactors (such as belonging) in the adoptive and home country affect their instrumental and patriotic perceptions of Australian and/or New Zealand and Sri Lankan citizenship?

\subsection{Significance of the research}

This research makes original contributions to the literature in three key areas: citizenship theory, qualitative methodology, and citizenship policy-making. Theoretically, the research emphasises the need to problematise the commonlyemployed dichotomy of instrumentalism vs patriotism in understanding complex citizenship meanings for immigrants. Methodologically, the research highlights the potential for qualitative approaches in studying immigrants' multifaceted citizenship perceptions that are affected by numerous factors in both adoptive and home countries. Policy-wise, the research contributes new knowledge of interest to policy-makers involved in developing host countries' naturalisation policies and home countries' dual citizenship policies. Below, I first elaborate the significance of the research specifically for theory and methodology, and then for policymaking.

\subsubsection{Theory and methodology}

An original contribution of this thesis is to the theoretical literature on citizenship. Theoretically, the research stresses the importance of problematising the 
predominant dichotomy of the citizen ship literature - in strumentalism vs patriotism ${ }^{1}$ - when studying citizenship in the context of migration. This dichotomy derives from the long-running debate on the concept of citizenship between liberals and communitarians. ${ }^{2}$ On the one hand, an instrumental view of citizenship entails individualism and individual rights, since it believes that citizenship is based on the individual relationship one has with the state (Conover, Crewe, \& Searing, 1991). On the other, influenced by communitarianism, the patriotic view of citizenship claims that citizenship is not an individualistic relationship but the collective identity of a shared history, culture, or homogenous society. Thus, a citizen's loyalty and belonging to a particular society plays a key role in the patriotic view.

These two views have been analysed mostly as two extremes that have no interrelationship. However, in my research I find that rather than being diametrically opposed, instrumental and patriotic perceptions are actually inseparable. ${ }^{3}$ According to my data, the instrumental perceptions immigrants generate about their adoptive country, specifically related to socio-economic and political conditions, play a critical role in the generation of patriotic perceptions. My findings show that there is a correlation between immigrants' instrumental and patriotic perceptions towards their adoptive country citizenship. I therefore argue that we ought to problematise the very polarised nature by which understandings of instrumentalism and patriotism are presented in understanding citizenship in the present context of migration.

Methodologically, I suggest diverse approaches should be used for future research examining immigration and citizenship. The majority of research on citizenship in Political Science has used a quantitative approach, which remains the predominant methodology for this field (Balistreri \& Van Hook, 2004; R. Bauböck, 1994; Bennour, 2020; Bueker, 2005; Evans, 1988; Forrest \& Dunn, 2006; Glover et al., 2001; Jones-Correa, 2001; Joppke, 2004; Kymlicka, 1995; Ronkainen, 2011;

\footnotetext{
${ }^{1}$ The litera ture review in Chapter Three provides a detailed summary of this dichotomy.

${ }^{2}$ Chapter Three explains this debate in detail.

${ }^{3} \mathrm{I}$ a nalyse this a spect more in detail in Chapter Six, where I argue that participants' patriotic perceptions a bout the host country citizenship a re based on their instrumental perceptions and that there is thus a close relationship between instrumental and patriotic perceptions.
} 
Simonsen, 2016). In contrast, a large number of studies in the migration field (specifically those which study immigrants' perceptions, transnational lives, belonging, and identity) are strongly influenced by Sociology, Anthropology and Psychology, fields where qualitative approach plays a pivotal role (Basch, Schiller, \& Blanc, 1994; Bloemraad, 2002, 2004, 2006a; Cassim, Hodgetts, \& Stolte, 2015; Fozdar \& Spittles, 2010; Raijman, Davidov, Schmidt, \& Hochman, 2008; Schiller, Basch, \& Blanc-szanton, 1992).

Since my research topic speaks to both citizenship and migration, and my main objective is to explore perceptions, in this study I employ a qualitative methodological approach. This allows me to capture nuanced aspects of perceptions that a quantitative approach might find difficult to reach. I use the constructivist approach in collecting and analysing data to understand the nuances of immigrants' perceptions. According to this approach, data is not merely out there in the world waiting to be discovered, but is rather constructed, since there are multiple realities, and it is essential to emphasise the reflexivity among them (Silverman, 2011).

Another important methodological contribution of this research is its focus on a micro case study: Sri Lankan immigrants in Australia and New Zealand. Migration is a rich academic field with a large number of studies. However, the large majority of these are conducted on a few select cases, i.e., on large immigrant communities such as Mexican, Indian, Turkish for example (Adamson, 2019; Arkilic, 2016; Avc1, 2006; Balistreri \& Van Hook, 2004; Baser, 2014; Bhatia, 2008; Bhattacharya, 2008; Dunand, 2004; Garcia, 1981; Janardhanam, 2013; Jones-Correa, 2001; Martínez-Saldaña, 2003; Merelo, 2016; Plüss, 2005; Quinn \& Devasagayam, 2005; Sharma, 2004; Varadarajan, 2014; Yanasmayan, 2015). Comparatively, research on smaller immigrant communities is limited (Ronkainen, 2011; Skulte-Ouaiss, 2013; Yanasmayan, 2015; Yang, 1994). Due to this gap, there is still much to learn about the complexities of smaller immigrant communities that determine their perceptions, actions, and behaviour (Glover et al., 2001). 
The Sri Lankan immigrant community 4 is one such highly diverse community that need further exploration (Cassim, 2017). Through its examination of Sinhalese and Tamil Sri Lankan immigrants in New Zealand and Australia, this study highlights the importance of understanding the heterogeneity of immigrants within the same community. As per my findings, Sinhalese and Tamil Sri Lankan immigrants report many differences in terms of their citizenship perceptions and hence, cannot be considered as homogenous by any means.

The other significant methodological contribution of this study is its comparative nature. In this research, I compare three key situations. First, I compare participants' perceptions of their host country citizenship (Australia and New Zealand) with that of their home country (Sri Lanka). In comparing these two views, I found that there are two patterns of perception regarding instrumental and patriotic aspects of adoptive and home country citizenship; depending on their self-positioning as native citizens or immigrants. Without appreciating these differences, it is likely that native citizens of host countries expect immigrants to citizenship in a similar way to the way they do. However, as shown in this study, immigrants are likely to experience the relationship between instrumental and patriotic aspects to citizenship differently to native citizens. Second, I analyse how the different experiences of naturalisation in Australia and New Zealand, both of which are popular destinations for Sri Lankan immigrants, but which have different citizenship policies, have affected participants' perceptions of becoming a citizen. Finally, this study compares perceptions and understandings in relation to ethnic orientation - here Sinhalese and Tamil. Home country experiences played an essential part in this aspect, since in both Sri Lanka, and amongst the participants interviewed for this study, Sinhalese are the majority ethnic group, while Tamil participants are the minority. ${ }^{5}$ Hence, participants' different ethnic orientations and position as either majority or minority group members, led to differing views of their home country citizenship.

\footnotetext{
${ }^{4}$ I give a detailed account of Sri Lankan immigrants in ChapterTwo.

${ }^{5}$ Chapter Two explains the history of Sri Lankan emigration and other aspects of Sri Lankan immigration in Australia and New Zealand.
} 


\subsubsection{Policy-making}

In addition to the above, this research makes a novel contribution towards citizenship policy-making processes of both host and home countries, in two ways. Firstly, it stresses the importance of considering immigrants' interests, actions, and behaviours when making citizenship policies that affect 1) immigrants' naturalisation in host countries and 2) immigrants' dual citizenship in their home countries. Secondly, it assists policymakers in measuring the effectiveness of existing citizenship policies, contributing to the formulation of more effective policies. Below, I discuss the policy level contribution of this study for both the host and home countries.

\subsubsection{Host countries}

In this research, I give specific attention to host countries' naturalisation policies, which are usually criticised by scholars on two key grounds. First, the postnationalist critique of citizenship argues that in a world where migration is common, national citizenship is outdated. In brief, postnationlist scholars suggest national level limitations of citizenship be curtailed, placing it within the spectrum of international law and human rights norms. For example, rather than granting citizenship rights based on national citizenship, Soysal (1994) argues that we ought to grant them on the basis of personhood, since in a world where human rights are conceived as a fundamental principle, every person should have the right to take part in state apparatus irrespective of their historical or cultural ties to that society. New Zealand, has some postnationalist features in its citizen ship policy orientation, and immigrants to New Zealand do not need to wait until they become a citizen to obtain many socio-economic and political rights. For example, New Zealand is one of only five countries in the world, and the only Western democratic country, that offers non-citizen voting rights (Barker \& McMillan, 2016, 2017). ${ }^{6}$ In this way,

\footnotetext{
${ }^{6}$ A detailed account of New Zealand policies is listed in Chapter Two.
} 
New Zealand does not distinguish between citizens and residents in granting political rights for immigrants, instead it is granted on the basis of personhood.

In contrast, given the challenges migration has produced, such as increasing ethnic and religious diversity, other scholars suggest that states should revalue citizenship, making its acquisition more difficult for immigrants by making active efforts to construct and sustain national citizenship (Back, Keith, Khan, \& Shukra, 2002; Kymlicka, 2003). For example, following $9 / 11$ and Islamist extremist terror attacks in various parts of Europe, countries such as the Netherlands, Austria, Denmark, France, and Germany, started offering civic integration courses to new immigrants, while also making requirements related to language ability, integration level, and other aspects such as citizenship tests, stricter (Joppke, 2008; Sejersen, 2008). By making naturalisation or citizenship acquisition the endpoint or top prize after a long and a hard journey of proving their integration with the host society, these countries expect immigrants to place more value on host country citizenship than in previous times (Joppke, 2008, p.12).

Australia follows this revaluing of citizenship orientation. In recent years it has introduced new restrictive policies to their citizenship application process, such as the mandatory citizenship test (Fozdar \& Spittles, 2009). To naturalise in Australia, one must pass this exam, proving knowledge of Australian values and adequate integration with the host society.

The policy significance of this research is such that it speaks to the debate between relaxing national restrictions towards citizenship vs revaluation of citizenship. It does this by comparatively exploring immigrants in New Zealand and Australia; two neighbouring countries with opposing citizenship policy paths. Specifically, I investigate whether Australia's and New Zealand's different citizenship policies have affected their Sri Lankan immigrants in similar or different ways. I ask critical questions, the answers to which will allow Australian and New Zealand policy makers to better understand how their policies affect immigrants, such as: What does citizenship (in the host country) mean to immig rants? Can immigrants become fully loyal host country citizens? How does relaxing citizenship policies or making 
them more restrictive affect immigrants' citizenship perceptions? How do transnational relations with home countries affect peoples' belonging to their host country as citizens? What factors contribute to immigrants' sense of belonging and loyalty to their country of residence?

This research also offers insights to help counter anti-immigrant rhetoric that questions immigrants' level of belonging and commitment to the host society. Such rhetoric is increasingly prevalent in a number of Western democracies (Alejandro Portes \& Rumbaut, 2014; Raijman et al., 2008; Yanasmayan, 2015). My findings suggest that immigrants think differently about their host and home country citizenship; for the former they position themselves as immigrants, and for the latter as native citizens. This implies that if we are to understand immigrants' behaviour, we should answer specific questions such as: What if immigrants cannot look at their host country citizenship as native citizens do? What if immigrants' instrumental needs play an important part in determining their patriotism towards the host society? If native citizens of host countries expect immigrants to demonstrate their patriotism in the same way that they do, they should first acknowledge that the way native citizens and immigrants perceive citizenship is inherently different. Hence, the reference objective of the citizen in the whole antiimmigrant rhetoric itself, could be argued as incorrect.

\subsubsection{Home countries}

In addition to the above, this research concerns dual citizenship policies in migrantsending countries. In the case of Sri Lankan immigrants in Australia and New Zealand, this research reports that participants retain their Sri Lankan citizenship mainly because of their sense of belonging (patriotic sentiments), rather than for instrumental reasons. If this is the case, home countries should carefully formulate dual citizenship policies (or more broadly, diaspora outreach policies) in ways that address emigrants' sense of belonging, as well as their instrumental expectations. 
Sri Lankan dual citizenship policy is largely based on the assumption that Sri Lankan emigrants are interested in obtaining dual citizenship for reasons such as buying property, running a business, and so forth. As explained in Chapter Two, to be eligible for Sri Lankan dual citizenship, Sri Lankan immigrants should prove to have either academic qualifications, professional qualifications, or financial capabilities, as listed by the Sri Lankan government. Those who do not have such qualifications or capability, such as many of the refugee immigrants, have no pathway to become dual citizens, no matter how much of an emotional matter becoming a Sri Lankan citizen is for them.

Nonetheless, many of my participants identify patriotic sentiments as the most significant reason for retaining their citizenship. Thus, this research stresses the importance of policy-makers in migrant-sending countries (specifically in the Sri Lankan case) revisiting their fundamental assumptions about the purpose and function of dual citizenship policies. That is, Sri Lankan policy makers should recognise immigrants' instrumental AND sentimental desires for retaining Sri Lankan citizenship.

As explained above, this study makes contributions at the theoretical, methodological and policy-making levels. That said, there are some limitations to this research that require further study. In the following section I describe the limitations of the study while also providing clarifications for some of the actions and decisions I made in this project.

\subsection{Limitations and clarifications}

In writing this thesis, I use the term home country to mean the country immigrants are originally from (Sri Lanka) and adoptive country/host country to mean the receiving country immigrants are now settled in (Australia and New Zealand). The term immigrant is used from the host country point of view, to identify the persons who arrived from another country to live there permanently. Emigrant is used from 
the home country point of view, to identify the persons who left to live permanently in another country. Migrant is used when the person's migratory feature is identified from both the host and home country point of view, meaning persons who left their home country and arrived in a host country.

As explained above and in Chapter Four, this research uses a qualitative approach, because the main objective is to explore immigrants' citizenship perceptions, and the factors affecting those perceptions. In order to present a micro-case level analysis, I recruited 49 participants, and conducted semi-structured interviews with all. I specifically use the constructivist grounded theory approach to analyse my findings, since immigrants' perceptions are highly contextual, relative, and subjective.

In using this approach, I acknowledge the limitations of qualitative methods in generalising the findings beyond the study presented. Even though all the participants are Sri Lankan immigrants, they are different from each other in many respects, such as age, gender, ethnicity and class. Therefore, I acknowledge the difficulty of generalising the findings of this study to other immigrant communities and for the larger Sri Lankan immigrant community. Nonetheless, I suggest that certain aspects of the findings can be used as hypotheses to be tested in the context of other immigrant communities for future research. For example, one key finding of this research, the separability/inseparability of instrumental and patriotic perceptions of citizenship, can be tested as a hypothesis, to examine its generalisability.

Another challenge I tried to overcome throughout the research is my positioning as researcher. As I explain in Chapter Four, my interest in this research topic eme rges from my own experiences. I acknowledge that being brought up in a Sri Lankan migrant family has affected my beliefs and opinions about Sri Lankan immigrants' lives and perceptions. This was not ethnographic research, so I did not position myself as an insider of the Sri Lankan immigrant community in Australia and New Zealand. However, I cannot deny that due to my background, there were points throughout this research where I felt like an insider of the communities I was 
studying. To address this, I have identified a range of ways in which my position as a Sri Lankan researcher might have impacted this study. Aspects such as my ethnicity, gender, class, race, and personal life experiences, might have affected my interpretations of the findings. I discuss this further in Chapter Four.

Due to the limitations of time and financial resources for this $\mathrm{PhD}$ study, I had to make some decisions to keep the study manageable and narrow. First, I focused only on first-generation immigrants, because recruiting participants from different generations would introduce numerous other dynamics, risking a loss of focus. Thus, this research does not capture the potential generational differences in immigrants' citizenship perceptions. Second, I recruited participants only from the large cities where Sri Lankan immigrants are concentrated, such as Melbourne, Sydney, Auckland and Wellington. All these cities are highly multicultural. Thus, this study does not capture the experiences of Sri Lankan immigrants living in smaller cities, less multicultural, cities.

\subsection{Thesis structure}

This thesis is organised into eight chapters. As mentioned above, the present chapter intends to provide introductory remarks and to describe the significance of the research at the theoretical, methodological and policy-making levels. It also presents the contributions, limitations, and clarifications regarding the study, as well as the overall structure of the thesis. In Chapter Two, I provide background information about the case study, specifically about: 1) Sri Lankan emigration and citizenship policies; 2) Sri Lankan immigrants in, and the naturalisation policies of, Australia; and 3) Sri Lankan immigrants in, and the naturalisation policies of, New Zealand.

Chapter Three situates the study in the extensive field of citizenship and migration literature, exploring the implications of relevant theories towards my research. Specifically, I explore the strengths and weaknesses of traditional, transnational, and dual citizenship theories in explaining immigrants' citizenship perceptions. I 
also present the theoretical debate between Betts and Birrell (2007) and Fozdar and Spittles (2010), on instrumentalism vs patriotism; the key distinction I use to understand my data. Finally, the chapter elaborates my use of Yang's (1994) "socioeconomic" and "political" factors in explaining instrumental perceptions, and Ronkainen's (2011) typology of "thin and thick citizenship ties" to explain patriotic perceptions.

Chapter Four elaborates the methodological approach I u sed in the three main stages of the study: pre-field, field, and post-field. The pre-field section discusses the design stage of the research, such as the reasons for selecting interviewing as the primary method of data collection, participant recruitment, and planning the fieldwork. The field section discusses the way interviews were conducted, as well as the challenges faced, and lessons learnt during this phase of the project. The postfield section discusses the methods used in the analysing and writing up the findings.

Chapters Five to Seven present the findings and discussions of the empirical data. These chapters are structured according to the three key themes of this study. Chapter Five focuses on the first theme: participants' instrumental perceptions of their adoptive country citizenship, i.e. the benefits my participants see accruing from becoming a citizen of the host country. Specifically, I discuss two key factors affecting these perceptions: socio-economic and political factors. The chapter also contains a detailed comparison between Sinhalese and Tamil participants' perceptions regarding either their Australian or New Zealand citizenship. Participants' instrumental perceptions presented in the chapter support the reversibility hypothesis presented by Portes and Rumbaut (2006), that suggests if the economic, political, social, and cultural conditions of the home country are less favourable than those in the host country, immigrants' probability of seeking citizenship in the host country is higher.

However, in Chapter Six I explain that I have some reservations regarding this hypothesis, which I explain by means of the second theme of the analysis: participants' patriotic perceptions of their adoptive country citizenship, and the 
factors affecting that. I use Ronkainen's (2011) four aspects - voice, roots, loyalty and exit - to decode participants' patriotic perceptions and to measure the thinness and thickness of these. In this chapter, I explain how participants' instrumental perceptions affect the development of their thin patriotic perceptions, as well as how participants' transition from thin patriotism to thick patriotism takes place. I also compare how the different receptions Sri Lankan immigrants experience in Australia and New Zealand (as perceived by the participants) affect the way they feel towards their adopted country.

Chapter Seven presents the third theme of the analysis: participants' instrumental and patriotic perceptions about home country citizenship. Despite having different degrees of positive patriotic perceptions, my research shows how both Sinhalese and Tamil participants had negative instrumental perceptions towards Sri Lankan citizenship. In this chapter, I thus compare Sinhalese and Tamil participants' patriotic perceptions, and the factors that have affected those. The findings show that Sinhalese participants had thick patriotic perceptions, while Tamil participants had thin patriotic perceptions.

In the conclusion, Chapter Eight, I present a number of points that arise from an interplay of the findings presented in the three empirical chapters. I present my key arguments in three main sections: 1) strengths and weaknesses of the reversibility hypothesis; 2) perceptions about host country citizenship: a potential causal effect of instrumental perceptions towards patriotic perceptions, and; 3 ) perceptions about home country citizenship: a potential separability of instrumental and patriotic views. In presenting these arguments, I position my findings in the broader fields of citizenship and migration studies.

\subsection{Conclusion}

In this chapter, I first gave an overview to this research. Next, I presented the key research question(s) and the contributions of this study at the theoretical, methodological, and policy-making levels. I also described the limitations of the 
study, while providing some necessary clarifications for reading this research. Finally, I presented the chapter structure of this thesis. In the next chapter, I present a detailed account of necessary background information, giving the context for the case of Sri Lankan immigrants in Australia and New Zealand. 


\section{CHAPTER 2: Background}

\subsection{Introduction}

This chapter provides background information on the case study of this research that is necessary to develop a holistic understanding of Sri Lankan immigrants and their perceptions of Australian, New Zealand, and Sri Lankan citizenship. It provides details on three main aspects of the case study: 1) emigration from Sri Lanka and Sri Lanka's dual citizenship policies as they affect emigrants;2) Sri Lankan immigration to Australia and Australian immigration and citizenship policies, and; 3) Sri Lankan immigration to New Zealand and New Zealand immigration and citizenship policies.

I begin the chapter with an overview of Sri Lankan emigration from the 1940s to the present. Throughout this period, a highly diverse group of Sri Lankans emigrated to countries around the globe for a variety of reasons. Emigres included people of different ethnic groups, such as Sinhalese, Tamil, Burgher, and Muslim; and emigrants who moved for different political reasons, such as those who left to seek asylum due to civil war or political insecurity; legal emigrants such as skilled workers or students, as well as illegal emigrants. The Sri Lankan emigrant community has been created by a range of different types of economic, political, and social factors. In this section, I also describe Sri Lanka's dual citizenship policy as the central policy of the country aimed towards its emigrants.

Australia remains a popular destination for immigration from Sri Lankans, and the Sri Lankan community in Australia is composed of professionals, refugees, students, and illegal immigrants. In the subsequent section, I discuss this community, as well as Australian naturalisation policies towards immigrants. I then provide details about Sri Lankan immigrants in New Zealand, followed by an overview of the relevant immigration and citizenship policies of New Zealand. 


\subsection{Sri Lankan migration}

Migration has shaped the history of Sri Lanka enormously. It is believed that the initial arrival of the Aryan people (later known as Sinhalese) from Northern India took place in the $5^{\text {th }}$ century BC (Cassim, 2017). Before the arrival of the Aryan people, the country's population was primarily indigenous people, known as Veddas (Reeves, 2013), although with the proximity to the Southern part of India, it is believed that Dravidian (Tamil) people arrived in Sri Lanka on various occasions throughout history (Reeves, 2013). Sinhalese and Tamil kings ruled Sri Lanka until the 1800s (Bandarage, 2008). For most of the time between 1505 and 1948, Sri Lanka was colonised, first by the Portuguese, then by the Dutch in 1658, and finally by the British in 1796. This was a critical phase of Sri Lankan history (Bandarage, 2008; Cassim, 2017). Sri Lanka was fully colonised by the British in 1815, and finally became independent in 1948 .

As of 2016, the population of Sri Lanka was recorded to be 20.7 million (United Nations Development Programme, 2016). Sri Lanka is a multicultural, multi-ethnic, and a multi-religious country with 74.9 percent of people reporting their ethnicity as Sinhalese, 11.2 percent as Tamil, 9.3 percent as Sri Lanka Moor, 4.1 percent as Indian Tamils, and 0.5 percent being other, unspecified, ethnicities (Department of Census and Statistics, 2012). People of all these ethnic groups have emigrated from Sri Lanka over the last few decades. In 2013, the United Nations recorded that 1.25 million Sri Lankan-born persons were living outside the country, equivalent to 5.9 percent of the current Sri Lankan population (as cited in Hugo \& Dissanayake, 2017). If we include the estimated two million temporary labour migrants living in the Gulf area, the total number of Sri Lankan emigrants is calculated at around three million (Reeves (2013). Of the one million permanently settled Sri Lankan emigrants, nearly 500,000 live in the Americas, 400,000 in Europe, and around 70,000 in Australasia. Other sources, such as the International Crisis Group (2010) claims that the permanently settled Sri Lankan diaspora amount to two million. Today approximately one in every twenty Sri Lankans permanently reside abroad (Reeves, 2013; Sriskandarajah, 2002), and Sri Lanka is thus known as one of the 
significant emigration nations in the contemporary world (Hugo \& Dissanayake, 2017).

Jayasuriya and McAuliffe (2013) have categorised Sri Lankan emigrants into five groups: temporary workers (skilled, semi-skilled and unskilled); skilled settlers; students; asylum seekers, and tourists (including pilgrims to Nepal and India). Meanwhile, Wanasinghe-Pasqual and Jayawardena (2017) identified five waves of Sri Lankan emigration since independence in 1948. The first wave, occurring at the time of independence, was comprised of Burgher Ceylonese people - Sri Lankans of European descent - whose motivation to emigrate was primarily related to concerns about living in Sri Lanka under a different regime than British colonialism. Certain pull factors of host countries were also influential. For example, because of their European descent, they received assistance to migrate to countries such as Britain and Australia (Gamage, 1998, 2002; Pinnawala, 1984). It is not clear how many Burgher people emigrated at the time, but presumably a considerable number (Jayawardena, 2020).

The second wave of migration occurred after 1956 when the Sri Lankan government introduced controversial national language reforms (the Sinhala Only Act) that made the majority ethnic language, Sinhalese, the national language (Gamage, 1998; Wayland, 2004). This made people who could not continue their professional work and day-today work in Sinhalese worried about living in Sri Lanka. Consequently, a group of Burghers, Sinhalese and Tamils from English educational and social backgrounds, left the country (Jayawardena, 2020).

A third wave occurred in the early 1970s. During this decade, the Government introduced drastic nationalisation reforms, which intervened in all the industries (Athukorala \& Jayasuriya, 2000). Due to the political and economic insecurities that emerged as a result of these policies, the second and third waves produced emigrants who were primarily Sri Lankan professionals with English education (Gamage, 1998). Ethnically both Sinhalese and Tamils were in this category; they mainly migrated to Western countries such as Great Britain, Australia, Canada, Switzerland and Germany (Henayaka-Lochbihler \& Lambusta, 2004). 
A fourth wave in the 1980 s marked the zenith of Sri Lankan emigration. During this time, two armed conflicts erupted: one in the northern part of the country and the other in the southern part (Siriwardhana \& Wickramage, 2014; Sriskandarajah, 2002). In the northern and eastern regions, Tamil leaders' demanded a federal system, with autonomy. This was repeatedly refused by the Sinhalese-Buddhist dominated Government (Samaranayake, 1990; Wayland, 2004), resulting in a reassertion of Tamil identity, and demands for a separate Tamil state, called "Eelam" (Sankaran, 2019; Wayland, 2004). This ethnic division was intensified in 1983 following ethnic riots across the country by Sinhalese against Tamils. Due to widespread and systematic discrimination against Tamils in favour of the majority ethnic group, Sinhalese, a separatist group called the Liberation Tigers of Tamil Eelam (internationally known as LTTE or Tamil Tigers, and later identified by the United Nations as a terrorist group) took arms against the Government of Sri Lanka (Arunatilake, Jayasuriya, \& Kelegama, 2001).

The southern conflict was led by Janatha Vimukthi Peramuna (known as JVPor the People's Liberation Front), a youth radical Marxist group (Arunatilake et al., 2001; DeVotta, 2007; Samaranayake, 1990). When the JVP sought to topple the Sri Lankan Government in 1971, it was crushed, suffering over 10,000 deaths (DeVotta, 2007). A second massive uprising occurred in 1988/89 based on opposition to the 1987 Indo-Lanka Accord under which the Government let Indian Peacekeepers intervene in the northern conflict (Samaranayake, 1990). JVP by this time had changed its original sympathetic positioning for the Tamils' plight towards a more Sinhalese - Buddhist nationalistic rhetoric (Arunatilake et al., 2001; Pinnawala, 1984). This second insurrection was again crushed by the Government, with over 20,000 young people killed (DeVotta, 2007).

These two conflicts added a new set of emigrants to the Sri Lankan migrant community; forced migrants. The northern conflict led Tamils to migrate on humanitarian grounds, as refugees or asylum seekers, while the southern conflict led Sinhalese to migrate on similar, humanitarian, grounds (Gamage, 1998; Sriskandarajah, 2002). Meanwhile, the previous professional emigrant category continued to leave the country (Gamage, 1998). However, unlike the earlier waves, 
in the 1980s Tamil migration surpassed Sinhalese significantly. Sriskandarajah (2002) noted that Tamil migration from Sri Lanka after 1983 comprised of asylum seekers who often arrived in the West through informal routes (such as on boats) and political refugees, but also skilled migrants, people arriving on family reunion programs. Another main difference of this wave, was that, as a result of their domestic experience, many of these emigrants had a strong ethnic identity of either "Sinhalese" or "Tamil" (Perera, 2020; Wayland, 2004).

While all the above-stated migrant categories continued to outflow from Sri Lanka, the fifth wave in the early 2000s included a considerable proportion of young Sri Lankans. They started emigrating due to dissatisfaction with domestic socioeconomic and political conditions (Pingama, 2016). At the same time, a trend of illegal migration (e.g. to migrating to Australia by boat) emerged, which continues until today (Howie, 2013; Hugo \& Dissanayake, 2017). In summary, these waves have been caused by various economic, political, social, and security-based factors in Sri Lanka. However, ethnic conflict constitutes the primary reason for Tamils' emigration (Sriskandarajah, 2002). Even after migrating to various host countries, Orjuela (2008) found that tension and rivalry remains between Sinhalese and Tamil immigrants. Therefore, according to Reeves (2013), the Sri Lankan diaspora is not a single entity. Instead, it consists of separate groups of "Sinhalese diaspora" and “Sri Lankan Tamil diaspora.” As a result, Sri Lankan immigrants from Sinhalese and Tamil ethnic groups tend to network only with the relevant ethnic community (Reeves, 2013).

Previous research on Sri Lankan' emigration has focused on a few selected elements of the phenomenon such as: Sri Lankan Tamil immigrants' transnationalism, labour emigration to the Middle East, and the Sri Lankan immigrant communities' integration in different host countries. Reeves's (2013) book "The Encyclopedia of the Sri Lankan Diaspora," stands as the main source providing an overview of Sri Lankan migration. Academic work on Sri Lankan Tamil diaspora includes Burgio's (2016) analysis on Sri Lankan Tamil diaspora as a model of a transnational identity, Cheran's (2003) and Wayland's (2004) work on their transnationalism, and Orjuela's (2008) study on the role of the Tamil diaspora 
in Sri Lanka's civil war. Some other scholars' work on Tamil immigrants' lives in host countries include a study on integration of Tamil migrants in Canada by Beiser, Goodwill, Albanese, and Mcshane (2015), an analysis of Tamil refugees' psychosocial experiences in Canada by Affleck, Thamotharampillai, Jeyakumar and Whitley (2018), a study of the intergenerational perspectives of belonging of Tamil immigrants in Australia by Perera (2020), and an investigation on home - host identification by Tamil diaspora by Sankaran (2019).

Studies examining aspects of Sri Lankan labour migration, specifically towards Middle Eastern countries, include those such as Ukwatta's (2013) chronological analysis of increasing migration from the 1960s, and Dias's and Jayasundere's (2002, 2004) exploration of Sri Lankan push factors encouraging this form of migration. There is also an academic curiosity to explore the feminisisation of the labour migration (Collyer, Wimalasena, Ansar, \& Ali Khan, 2009; Dias \& Jayasundere, 2004), while Sriskandarajah (2002) pays attention to the migration development nexus of Sri Lanka. Meanwhile, Farrag (1997) looks at the economic benefits labour migration to the Middle East could bring to Sri Lanka, and Hugo and Ukwatta (2010) focus on the effect of labour migration on children left in Sri Lanka.

The other significant element of Sri Lankan migration that has received academic attention is Sri Lankan immigrants' integration experiences in host countries. Australia has been central to many of these investigations. For example, in his extensive pioneering study on Sri Lankan immigrants in Australia, Weerasooria (1988) explores the links between Sri Lanka and Australia, investigating the historical migration roots between the two countries. Gamage $(1998,2002)$ examines the composition of the Sri Lankan immigrant community and their adaptation experiences in Australia. Perera (2015) looks at how Sinhalese and Tamil immigrants in Australia maintain the use of their mother language. Silva (2017) pays attention to older adults of Sri Lankan-Australian transnational families. In addition to these studies, Henayaka-Lochbihler \& Lambusta (2004) study Sri Lankan immigrants in Italy, and Cassim (2017) studies Sri Lankan immigrants in New Zealand, specifically exploring how they navigate distance 
(geographical, social, and imagined) and establish a sense of continuity between Sri Lanka and New Zealand.

Some other aspects of Sri Lankan migration such as irregular migration have received some academic attention (Howie, 2013; Hugo \& Dissanayake, 2017; Jayasuriya \& McAuliffe, 2013), but need further exploration. Other lacunae include citizenship concerns, which have not been explored widely (although Ganeshathasan and Welikala (2017) examine dual citizenship laws in Sri Lanka, their study is from a legal and a political angle). Sri Lankan immigrants' perceptions about their home and host country citizenship have never been studied before. Hence, through this study, I highlight the significance of exploring Sri Lankan migrants' citizenship perceptions as a distinct research area for understanding them in more depth. I describe Sri Lankan citizenship policy towards its emigrants in the following section.

\subsubsection{Sri Lanka’s citizenship policy for Sri Lankan emigrants}

Sri Lanka has a limited set of policies for their emigrants but it does allow dual citizenship. In granting dual citizenship, however, Sri Lankan policymakers and politicians seem to believe Sri Lankan emigrants decide to retain, or resume, their citizenship mainly for instrumental reasons (Gamage, 2015; Jayanath, 2015).

Sri Lankan Dual citizenship was introduced in 1987 (Government of Sri Lanka, 1987b). until that point, any Sri Lankan who became a citizen of another country automatically had their Sri Lankan citizenship cancelled, without exception. However, many Sri Lankan emigrants had expressed considerable interest in retaining their Sri Lankan citizenship, even if they had become citizens elsewhere. In justifying the introduction of a dual citizenship policy, then Prime Minister R. Premadasa declared the following:

There are a large number of Sri Lankans who have obtained citizenship in other countries but still regret that they do not have citizenship in their motherland ... 
such people [emigrants who have become citizens in other countries] would like to invest in various projects in this country and contribute to the wellbeing of the country. The purpose is to get their participation. Such people will be an asset to this country. And we thought that this request made to us by our own citizens should be entertained (Government of Sri Lanka, 1987a).

The Minister of Internal Affairs was granted the power to offer dual citizenship for interested emigrants, and emigrants who wanted to become SriLankan dual citizens were invited to apply to either retain or resume dual citizenship (Government of Sri Lanka, 1987b). If the emigrant was still in the process of becoming a citizen of another country, they could apply to retain their Sri Lankan citizenship. If the emigrant had already become a citizen elsewhere, they could request that their Sri Lankan citizenship be reinstated. Each application was handled on a case-by-case basis by the Minister of Internal Affairs. According to the Citizenship (Amendment) Act (1987), “...the minister may make the declaration for which the application is made if he is satisfied that the making of such declaration would, in all the circumstances of the case, be of benefit to Sri Lanka."

I argue that the Government's interpretation of the phrase "be of benefit to Sri Lanka" has a materialistic meaning. As evident in the Sri Lankan Dual Citizenship application (Department of Immigration and Emigration Sri Lanka, 2018), the Government explicitly shows their assumption to be that emigrants are interested in obtaining Sri Lankan Dual Citizenship mainly for instrumental reasons, and have designed governmental policies according to this. An example is the criteria through which an emigrant can apply for Dual Citizenship. There are seven eligibility categories through which Sri Lankan emigrants can request dual citizenship. All the relevant categories, except No 1 and No 7, require emigrants' financial, educational, or professional qualifications.

The seven categories are as follows:

1. Exceeds the age of 55;

2. Fulfils the academic/professional qualifications (minimum one-year diploma or higher or any professional qualification); 
3. Owns assets/immovable properties in Sri Lanka worth Rs. 2.5 million or above;

4. Has a fixed deposit of Rs. 2.5 million or above for a minimum of a three year period in any of the commercial banks approved by the Central Bank of Sri Lanka;

5. Has a fixed deposit of USD 25,000 or above for a minimum of a three year period under Non Resident Foreign Currency (NRFC), Resident Foreign Currency Account (RFC), or Senior Foreign Invest Deposit Account (SFIDA) in any of the commercial banks approved by the Central Bank of Sri Lanka;

6. Has invested USD 25,000 or above for a minimum of the three year period under TB (Treasury bonds) or SIA (Security Investment Account);

7. Qualifies by way of being the spouse of the applicant, or an unmarried child under the age of 22 of the applicant.

Out of these seven categories, five (No. 2, 3, 4, 5, and 6) require professional, educational, property, or financial assets for a person to be eligible. These five categories do not allow emigrants without academic, professional qualifications or property, fixed deposits or investments to be able to become Sri Lankan dual citizens. I argue the reason for such a categorisation to be the Government's misbelief that emigrants have only materialistic interests towards dual citizenship. In that case, the Government attempts to benefit from it.

Despite this, in 2011, the Government temporarily discontinued offering dual citizenship. The reason given for this temporary shutdown was that the scheme no longer served its purpose of benefitting the country (David, 2011). The main argument declared was that dual citizens return to Sri Lanka only to buy properties, but they avoid the higher taxes that residents pay (David, 2011). Therefore, according to the Government, dual citizenship was not of benefit to Sri Lanka anymore (Ganeshathasan \& Welikala, 2017).

It cannot be ignored that by 2011 there was societal scepticism towards offering dual citizenship. This scepticism largely emerged in the aftermath of the end of the 
civil war in 2009, specifically from the majority Sinhalese society based on the possibility of offering dual citizenship to Tamil emigrants who support the LTTE's separatist ideology. There was a fear that after defeating the LTTE militarily on the ground, LTTE's international network would rise again in some other form, and it was believed that offering dual citizenship for Sri Lankan Tamil emigrants carrying separatist intentions may fuel such a rise. At the same time, Sri Lanka was also facing heavy international pressure to investigate war crimes allegations in the aftermath of the civil war. This pressure was also perceived by the majority of the Sri Lankan public to be an international conspiracy, initiated and intensified by the Sri Lankan pro-LTTE Tamil emigrants' lobby groups around the world. In this context, there was a view that granting dual citizenship would be a national threat to Sri Lankan security (Rajasingham, 2013), because it would allow pro-LTTE Sri Lankan Tamil migrants to gain access to all rights in Sri Lanka. This background allowed the Government to justify their decision and gain public support for discontinuing the offer of dual citizenship.

In 2015 a new party came to power and resumed granting dual citizenship. In the same year, the new Government introduced a controversial amendment to the constitution, popularly known as $19^{\text {th }}$ amendment. Under this amendment, the Government listed new restrictions for dual citizens, such as preventing them from running for, or sitting and voting in, parliament (Government of Sri Lanka, 2015). To justify this restriction, the Government drew a connection between dual citizenship and corruption (Jayanath, 2015), arguing that Sri Lankan politicians with dual citizenship could steal public money in Sri Lanka, then flee and find protection in their other country of citizenship (Jayanath, 2015). Because of the new law, several members of Parliament who were dual citizens at the time, had to resign from their positions (Tennakoon, 2017). The same argument (the relationship between dual citizenship and corruption), has become the centre of a controversial debate in Sri Lanka today against dual citizens obtaining key administrative or ministerial positions (Pothmulla, 2017). The public has started questioning the loyalty of dual citizens and their ethical right to be in top administrative positions. Today, those who retain Sri Lankan citizenship will have financial and property 
ownership privileges (Silva, 2017), but obtaining political rights are limited. Therefore, Sri Lanka seems to consider dual citizenship a privilege, not a right (Wijesinghe, 2017).

\subsection{Sri Lankan immigration to Australia}

Australia remains one of the most popular destinations for Sri Lankan emigrants. The 2016 Australian census found that there are 109,853 Sri Lankan-born people living in Australia (Australian Bureau of Statistics, 2016). According to the census, 60.3 percent of them are Australian citizens, while 38.3 percent are not. Of that 109,853 people, 55,830 (50.8 percent) live in the state of Victoria (Victoria State Government 2018), while 28,732 people - 26.2 percent of the entire Sri Lankanborn immigrant population - live in New South Wales.

The first recorded Sri Lankan immigrant to Australia arrived in 1882 (Weerasooria, 1988). According to Weerasooria (1988), in the late nineteenth and the twentieth centuries, 500-1000 Sri Lankans were brought to work in the sugar plantations of Queensland and pearl fisheries in the Torres Strait. The next significant wave of Sri Lankan immigrants to Australia arrived after independence in 1948 (Gamage, 1998). As explained in the previous section, these were mainly members of the Burgher community who were fearful of living in Sri Lanka after the end of colonial rule. With the change of the official language from English to Sinhala in 1956, another wave of Burgher immigrants arrived in Australia in the 1960s (Gamage, 1998). The White Australia policy supported their arrival at the time (Gamage, 1998; Perera, 2015; Pinnawala, 1984). Gamage (1998) also identifies student arrivals as another important aspect of Sri Lankan emigration to Australia from the 1950s. The Colombo Plan that started in 1949 offered Sri Lankan students the chance to pursue an education in areas such as nursing, radiography and architecture. Some of the students who arrived in Australia to study under this plan settled in Australia. Later, other scholarship opportunities were opened to Sri 
Lankan students, encouraging them to move to Australia for education. Many eventually settled there.

In the 1970s, because of economic and political instability in Sri Lanka, a wave of economic migrants began arriving in Australia (Gamage, 1998; Perera, 2015; Pinnawala, 1984; Weerasooria, 1988). According to Gamage (1998), this wave mainly included Sinhalese professionals. This was followed by a fourth wave in the 1980s following the northern and southern conflicts, as described above.

One of the larger Sri Lankan immigrant groups arriving in Australia during the 1980s was Tamils. They came in under refugee and humanitarian categories, as well as under the professional class. Meanwhile, professional Sinhalese emigrants also continued to arrive in as skilled and independent groups (Perera, 2015; Pinnawala, 1984). The influx of Sri Lankan immigration to Australia became more complicated when a set of Sri Lankan immigrants started to arrive through irregular maritime methods. According to Hugo and Dissanayake (2017), during 2012 and 2013, a sudden influx of over 6,000 Sri Lankan immigrants arrived in Australia through irregular maritime means, seeking asylum. Thus, the Sri Lankan immigrant community in Australia is highly diverse with migrants from different backgrounds.

\subsubsection{Australian immigration and citizenship policies for immigrants}

Citizenship in Australia has changed widely since the formation of the Australian Federal Commonwealth in 1901 (Galligan, 2017). According to Galligan (2017), citizenship in modern Australia has two main aspects: 1) citizenship as formal membership with rights and obligations; and 2) citizenship as a fuller sense of belonging or becoming a real Australian citizen. The Australian Citizenship Act (2007) recognises Australian citizenship as "full and formal membership of the community of the Commonwealth of Australia, and ... a common bond, involving reciprocal rights and obligations, uniting all Australians, while respecting their diversity." 
Until the 1950s, the White Australia policy offered preferential treatment to British emigrants (White \& Tadesse, 2007). This policy was widely supported by rural and urban Australian people, including all the major political parties, as well as industrial capitalists (Galligan, 2017). As a result, by 1947, 89.8 percent of the Australian ethnic composition was British (Price, 1999). The White Australia policy was based on an assimilationist view. Fluency in English, ability to obtain a job, and finding a house, were seen as the leading indicators of becoming part of Australian society (Galligan \& Roberts, 2003). The assimilationist policies required immigrants to become indistinguishable from native Australian citizens as quickly as possible (Koleth, 2010). This was particularly easy for British immigrants, given their cultural familiarity with Australian society. Other non-English speaking immigrants from different parts of the world found it harder to adapt (Koleth,2010).

However, by the early 1950s, due to the dynamics of World War II, the number of British immigrants declined (Galligan, 2017). Simultaneously the number of nonEuropean immigrants (particularly refugees of World War II) increased (Australian Government, 2018c). Consequently, in 1949, 800 non-European refugees were allowed to stay in Australia - the first step in relaxing the White Australia policy (Australian Government, 2018c; White \& Tadesse, 2007). In 1966, the announcement of the possible abolishment of the White Australia policy increased the number of arrivals to Australia. Between 1966 and 1971, the yearly nonEuropean arrivals increased from 746 to 2,696 people (Australian Government, 2018c). In 1973, Australia formally abandoned the White Australia policy and started promoting “multiculturalism” (Galligan, 2017; White \& Tadesse, 2007).

Multiculturalism is significant to Australia not only as a policy, but also as a part of the national identity. According to Mann (2017), multiculturalism in Australia is not natural or inevitable, rather, it is constructed. The term multiculturalism was first used in Australia in 1973 in a speech titled "A Multicultural Society for the Future" by then Immigration Minister Al Grassby, as the basis for migrant settlement, welfare, and social-cultural policy (Grassby, 1973; Koleth, 2010). The 1973 policy is viewed as a particular response to changes in the Australian immigrant population brought about by immigration programmes in the post-World 
War II period (Jordens, 1997; Koleth, 2010). It was expected that multiculturalism would cater to the pluralism and ethnic diversity of Australian society (Economou, 2007; Zubrzycki, 1995). Ultimately, multiculturalism became prominent, not only as a policy, but also as an identity aimed at shaping the character of the Australian people and the culture (Galligan \& Roberts, 2003). It not only introduced an actual state of affairs as a policy, but also imposed a preferred vision of what Australian society ought to be: a normative ideal (Galligan \& Roberts, 2003). Introduction of the new policy enabled any migrant, irrespective of their origin country, to become eligible to obtain citizenship after three years of permanent residency (Australian Government, 2018c).

The new policy aimed at eliminating the previous assimilationist view completely. The assimilationist view assumed that immigrants needed to give up their original languages and cultures, viewed as a barrier to becoming a real part of Australian society (Zappala \& Castles, 1999). The new policy gave immigrants the right to maintain their language and cultural practices, and to form ethnic communities within Australia (Zappala \& Castles, 1999). This view was praised as a humane policy, offering non-English speaking immigrants an opportunity to become part of Australian society while maintaining aspects of their original heritage.

After the introduction of the new policy, the number of permanent residents taking up citizenship gradually increased (Galligan \& Roberts, 2003; Jordens, 1997; Zappala \& Castles, 1999), and by 2001, the proportion of permanent residents eligible to acquire citizenship reached 95 percent (Galligan \& Roberts, 2003), a dramatic increase compared with 50 percent in the 1960s, and 70 percent in 1991 (Galligan \& Roberts, 2003). Jordens (1997) believes that before this, the fact that Australian citizenship was viewed as a status based on British ethnicity and culture discouraged non-British permanent residents from applying.

Galligan and Roberts (2003) note, however, that Australia's multiculturalism was not as strong as it was praised for being. According to these authors, only the firstgeneration immigrants maintained cultural differences in Australian society, while second and third-generation immigrants did not. In other words, second and third- 
generation immigrants are not multicultural, but have become Australianised. These immigrants have actively assimilated to Australian society through education, social mixing, and marriages. According to Galligan and Roberts (2003) and Galligan, Boese, and Phillips (2014), the migrant intake in Australia is genuinely multicultural, because migrants are drawn from many diverse cultural and ethnic groups, however, their integration to Australian society is not.

The theoretical contradiction between multiculturalism and citizenship in the context of Australia raised by Galligan and Roberts, argued that multiculturalism rejects the unity of Australian society because it favours separate ethnic and cultural identities. According to them, the introduction of multiculturalism has reduced citizenship to the principles of civic obedience and participation. This excludes emotional sentiments of affiliation or attachment to a united national identity. According to Koleth (2010), one reason for this is that the introduction of multiculturalism in 1973 was based on instrumental needs. It was targeted at resolving the economic, political, and social issues of Australian society by allowing a diverse set of immigrants with qualifications to fix those. Other than that, multiculturalism did not pay much attention to the patriotic value of citizenship at the time. Galligan and Roberts see this as the reason for the backlashin Australian society in terms of public dislike and distrust towards the multiculturalism policy today.

As a result of the multicultural policy introduced in 1973, Australia's population diversity rapidly increased. Even though Australians were asked to accept a new cosmopolitan form of national identity, embracing ethnic diversity (Forrest \& Dunn, 2006; Johnson, 2009), there was a level of resistance against it among AngloAustralians (Fozdar \& Spittles, 2009; Joppke, 2004). The need to give up their privileged position in society made some feel marginalised and disadvantaged (Forrest \& Dunn, 2006; Fozdar \& Spittles, 2009). Subsequently, a large amount of debate took place regarding the value of Australian citizenship. Some claimed that Australian citizenship was so easily acquired that it had lost its value and meaning (Betts \& Birrell, 2007). The growing, international, anti-migrant and anti-Muslim rhetoric further fuelled these debates (Walters, 2004). 
As a consequence of different public debates, since its introduction, different Australian governments have felt the need to modify the multiculturalism policy. The Labour government (1991-1996) suggested introducing a new Australian identity that reflected the multicultural nature of modern Australian society at the time (Forrest \& Dunn, 2006). Prime Minister John Howard, who came to power in 1996, suggested a version of Australian multiculturalism based on AngloAustralian values (Forrest \& Dunn, 2006; Fozdar \& Spittles, 2009). Collins (2007), describes this as a replacement of multiculturalism with integration by both the Howard government and the Labour opposition. Meanwhile, the emergence and popularity of Pauline Hanson's nationalistic One Nation Party in 1996, intensified discussions on immigrants in Australia (Economou, 2007; Fozdar \& Spittles, 2009). A violent, race-based, riot, which took place in the Sydney suburb Cronulla in $2005,{ }^{7}$ further fuelled the anti-migration wave in Australia (Collins, 2007; Economou, 2007).

Against this background, the Howard Government introduced a mandatory test to all citizenship applications (Fozdar \& Spittles, 2009). The test aimed to assess whether the applicant had adequate knowle dge of Australia, the responsibilities and privileges of citizenship, and knowledge of the English language (Department of Home Affairs Australia, 2014). If an applicant can successfully pass this test, they are eligible to become an Australian citizen. Accepting and knowing Australian values played a critical role in this test, however, as pointed out by Fozdar and Spittles (2009), how the Howard government decided on these Australian values is unclear. As they argue, the identified values; for example, respect for equal worth, dignity and freedom of the individual, freedom of speech, freedom of religion, freedom of association, and a secular Government, and are not uniquely Australian. In addition, they express severe concerns about the omission of indigenous people, and their history and influence on Australian culture. Thus, they claim, the stated list of Australian values is only a list of the Howard government's idea of what Australian values are. Forrest and Dunn (2006) identified this as simply replacing

\footnotetext{
${ }^{7}$ On $11^{\text {th }}$ December 2005 , nearly five thousand white male Australians attacked a few individuals of Middle Ea stern appearance.
} 
the previous civic nation approach in Australian society with an ethnocultural, or assimilationist policy. Some scholars have also argued that it is not a sustainable policy change, but an opportunist political move to utilise the anti-migrant sentiment in Australia (Fozdar \& Spittles, 2009).

\subsection{Sri Lankan immigration to New Zealand}

Sri Lankan immigration to New Zealand is a relatively recent phenomenon (Reeves, 2013). According to Reeves (2013), Sri Lankan emigrants started to arrive in New Zealand in the 1970s as a result of the economic and political instabilities in Sri Lanka. This means that of the primary five waves of Sri Lankan emigration explained earlier, the first recorded arrivals of Sri Lankans to New Zealand took place during the third wave. During this time, there were only 150 Sri Lankan migrants living in New Zealand (Cassim, 2017; Reeves, 2013; Swarbrick, 2005).

According to the New Zealand Ministry of Foreign Affairs and Trade (2019), approximately 16,000 SriLankans now live in New Zealand. According to the 2013 Census, over 50 percent of these immigrants are Sinhalese, and nearly 30 percent are Tamils (Statistics New Zealand, 2013a). Auckland is the most popular city among Sri Lankans in New Zealand, with 61.3 percent of the total Sri Lankan population living there. Wellington is the second most popular city, hosting 16.8 percent of New Zealand's Sri Lankan population (Statistics New Zealand, 2013a). The median age of Sri Lankans is 33.4 years, and 14.9 percent were born in New Zealand. 95 percent of those who are aged 15 or over have a formal qualification. The median income is calculated as $\$ 25,200$ per annum.

2.4.1 New Zealand immigration and citizen ship policies for immigrants

For the New Zealand Government, citizenship means not only a legal status but a high level of belonging, and an emotional attachment to the land (Department of 
Internal Affairs New Zealand, 2014). The country has a vibrant immigrant community (Fleras \& Spoonley, 1999) with 25.2 percent of the total population being born overseas (Statistics New Zealand, 2013b). As a country that encourages immigration, New Zealand explicitly accepts ethnic and cultural diversity (Butcher, Spoonley, \& Trlin, 2006; Fleras \& Spoonley, 1999). It also allows non-citizen voting, and is known to have the most robust alien suffrage regime in the world (Earnest, 2003; Rodríguez, 2010); immigrants in New Zealand can vote in both local and national elections after one year of permanent residence (Barker \& McMillan, 2016, 2017).

With its traditionally strong ties with Britain, immigration policies for people with British or Irish descent were relaxed and most immigrants who arrived in New Zealand from the pre-World War I era until 1970 were British (Statistics New Zealand, 2010). In 1974, the Labour Government changed New Zealand's racebased immigration policy to a skill-based policy (Bedford, 2006; Simon-Kumar, 2015). This enabled immigrants to apply under the category of fulfilling skills shortages in the country, rather than on race or nationality-based criteria. This policy led to a diverse group of immigrants in New Zealand. As well as to fill skills shortages, people could emigrate to New Zealand as investors. In 1986, in attempts to attract Asian business migrants (Ho, 2015), New Zealand replaced its Business Investor Category with the Entrepreneur Investment Category (Statistics New Zealand, 2010). In 1991, New Zealand introduced a points-based system to its immigration policy (Bedford, 2006; Simon-Kumar, 2015). With the introduction of this system, New Zealand further moved from receiving homogenous western immigrants to an increasingly diverse group of immigrants with different national origins (Butcher etal., 2006; Simon-Kumar,2015). As a result, the number of Asian arrivals increased significantly (Statistics New Zealand, 2010).

Towards the late twentieth century, immigration policies in New Zealand were leveraged by economic considerations such as the ability to invest or fill labour shortages (Simon-Kumar, 2015). Fleras and Spoonley (1999) described New Zealand immigration policy as a balancing act between the pragmatic (serving economic interests), the compassionate (including family or humanitarian) and the 
statutory (the Western Samoan category). Putative migrants can apply under three residence streams: skilled/business stream, family stream, and international/humanitarian stream (Ministry of Business Innovation \& Employment, 2015). Skilled migrants need to go through a selection process that stresses the economic benefit of their skills, resources, or other personal attributes (Butcher et al., 2006). Under the humanitarian stream, New Zealand provides resettlement for refugees: in 2020 this was raised from 750 people to 1,500 per annum (New Zealand Immigration, 2018). In addition to these refugees, it assists 200 - 300 asylum seekers every year (Butcher et al., 2006).

While many New Zealanders have embraced the diversity created by immigration, some individuals and groups remain anti-immigrant (Bedford, 2002; Fleras \& Spoonley, 1999; Spoonley \& Butcher, 2009). Opposition to immigration has been justified in terms of concerns about environmental pollution from an excessive population, shrinking job opportunities for native-born New Zealanders, traffic congestion, overcrowded schools, and increasing crime levels (Fleras \& Spoonley, 1999). There is particular resentment against Asian immigrants because they are perceived by some as being aggressive and pushy individuals who keep themselves isolated and avoid taking part in community events (Fleras \& Spoonley, 1999; Spoonley \& Butcher, 2009).

While some political parties such as New Zealand First inspire a substantial public opposition towards Asian immigration (Bedford, 2002; Spoonley \& Butcher, 2009), scholars have identified other structural factors that prevent immigrants from belonging to New Zealand society (Fleras \& Spoonley, 1999; Ho, 2002). Fleras and Spoonley (1999) point out that even though the Government encouraged people with wealth or skills to arrive in New Zealand, it does not adequately support immigrants' settlement in society. For example, one of the problems for professional immigrants has been their overseas qualifications becoming worthless in New Zealand without New Zealand experience or recognition (Fleras \& Spoonley, 1999; Forsyth, 2013). According to Fleras and Spoonley (1999), this difficulty makes many immigrants in New Zealand feel unwelcome. It has also hindered their sense of belonging to the society. Meanwhile Ho (2002), through his 
research on Hong Kong Chinese families in New Zealand, suggests that the transnational relations people keep with their home country are another barrier to belonging. Ho states that immigrants who continue to have transnational family structures spread across several countries cannot fully belong to New Zealand society fully.

\subsection{Conclusion}

This chapter provided background information about the specific case studies informing this research. I first described the history of Sri Lankan migration, and Sri Lankan citizenship policies for its emigrants. I then provided details about Sri Lankans in Australia, and the Australian immigration and citizenship policies related to this study. Finally, I provided details about Sri Lankans in New Zealand, and the New Zealand immigration and citizenship policies relevant to this study. In the next chapter, I explore the literature in the fields of citizenship and migration that assist me in finding answers for the key research question/s of this study.

\section{CHAPTER 3: Literature Review}

\subsection{Introduction}

In this chapter, I describe the relevant literature relating to the key academic question asked in this study: How do immigrants view their home and adoptive country citizenship? Specifically, I employ traditional citizenship theory, transnational citizenship theory, and dual citizenship theory. This chapter also 
situates my study in the broader field of citizenship by highlighting the existing theoretical debates to which the findings of this study contributes.

Given that the first notable discussion about the role of citizen dates back to Aristotle's period (Bellamy, 2008; Heater, 1990), the literature on citizenship is extensive. However, citizenship in the context of mass migration is still an emerging field of research. Although migration itself is not a new phenomenon, its implications are challenging the traditional ideas of citizenship more than ever before (Bauböck, 2005). Yet, until recently, immigrants' perceptions of host and adoptive country citizenship have been given little attention (Fozdar, 2013; Fozdar \& Spittles, 2010).

Among different ways of understanding citizenship, my study navigates through three main theoretical frameworks in the literature:

1) Traditional citizenship: an understanding related to concepts of the nationstate, whereby a loyal citizen can only belong to one state;

2) Transnational citizenship: a transnational view in which citizens can have multiple belongings to two or more states simultaneously;

3) Dual citizenship: a legal relationship citizens hold simulteneously with more than one state.

In what follows, I analyse these versions of citizenship in three steps. First, I describe the implications of traditional citizenship for this study, as I investigate immigrants' citizenship perceptions of their home and adoptive countries separately. Second, I explore the implications of transnational citizenship for this study, as I seek potential relationships between participants' perceptions of home and host country citizenship. Third, I explore the dual citizenship literature and its cross-overs with transnational and traditional citizenship.

I employ three key perspectives through which other theorists have studied traditional, transnational, and dual citizenship: 1) immigrants' naturalisation and political participation in the host country (Balistreri \& Van Hook, 2004; Bennour, 2020; Bernard, 1936; Bueker, 2005; Cho, 1999; Foner, 2001; Garcia, 1981; JonesCorrea, 2001; Miller \& Barry, 2009; Paquet, 2012; Portes \& Mozo, 1985; Yang, 
1994); 2) immigrants' integration with the host society (Ager \& Strang, 2008; Bloemraad, 2000, 2006; Bloemraad, Korteweg, \& Yurdakul, 2008; Constant, Gataullina, \& Zimmermann, 2009; Ersanilli \& Koopmans, 2010; Glover et al., 2001; Hoonaard \& Hoonaard, 2010; Joppke, 2004; Nagel \& Staeheli, 2004; Ramakrishnan, S Karthick Espenshade, 2001; Scipioni, 2017); and 3) immigrants' relations with their home country (Adamson, 2019; Arkilic, 2016; Cheran, 2003; Cohen, 1996, 2008; Faist, 2010; Henayaka-Lochbihler \& Lambusta, 2004; McDowell, 1996; Orjuela, 2008, 2011; Ragazzi, 2014; Safran, 1991; Sriskandarajah, 2002; Zhou \& Liu, 2016).

The chapter also presents the theoretical debate regarding instrumental vs patriotic ways of viewing citizenship, the key distinction I employ in interpreting my data. The difference between instrumentalism and patriotism - has been presented by both Betts and Birrell (2007) and Fozdar and Spittles (2010). However, each gives different treatment to these terms. In this thesis, I test which approach better explains Sri Lankan immigrants' citizenship perceptions. Finally, I present the explanations I borrow from the literature to understand my research participants' perceptions of home country citizenship (Sri Lanka) and adoptive country citizenship (Australia and New Zealand). I use the socio-economic determinant model that discusses the influence of social, economic and political factors in immigrants' citizenship views to explore instrumental perceptions, while using the non socio-economic determinant model that discusses the influence of aspects such as integration to the host society and transnational relations with the home country, to explore patriotic perceptions. I test the potential of Yang's (1994) socioeconomic and political factors argument in explaining instrumental perceptions while testing the potential of components of Ronkainen's (2011) typology of thin and thick citizenship ties in understanding patriotic perceptions: voice, roots, loyalty and exit. I find participants' citizenship perceptions of both their home and host nations to be affected by a range of socio-economic, political, and other factors. I also find Sri Lankan immigrants' instrumental and patriotic perceptions to be entangled, rather than distinct.

In brief, the hypotheses I test in this study are: 
Hypothesis 1: Sri Lankan immigrants' perceptions of their host country citizenship are reversibly affected by their perceptions of their homecountry citizenship, and vice versa;

Hypothesis 1.1: Sri Lankan Tamil immigrants' discriminatory experiences in Sri Lanka (as citizens from a minority group) have led them to view Sri Lankan citizenship more negatively than Sinhalese immigrants, while also enabling them to generate positive perceptions about host country citizenship more quickly than Sinhalese immigrants;

Hypothesis 2: Sri Lankan immigrants' instrumental and patriotic citizenship perceptions (both towards home and adoptive country citizenship) are not distinct, but entangled;

Hypothesis 3: Both Sinhalese and Tamil participants' thin and thick patriotic perceptions towards host country citizenship are the same, while their views towards home country citizenship are different;

Hypothesis 4: Socio-economic factors affect immigrants' instrumental views as well as their patriotic views.

\subsection{Traditional citizenship}

In this section, I first provide an overview of the evolution of traditional citizenship theory - the most influential theory that has shaped debates around citizenship while also presenting the key aspects that are important for this study. This theory proposes an exclusive link between the citizen and one sovereign nation-state. In the nineteenth century, it was believed that the state should overlap with the nation (Anderson, 1991). As a result, citizenship - as the main tool that legitimises the above said exclusive link - represented the legal status of a citizen as an official member of a society. It also represented various emotional statuses, including identity, loyalty, and sense of belonging to a community. 
The theoretical grounds of traditional citizenship evolved alongside historical discussions defining who a citizen or member of society is. These date back to the Greek and Roman city-states (Bellamy, 2008) where there was a measure of popular participation in public life (Turner, 1993). Aristotle is believed to be the first political theorist who discussed and wrote about citizenship (Bellamy, 2008; Heater, 1990; Turner, 1997). In his opinion, citizens are all those who take part in making decisions about ruling, and are themselves ruled in turn (Heater, 1990).

In medieval and early modern times, the principles of membership were understood as being both to the church and society. Hence, citizenship included multifaceted loyalty, as both church and the sovereign claimed allegiance (Heater, 1990; Turner, 1993). There was a tension in this era between a regional sense of identity and the attractions of a burgeoning nation-state. As Heater (1990) explains, inhabitants of particular nation-states identified themselves as Englishmen or Frenchmen and, therefore, feelings of patriotism at the national level began to blossom. That said, feelings of local or regional identity persisted to a high degree. In their day-to-day lives, ordinary citizens felt a greater sense of belonging to their village or region; for example as people of Sussex or Yorkshiremen. Of significance in this era was the introduction, by a number of city-states, of a set of material qualifications for citizenship (Heater, 1990). For example, in Parma, a "stranger" would be admitted to citizenship if he built a house worth 100 lira, on condition that he was a true friend of Parma and had not committed any crime (Heater, 1990, p. 21).

Even though ideas related to citizenship were influenced by city-state and medieval experiences, scholars believe the concept is essentially modern (Heater, 1999; Turner, 1993). The French Revolution is widely regarded as the milestone embodying and spreading contemporary ideas such as citizenship and democracy (Brubaker, 1992; Hammersley, 2015; Turner, 1993). The title of "the citizen" was adopted by the French Revolution as a result of the political struggle to pronounce the symbolic reality of equality by expunging aristocratic distinctions. This period opened the way to "liberalism's language of individual rights, a central part of contemporary citizenship" (Bloemraad et al., 2008, p. 155). 
By 1990, there was an explosion of scholarly interest in the concept (Kymlicka \& Norman, 1994) and the term citizenship became the buzz word among academics and policy-makers (Heater, 1990). Numerous factors affected this increase in interest. According to Kymlicka and Norman (1994), some of the reasons behind this are increasing voter apathy, long-term welfare dependency in the United States, nationalistic movements in Eastern Europe, the backlash against the welfare state in England, and the challenges posed by multicultural and multiracial populations in Western Europe. These developments challenged the core ideals of traditional citizenship: for example, it brought up concerns such as how citizens perceive nationality, identity, and a sense of belonging; how they behave under multiculturalist regimes; and how they tolerate and work together with those who are different to them (Kymlicka \& Norman, 1994). Those attitudes and practical concerns by citizens were imperative for states to determine the direction s for modern democracy.

It is important to note that even though today citizenship is known as a universal concept, its emergence and development was shaped by Western cultural and structural conditions (Turner, 1993). As Max Weber (as cited in Heater, 1990, p.2) notes, at the time the concept was evolving in the West "the notion of citizens of the state [was] unknown to the world of Islam and India and China". However, Heater (1999) suggests that, today, citizenship is a commonly held status throughout the world, although the equality that the status promises in theory is problematic in principle and law.

Marshall's (1950) seminal research considered citizenship and class to be the basic features of contemporary capitalist societies. Marshall believed that citizenship is a matter of ensuring everyone is a full and equal member of a society (Kymlicka \& Norman, 1994). Influenced primarily by England's history, Marshall claimed that in the seventeenth and eighteenth centuries there was an expansion of legal rights, followed by an expansion and institutionalisation of political rights in the eighteenth and nineteenth centuries, and finally an important expansion of social rights in the nineteenth and twentieth centuries (Rees, 2016). 
Marshall believed that the inequality produced by capitalism in modern societies could be minimised through resource redistribution (Revi, 2014; Turner, 1997). He explained the significant role of social rights in reducing such inequality (Revi, 2014). In his "The Right to Welfare and Other Essays" published in 1981, he described modern, capitalist, industrialised societies as "hyphenated societies" (Marshall, 1981) because he saw them as combining some elements of democratic egalitarianism (at least through citizenship) with the inequality of capitalist relations in the market-place and economy (Revi, 2014; Turner, 1997). While Marshall's explanation of citizenship has been criticised (Harris, 1999; Roche, 1987), scholars agree that he laid the foundations for writing and analysis of citizenship in modern societies (Rees, 2016; Revi, 2014; Turner, 1997).

In 1990, Brubaker suggested that the ties between a member of a society with that state should be singular, not multiple, and, therefore, citizenship should be egalitarian, sacred, and national. Thus, proponents of traditional citizenship theories deny the possibility of holding attachments or memberships with multiple states because of their scepticism about the level of true loyalty such attachments would let citizens to hold towards the states (Renshon, 2001).However, with the emerging complex realities of globalisation and migration, scholars suggest that the theoretical grounds of such traditional citizenship are illiberal (Bauböck, 1994; Carens, 1987; Shachar, 2009; Stasiulis, 1997). Carens (1987), for example, identifies traditional citizenship as the modern equivalent of feudal privilege - an inherited status that greatly enhances one's life chances.

In the following section, I explain the emergence of transnationalism as a theory that explains immigrants' multiple belongings towards home and adoptive countries, while also presenting the key theoretical grounds of this theory relevant for this research.

\subsection{Transnational citizenship}


In contrast with traditional citizenship theories, researchers of transnational citizenship believe in citizens' multiple belongings. Bauböck (1994), in his groundbreaking book "Transnational Citizenship," argues that liberal democratic countries should extend their citizenship rights beyond nationality and state territory if they wish to remain true to their principles of inclusive membership and equal basic rights. Thus, transnationalism theorists accept dual citizenship. As Basch, Schiller, and Blanc (1994) suggest, migrants' and states' desire for dual citizenship creates new "deterritorialized" nation-states.

As explained in the previous section, while citizenship was historically understood within the context of nation-states, the increasingly high volume of contemporary migration brought up numerous economic, social, cultural, and political challenges to traditional citizenship, both as a theory and a policy. On the one hand, the increase in the provision of dual and multiple citizenship by many sending and receiving countries has made it possible for immigrants to continue their legal affiliations with two or more countries simultaneously. On the other hand, the advancements in communication, technology, and transportation, together with mass migration, have made it possible for immigrants to continue their social and emotional relations with their home country even though they are physically settled elsewhere (Portes \& Rumbaut, 2006).

In other words, migration has led migrants to attach different meanings and interpretations to citizenship as a legal status or as an emotional attachment, depending on their level of attachment with home and adoptive societies, by putting the traditional meanings of citizenship (one citizen-one state relationship) at stake. Nonetheless, there is a significant gap in the literature exploring immigrants' perceptions of citizenship, with a few, notable exceptions (Betts, 2002; Foner, 2001; Fozdar \& Spittles, 2010; Leitner \& Ehrkamp, 2006; Phalet \& Swyngedouw, 2002; Yang, 1994). While these exceptions have studied immigrants' citizenship views, none of them has adequately explored it comparatively, considering how immigrants' legal and sentimental attachments with both home and host countries affect their opinions about citizenship of both locales. 
Considering this shortcoming in the literature, I investigate the relationships between immigrants' perceptions of home and adoptive country citizenship to understand immigrants' own views of both. Transnational citizenship theory helps me explore this question in three regards. First, this theory connects immigrants' perceptions of citizenship to their transnational relationships with both home and adoptive countries. Second, the transnationalism literature reveals the complexity of the transnational social spaces immigrants inhabit, while also listing a range of home and adoptive country factors that affect immigrants' beliefs. Third, it highlights the importance of using a holistic approach in understanding immigrants' lives.

Scholars of this area have studied various aspects of immigrants' relationships with both home and host country, and have considered how these dual or multiple relationships lead to a host of complications in immigrants' actions and perceptions (Avc1, 2006; Bauböck, 1994; Bloemraad, 2000; Castles, 2004; Clayton, 2016; Conway, Potter, \& St Bernard, 2008; Flores, 2005; Jones-Correa, 2001; Kivisto \& Faist, 2010; Kivisto, 2010; Levitt \& Nyberg-Sørensen, 2004; Portes \& Rumbaut, 2006; Portes, Haller, \& Guarnizo, 2002; Schiller, Basch, \& Blanc-szanton, 1992). According to Schiller et al. (1992), transnationalism is the process by which immigrants build social fields that link together their country of origin and their country of settlement. One of the main differences between contemporary immigrants and the late nineteenth or early twentieth century immigrants is that the former group had mostly broken off ties with their home country, while the latter continued to have networks, activities, and lifestyles that encompassed both home and host countries. This difference has made an enormous impact on immigrants' thoughts and beliefs today.

Portes and Rumbaut (2006,p.130) point out two noveldevelopments that reinforced transnationalism: 1) the technological innovations in transportation and communications; and 2) sending states' new attitudes toward their respective immigrant diasporas. In this study, I assume that my participants' citizenship perceptions are affected by these two developments. On the one hand, due to the technological innovations in transportation and communication, my participants are 
able to maintain their social and emotional relations with their home country, even though they are physically settled in another. Understanding the nature of these relations can help explain participants' perceptions of being a host country citizen. On the other hand, understanding participants' reasons to retain citizenship in the home country if it is available, can explain immigrants' perceptions of their home country citizenship.

Theorists of transnationalism have presented different units of analysis in studying immigrants' transnational actions and behaviours, which are of particular importance in three ways. First, Portes (as cited in Kivisto \& Faist, 2010) identifies the individual as the unit of analysis in transnationalism theory. Second, Schiller et al. (1992) suggest these actions and behaviours should be examined from a global perspective. Finally, Faist (2000) lists four units of study: 1) groups and institutions of the receiving nation; 2) the state in host societies; 3 ) the state in homelands; and 4) immigrant groups. According to him, for a viable transnational community to be well established, a regular pattern of involvement with both governmental and civic institutions in the homeland and host country is essential. Because my focus is individual immigrants' citizenship perceptions, I employ Portes's unit of analysis the individual - and I position immigrant as the centre of the debate.

In studying transnationalism, Østergaard-Nielsen (2001, p.5) focuses specifically on transnational political affairs. Her findings contribute to this study in instrumentalising the existing measurements to investigate immigrants' political relationships between home and host country. She pays attention to various forms of direct and indirect cross border participation by migrants and refugees in home country as well as host country politics. Østergaard-Nielsen (as cited in ZapataBarrero, Gabrielli, Elena, \& Jaulin, 2013, p.6) defined transnational political practices as "the proliferation of political ties, networks and practices across borders, a phenomenon strictly linked to the sending countries' particular politicoeconomic incentives to mobilise their current and former citizens abroad, among other factors." In her opinion, there are four main types of transnational political practices: 
1) Immigrant politics: political activities that immigrants or refugees undertake to better their situation in the receiving country;

2) Homeland politics: emigrants' and refugees' political activities pertaining to the domestic or foreign policy of their homeland;

3) Diaspora politics: political activities by groups that are barred from direct participation in home country politics, or by those who do not have a homeland political regime;

4) Transnational politics: an overlapping subset of homeland politics that is initiatives from abroad used to better the situation in the community where one originates from.

Taking into account the importance of multiple belongings for immigrants who live transnational lives, Bloemraad et al. (2008) identify four dimensions of citizenship. These are important to this study because they generate a broader meaning of citizenship that captures and combines both legal and sentimental aspects. Those four aspects are: legal status; rights; political participation; and a sense of belonging. Legal status concerns who is eligible to become a citizen, with jus soli and jus sanguinis being the two main conventional ways to qualify for citizenship. Jus soli means receiving citizenship through birth in the territory. Jus sanguinis refers to obtaining citizenship because of parental origin. Immigrants - those who move to a new country and are thus outsiders both legally and socially (Bloemraad, 2000) - are not eligible for citizenship either through jus soli or jus sanguinis and must, therefore, acquire it through naturalisation (Bloemraad et al., 2008).

The rights dimension refers to liberalism's understanding of the contractual relationship between individuals and the state (Bloemraad et al., 2008). Here, states guarantee to provide fundamental rights to individual citizens and, in return, citizens are expected to fulfil duties and responsibilities such as paying taxes (Janoski, 1998). The third dimension, political participation, is about determining who can participate in politics. This is seen as an individual and, in some cases, a human, right that is held irrespective of the legal status of citizenship (Brysk \& Shafir, 2004). The fourth dimension, a sense of belonging, is closely linked with nationalism and citizenship. According to Bosniak (as cited in Bloemraad et al., 
2008), it demands a demarcation of those who should be excluded from those to be included, in order to create a common we. According to Bloemraad et al. (2008), these four dimensions of citizenship may complement, or stand in tension, with each other.

In brief, transnational citizenship contributes to a deterritorialised vision of multinational belonging for immigrants (Basch et al., 1994). It is suggested that immigrants exchange their national allegiances and identities for an imagined multinational community (Anderson, 1991; Conway, 2000). In this research, I borrow the transnational interpretations as discussed above to ex plore immigrants' multiple loyalties and sense of belonging towards their home and host societies. In the following section, I present the implications of dual citizenship for this study.

\subsection{Dual citizenship}

Another body of knowledge contributing to the investigation of immigrants' citizenship perceptions is the literature related to dual citizenship. In its basic sense, dual citizenship means holding more than one citizenship simultaneously. A dual citizen has rights and responsibilities as a citizenship in the two or more countries in which she is a citizen, regardless of the length of the stay or actual residence in a country (Renshon, 2001). As explained by Bloemraad (2004), dual citizenship heavily overlaps with the theory of transnationalism. On the one hand, dual citizenship is a cause of transnationalism, because the multiple legal attachments, such as receiving passports or rights in multiple countries, reinforce one's various identities and multinational belongings. On the other hand, dual citizenship is a consequence of transnationalism, since when immigrants lead transnational lives, and desire to continue relations with home countries, they would obtain the legal tools, including multiple passports, to facilitate this. In this section, I explain the implications of dual citizenship for this study, while presenting its overlaps with both traditional and transnational theories. Towards the end of the section, I present one of the key hypotheses I test in the research. 
The past few decades of economic and cultural globalisation led many people to hold simultaneous attachments with multiple countries, making dual citizenship an unavoidable and a widespread phenomenon (Howard, 2005). Since the 1990s, a number of scholars were interested in exploring dual citizenship as a theory as well as a policy (Bauböck, 2005; Bloemraad, 2004; Conway et al., 2008; Escobar, 2006; Faist, 2007; Faist, Gerdes, \& Rieple, 2004; Howard, 2005; Koenig-Archibugi, 2012; Miller \& Barry, 2009; Mügge, 2012; Ronkainen, 2011; Sejersen, 2008; Yanasmayan, 2015). It is estimated that four to five million American citizens (Howard, 2005; Kivisto \& Faist, 2010), and over a million French citizens, are dual citizens (Koslowski, 2003 as cited in Kivisto \& Faist, 2010). Even though it is challenging to gather numerical data about the number of dual citizens, the liberalisation of dual citizenship policies is definitely showing an upward trend (Howard, 2005; Kivisto \& Faist, 2010; Ragazzi, 2014).

Even though there is currently an increasing tolerance for dual citizenship across the world, it has historically been disfavoured so strongly, that the current trend is astonishing compared to a few decades ago (Faist, 2007; Spiro, 2017). This is because, as discussed above, traditionally, many nation-states believed in their citizens' undivided loyalty due to a nation-state understanding of citizenship (Yanasmayan, 2015). Hence, traditional citizenship theorists deny dual citizenship as it jeopardises the neat trinity of state territory, state authority, and the people (Faist, 2007b, p.3).

When a citizen of one country migrates to another and decides to naturalise, this disrupts the linear relationship between that citizen and state. The nation-state approach thus assumes that citizens who emigrate do so because they have reduced, or zero, loyalty to the home country. Moreover, some receiving countries also assume that immigrants are unable to belong to their new society completely, given their continuous legal, political, social, or cultural attachments to the home country. A main criticism of dual and multiple citizenship stems from these assumptions and from immigrants' presumed divided loyalties to host and adoptive countries (Kivisto \& Faist, 2010). Thus, according to Bloemraad (2004), this is an "either/or" preposition: either you are a citizen of your home or of your host country. 
In this context, dual citizenship clearly undermines the core premises of the traditional approach, as it encourages citizens to hold multiple citizenships legally, and multiple belongings emotionally, at the same time. However, Bloemraad(2004) suggests that it is unfair to identify dual citizenship as a total opponent of traditional citizenship, since it includes some elements of traditional citizenship; for example, it re-emphasises the centrality of nation-states as the key political and legal entity entitled to grant citizenship.

The literature on dual citizenship involves arguments about the ways obtaining dual citizenship in your home country affects one's naturalisation in another. Reviewing such arguments allows me to ground this study in the dual citizenship literature. Renshon (2001) proposes that dual citizens might not be sufficiently loyal to their host countries given their divided loyalties. However, Jones-Correa (2001) argues that dual citizenship not only has the potential to positively affect immigrants' loyalty towards the host society, but in certain cases, it can encourage immigrants' incorporation into the receiving country. This is because if an immigrant is loyal to the host country, he or she tends to fulfil his or her duties as a citizen, such as taking part in political matters.

Bloemraad (2004) finds that in the case of Canada, most immigrants were enthusiastic to become a Canadian citizen while also being keen to retain their home country citizenship. She proposes that immigrants with higher human capital are more likely to obtain dual citizenship rather than the economically marginalised ones. This is because they are more aware of the value of having access to legal entitlements simultaneously in two countries. However, Leitner and Ehrkamp (2006) suggest that it is unfair to suggest every non-refugee migrant obtains dual citizenship only for instrumental purposes. According to them, non-refugee migrants also obtain dual citizenship as a recognition of their multiple attachments and commitments.

Meanwhile, Portes and Rumbaut (2006) identify a reversible effect between immigrants' perceptions and decisions regarding their home and host country citizenship. Their "reversibility hypothesis" emphasises the importance of studying 
immigrants' home country conditions in order to understand their perceptions and decisions regarding host country citizenship. That is, if the economic, political, social, and cultural conditions of the home country are less favourable than those in the host country, immigrants' probability of seeking citizenship in the host country is higher.

For example, if the economic situation of the home country is negative, while simultaneously the economic condition of the host country is positive, this would reduce immigrants' desire to return to their home country, and would therefore inspire them to naturalise in the host country. Conversely, if the conditions of the host country do not appeal to immigrants, while the similar conditions in their home country appeal more, immigrants tend to retain their home country citizenship. For example, if an immigrant had to take up a low level or poorly paid job that was below his or her qualifications, such a person may develop a sense of economic marginalisation in the host country (Bloemraad, 2004). Therefore, as a strategy to deal with feelings of discrimination, marginalised immigrants engage in transnational lives more actively to affirm their belonging to their home country identity. In this case, the economic marginalisation of the host country creates a reversibility effect on immigrants, encouraging a more positive attitude to retaining citizenship of their home country.

Sharma (2004) offers a similar hypothesis to Bloemraad's (2004). Studying Indian immigrants in the USA, Sharma (2004) found that many continue their Indian cultural practices in their host country. In her opinion, this is a "defensive mechanism" since "immigrants find their culture as a defence mechanism against a sense of insecurity in the alien setting" (p. 49). I suggest that this phenomenon can also be comprehended through the reversibility hypothesis; that the lack of cultural familiarity in the host country leads immigrants to maintain their home country cultural practices. Accordingly, my first hypothesis is as follows:

Hypothesis 1: Sri Lankan immigrants' perceptions about the ir host country citizenship are reversibly affected by their perceptions about the ir home country citizenship, and vice versa. 
To test this hypothesis, I position the immigrant at the centre of the citizenship discourse, since I aim to explore the meanings of citizenship through an immigrant's point of view.

Since the Sri Lankan community has a considerable number of political emigrants, I borrow Hirschman's formula of "exit, voice and loyalty" to specifically study them. Hirschman (as cited in Hoffmann, 2010) recognises political immigrants' perceptions and behaviours to be more intensive than other immigrants. His formula suggests an intensive reversible effect in such immigrants' actions. He suggests that if an immigrant decides to leave her home country (exit) due to reasons such as political dissatisfaction, they would then use their voice as a medium to externalise this dissatisfaction, especially if this voice has been suppressed before. If a home country granted very limited, or zero, space to a person to express their opinion, while the host country was more permissive, such persons would use their voice in a greater intensity to express their frustration. In addition, political immigrants such as refugees, may have a higher sense of belonging and loyalty to the host country, because they helped them escape persecution and have relief from memories of the emotionally painful past attached to the home country (Leitner \& Ehrkamp, 2006). Based on the above arguments, in the case of the Sri Lankan immigrant community, I assume that the discriminatory experiences many Tamil immigrants faced have complicated their attachments to Sri Lanka, and have affected their host country citizenship perceptions in ways different to those of Sinhalese immigrants. Thus, I test a sub-hypothesis to see whether or not Sri Lankan Tamil emigrants who left Sri Lanka due to political reasons carry negative sentiments about Sri Lankan citizenship while carrying positive sentiments about the Australian or New Zealand citizenship:

Hypothesis 1.1: Sri Lankan Tamil immigrants'discriminatory experiences in Sri Lanka (as citizens from a minority group) have led them to view Sri Lankan citizenship more negatively than Sinhalese immigrants do, while also enabling them to generate positive perceptions about the host country citizenship more quickly than Sinhalese immigrants. 
While exploring the impact of obtaining home country citizenship on host country citizenship perceptions and vice versa, I also aim to explore the nature and the interrelationships of such perceptions. In the following section, I describe how I plan to investigate these aspects.

\subsection{Instrumentalism vs Patriotism}

In this study, I use the distinction between instrumentalism and patriotism as a way to understand my participants' perceptions while also exploring the relationships between the two notions. Moreover, I test which argument of the "patriotic vs instrumental" debate between Betts and Birrell (2007) and Fozdar and Spittles (2010) applies to my case. These two notions are ingrained in the traditional communitarianism and liberalism debate. Thus, I provide a detailed summary of this debate, extracting its implications for this study. Towards the end of the section, I present the second hypothesis I test in this research.

The foundation for liberal citizen ship is the contractual vision of citizenship based on individualism and individual rights that goes back to Locke and Hobbes (Conover et al., 1991). According to this liberal notion, humans freely choose agents who deserve identical individual protections (Bloemraad et al., 2008). In contrast, communitarians claim that "individual agency is embedded in particular social and cultural collectives that provide individuals with the meaning" (Bloemraad et al., 2008, p.159). Associated with both liberal and communitarian ideas, citizenship "is intimately linked to ideas of individual entitlement on the one hand and of attachment to a particular community on the other han d" (Kymlicka \& Norman, 1994, p.352). In the context of migration, even though the liberal notion of citizenship exists without much challenge, the communitarian notion is problematic (Fozdar, 2013). Migration makes societies more diverse with new populations who do not share a homogenous identity, a similar culture, or a shared history. This makes one's sentimental attachment to a particular community difficult. 
Habermas (1994) questioned the continuation of the communitarian character of citizenship when societies become more diverse through migration. In his opinion, as a result of nation-states becoming more diverse, people can no longer rely on common ties of ethnicity, shared histories, or shared values, for cohesion. Consequently, he suggested the need to form the national identity based on citizens' legal relationship with the state and civic institutions (in an instrumental sense) instead of only ethnonationalistic (in a patriotic sense) aspirations.

Given the complexities migration has brought to societies, Castles (1997) also discussed the importance of divorcing citizenship and nationality from each other. This scholar explored the notion of the citizen as an individual abstracted from cultural characteristics, and the assertion that being a national means being a member of a community with shared cultural values. In the context of migration, the category of the citizen should thus be understood in terms of its legal and civic relationship with the state.

While criticised by many liberal theorists, the relevance of theories of communitarianism, specifically in citizenship policy-making today, cannot be ignored. Many nation-states give serious attention to this communitarian character in making their citizenship (including naturalisation) and diaspora policies. In what follows I present the arguments of both liberal and communitarian scholars to demonstrate how these two notions work in the context of migration.

Many scholars have considered the overlapping characteristics of liberalism and communitarianism. For example, Brown (1999) used a civic vs cultural categorisation to understand citizenship, in which a civic model refers to a citizens' ability, irrespective of their diverse ancestry, and even though they may lack emotive power, to move towards a common future through their involvement with state and civic society institutions (a model thus influenced by the liberal notion of citizenship). In contrast, his cultural model includes people's deep-rooted beliefs in myths of a common ancestry, a homeland, and pride in the linguistic, cultural, or physical evidence of common kindship. However, he questioned the liberal and rational associations with civic while associating illiberal and irrational connotation 
with cultural, and suggested instead that cultural and civic nationalisms can emerge in both liberal or illiberal forms.

Mean while, in their study of how citizens of the United States and England perceive citizenship, Conover et al. (1991) use a contractual vs communitarian dichotomy. The contractual view of citizenship is based on the premise that citizens are autonomous individuals who make choices because they are bound together by a social contract, not as friends or neighbors united by everyday activity (Conover $e t$ al., 1991). Being bound by a contract, citizens receive their individual rights while their political participation becomes largely instrumental. In this context, the contractual view serves citizens' private interests rather than the public or common good. Since this view concentrates on rights and duties rather than identities, scholars argue that it creates only a thin relationship between the citizen and the state (Dagger, 1981; Faulks, 2000). In contrast, in the communitarian view of citizenship, citizens share common traditions and understandings with others in society, to pursue the common good. Thus, identities are central in this approach, since communal citizens perceive the foundation of a good life as an interdependent relationship with the political community she belongs to (not the state). Because of this, public interest is more important than individualistic, private, interest (Faulks, 2000) and the moral aspirations of citizenship are more valuable than the legal aspirations, creating a "thick" relationship with the state (Faulks, 2000). Even though Conover et al. (1991) do not specifically look at immigrants' perceptions, their study helps us to identify some salient features of people's citizenship perceptions.

In addition to these, Kymlicka and Norman (1994) name instrumental and patriotic ways of viewing citizenship as "citizenship-as-legal-status" and "citizenship-asdesirable-activity." According to them, the former is full membershipin a particular political community, which overlaps with the core ideas of the liberal notion of citizenship. In contrast, the latter overlaps with the communitarian approach, as it suggests that the extent and quality of one's citizenship is a_function of one's participation in that community. 
Leitner and Ehrkamp (2006), in their study on how immigrants perceive citizenship, identify three dominant aspects, from which this study benefits:

1. Citizenship as security, protection, and mobility: resident status, without citizenship, gives immigrants a sense of insecurity. This is particularly evident among those who have traumatic experiences in their home countries, such as civil war, persecution, or limited rights. These immigrants perceive host country citizenship as a guarantor of their security and protection. Particularly for those from the Global South, a Western passport is one of the most desirable benefits easing their international mobility;

2. Citizenship as equality: immigrants perceive naturalisation as a prerequisite for equal participation in economic, social, and political spheres. Specifically, for immigrants who have had discriminatory experiences back at home believe, the acquisition of citizenship in the host country makes them feel equal;

3. Citizenship as identity: this interpretation overlaps with communitarianism notions of citizenship. Leitner and Ehrkamp argue that many immigrants have a sentimental bond and a strong allegiance with their home country and, therefore, renouncing this citizenship is viewed as the highest "cost" to be paid to acquire citizenship of the host country. Exceptions to this are those, such as refugees, who were forced to flee, who lost the loved ones, or who lost a sense of belonging to their homeland; these expressed allegiance only to their host country.

As is evident, the first two aspects emphasise the instrumental value immigrants place on host country citizenship, with the first being associated with security, protection, and mobility, and the second associated with equality. In other words, the first two types of citizenship are based on the economic, political and social benefits (in actual terms as well as perceived) embedded in citizenship of the host country. The third aspect, however, has more patriotic features because it describes the emotional bond one has with his/her own society. 
Important studies in assessing the instrumental vs patriotic debate, are those by Betts and Birrell (2007) and Fozdar and Spittles (2010). Both have clear roots in the liberal and communitarian debate. Betts and Birrell argue that if someone views citizenship as a sense of belonging to, and affective connection with, a respective state and its people (which overlaps with the meaning of communitarianism), it is a patriotic view of citizenship. In contrast, if someone views citizenship as a tool to access certain rights, it is instrumental. Hence, according to them, persons who view citizenship instrumentally do not have compassionate feelings for others in society. They imagine the state without the nation, seeing the state as a service station. For Betts (2002), citizens with patriotic aspirations are the only people who contribute to the collective identity and common good in society. She uses the terms "peoplehood" and "communitarianism" interchangeably to mean patriotism (Betts, 2002, p.57). This view is supported by Foner (2001, p.29), who uses the terms "instrumental" and "selfish" interchangeably. In Foner's opinion, many immigrants only acquire citizenship to secure government benefits, but they do not pledge any true allegiance to the host country.

Fozdar and Spittles (2010) have opposing arguments about the two notions. While Betts and Birrell see instrumental and patriotic as two distinct aspects, Fozdar and Spittles (2010) suggest they are overlapping views that are not practically distinguishable. Fozdar's and Spittles's key argument is that separating one's emotional ethnocultural bond (to the nation) from a civic legal-rational connection (to the state), particularly in migrant states such as Australia, is not practically possible. As stated by them (2010, p.127):

Such a distinction is fundamentally problematic for settler nations with diverse migrant populations. Australia is such a society built on the integration of migrants into an increasingly multicultural polity. The role of citizenship in this process of integration and nation-building is contested.

Their other argument relates specifically to the way immigrants perceive citizenship: in their study of immigrant conceptualisations of Australian citizenship, they found that peoples' perceptions were neither completely instrumental nor patriotic, but are rather a combination of both those values. Thus, they argue that 
no view is entirely free from the other competing view, but are intertwined and inseparable. For example, if a person decides to become a citizen of a respective state because of the love for the place and people (a patriotic value), perhaps that attractive place and people are a product of rights and opportunities received (an instrumental value). Thus, Fozdar and Spittle report immigrants' citizenship perceptions to be more complex and ambivalent than argued by Betts and Birrell.

Based on these arguments, I explore whether the two notions of instrumentalism and patriotism are distinct as Betts and Birrell argue, or entangled as Fozdor and Spittle sustain. To do so, I test Fozdor's and Spittles's argument that instrumental and patriotic perceptions are practically undistinguishable. However, unlike Fozdar and Spittles, who specifically looked at immigrants' views on host country citizenship, I explore Sri Lankan participants' perceptions towards home and host country citizenship separately, and then compare those two views. In other words, I compare the patterns of inter-relations between instrumental and patriotic views of home country citizenship with that of their host country. Such comparative knowledge about immigrants' citizenship perceptions is lacking in the literature. Accordingly, my second hypothesis is as follows:

Hypothesis 2: Sri Lankan immigrants' instrumental and patriotic citizenship perceptions (both towards home and adoptive country citizenship) are not distinct, but entangled.

In the next section, I explain the two explanations I borrow from the citizenship and migration literature to measure participants' instrumental and patriotic perceptions. I first explain my use of socio-economic and political factors as interpreted by Yang (1994) in understanding instrumental perceptions. I then explain the use of thin and thick citizen ship ties as interpreted by Ronkainen (2011) in understanding patriotic perceptions.

3.6 Explaining instrumental and patriotic perceptions 
Previous studies show that because perceptions are ambivalent (Fozdar \& Spittles, 2010) and affected by a range of socio-economic and other factors (Yang, 1994), studying immigrants' citizenship perceptions is a complex task. As a result, separating immigrants' instrumental and patriotic perceptions from each other in this research becomes challenging. However, my study emphasises the importance of identifying the salient features of immigrants' citizenship perceptions, both instrumental and patriotic, in order to find the inter-relations between them. Therefore, while acknowledging the limitations of decoding citizenship perceptions, below I explain the working definitions and framework within which I distinguish the two in this research. I first explain my use of the socio-economic determinants model interpreted by Yang (1994) to explore instrumental perceptions. Then, I explain the use of the non socio-economic determinants model (Yang, 1994) and Ronkainen's (2011) four aspects: voice; roots; loyalty; and exit, in his typology of thin and thick citizenship ties, to explore patriotic perceptions.

\subsubsection{The socio-economic determinants model}

Reviewing the hypotheses in previous studies' that discussed immigrants' citizenship perceptions, Yang (1994) suggests that there are two key models: the socioeconomic-determinants model and non-socioeconomic-determinants model. The socio-economic determinants model draws from Bernard's (1936) pioneering study where he found that the higher the levels of socio-economic and political status immigrants possess in the host country, the higher the probability they will seek and acquire citizenship in that country. Socio-economic factors include a range of components such as income, welfare assistance, job opportunities, travel benefits, educational opportunities, social security, health care entitlements, subsidised housing, retirement packages, taxations concessions, and so forth (Turner, 1997; Yang, 1994). In many host countries, citizenship is required to access some of these benefits, such qualif ying for some educational opportunities, awards or loans, and certain health care services. Moreover, some government jobs require host country citizenship, which means that some immigrants decide to 
naturalise mainly to be eligible for such employment. Therefore Yang (1994,p.452) suggests that, in these cases, "[citizenship] offers immigrants important avenues of economic and social mobility."

Furthermore, if an immigrant is successful in adapting to their new country economically, their commitment to that country increases while their will to return to the state of origin decreases (Yang, 1994). This economic dependence will positively affect immigrants' views of the benefits of having citizenship status, making them more likely to want to acquire it in the state of settlement. An immigrant's decision about whether to pursue citizenship in their host country, therefore, involves a comparison of the respective economic benefits of either their home or host countries. As Yang (1994, p. 457) states : "poor economic conditions and low standards of living in the country of origin may deter immigrants' desires to return to their homelands and therefore inspire them to stay in the host country." Immigrants from such countries may also get social pressure from people in their home country to acquire host country citizenship, because it increases the opportunity for other family members to migrate. This is because certain host countries - such as the United States - have special immigration provisions that support family reunion. Yang also points out that immigrants' level of economic integration influences decisions about naturalisation, since economic adaptation increases peoples' commitment to their host society (Yang 1994; 455).

Political factors, meanwhile, include factors such as the level of political freedom, political stability, political participation, equality, and democracy. According to Yang, immigrants from countries that impose tighter political control over individuals may be deterred from wanting to return or continue their citizenship links with home. If their home country has less political stability than their adoptive country, immigrants are more likely to naturalise in the host country. In the case of refugees, Yang states that those who were forced to leave the home country due to reasons such as wars, revolutions, religious persecutions, ethnic disc rimination, or other political chaos, are more likely to naturalise in the adoptive country because 
of their fear of return. Naturalising elsewhere provides benefits such as being able to help friends and relatives migrate.

Skulte-Ouaiss (2013) argues that receiving a passport from a Western democratic host country is both a socio-economic and political factor. Studying Lebanese citizens who are also citizens of the European Union (EU), Skulte-Ouaiss (2013) argues that Lebanese immigrants view EU citizenship as a means of improving their safety and prosperity. Safety here has a political meaning, whereas prosperity is economic. For example, obtaining an EU passport is perceived as a safeguard to be used when the situation in Lebanon gets rough. For them, EU citizenship is a symbol of security, access to the rule of law, and an opportunity, without necessarily entailing any sense of belonging. This suggests that for the people of their study, EU citizenship provides instrumental benefits that are of social, economic and political interest, as well as a form of protection. Hence, these immigrants' decision to obtain EU citizenship was not only influenced by the positive socio-economic and political factors in Europe, but also because of negative elements in their home country.

The level of access for socio-economic and political rights and privileges are critically important in shaping immigrants' instrumental citizenship perceptions (Bernard, 1936; Bloemraad, 2004; Portes \& Rumbaut, 2006; Yanasmayan, 2015; Yang, 1994). Therefore, I borrow this socio-economic determinants model because it offers useful ways of this. However, while Yang uses these factors as variables to understand immigrants' views of adoptive country citizenship, I use them comparatively to understand participants' views of both home and adoptivecountry citizenship. In other words, I explore whether or not socio-economic factors of home countries have affected participants' host country citizenship perceptions, as well as whether or not those of host countries have affected how they consider their home country citizenship. The following section explains the non socio-economic factors I use in exploring participants' patriotic views. 


\subsubsection{The non socio-economic determinants model}

Barken and Khokhlov (as cited in Yang, 1994) counter the above-discussed socioeconomic hypothesis as the single explanation for immigrants' citizenship perceptions. They introduce a second research model; the non socio-economic determinants model. These scholars argue that, as well as socio-economic and political factors, elements such as cultural and structural assimilation into the country of the settlement are essential factors that increase immigrants' propensity for naturalisation. For example, if the host country shares cultural similarities with the home country, it would affect migrants' positive attitudes towards citizenship.

There are two key non socio-economic situations explored widely in the literature: 1) the level of integration with the host society (Ager \& Strang, 2008; Arvizu \& Garcia, 1996; Avc1, 2006; Bennour, 2020; Bloemraad, 2006a, 2006b; Ersanilli \& Koopmans, 2010; Paquet, 2012; Scipioni, 2017; Zhou \& Liu, 2016); and 2) transnational relations with the home country (Arkilic, 2016; Basch et al., 1994; Bauböck, 1994; Bloemraad, 2004; Brown, 2014; Brun \& Van Hear, 2012; Cassim, 2017; Conway et al., 2008; Jones, 2016; Leitner \& Ehrkamp, 2006; Levitt \& Schiller, 2004; Merelo, 2016; Mügge, 2012; Orjuela, 2008; Simonsen, 2016, 2017; Tölölyan, 1996; Wayland, 2004).

I argue that immigrants' level of integration in the host society is one of the main factors that affect immigrants' patriotic views towards being a citizen. Studies show that when an immigrant is successfully integrated into any society, they develop a sense of belonging to that society (Bloemraad, 2000, 2006a; Cassim, 2017; Constant et al., 2009; Ersanilli \& Koopmans, 2010; Fozdar \& Spittles, 2010; Merelo, 2016; Zhou \& Liu, 2016). As the result, such an immigrant is highly likely to obtain host country citizenship (Bloemraad, 2006a).

In studying immigrants' integration, (Bloemraad, 2006a) observed that there is a different pattern of citizenship acquisition in Canada and the USA. She found that immigrants' interest of naturalisation in the USA has declined, while there is no such decrease in Canada. In her opinion, this is due to the fact that immigrants' 
level of integration in Canadian society is much higher than that of the USA, due, perhaps, to the fact that these countries have different governmental policies supporting integration and settlement. While public funding to support settlement has been reduced in the USA, there was no such decline in Canada. Therefore, following the Canadian example, Bloemraad (2006a) suggests immigrants' citizenship acquisition is higher when they are integrated in the host society.

Apart from government policies, Bloemraad also pays attention to societal-level factors affecting immigrants' integration and naturalisation. Here, she stresses the importance of fellow immigrants and local organisations in encouraging integration. In fact, Bloemraad inteprets immigrants' settlement as a social process of mobilisation by friends, family, community organisations, and local leaders, which is embedded in an institutional context shaped by government policies of diversity.

Bloemraad's findings are useful in understanding the state-related factors affecting immigrants' emotions about integration and, eventually, naturalisation. This is an essential argument for my research, since I use it to compare and contrast the Australian and New Zealand institutional and governmental arrangements for immigrants' integration. Ward and Masgoret (2008) stated that while New Zealand is a multicultural country with relatively positive attitudes towards immigrants that provides public funding and programmatic support for immigrants, Australia and its migration and citizenship policies are affected by anti-immigration rhetoric (Fozdar \& Spittles, 2009, 2010). They are therefore restrictive and problematic.

On immigration, refugee integration has gained attention as a distinct research theme. In studying such integration in Australia, Fozdar (2013) explored how Australian settlement facilities for refugees have resulted in the development of a sense of belonging with its society. She found that while such settlement facilities have assisted refugee migrants' civic belonging, their ethno-belonging is more ambivalent. Fozdar argues the reason for this is refugee immigrants' perceptions of exclusion from the mainstream population. She suggests that for refugee immigrants, belonging is not an end point, but an ongoing project that takes time. 
While integration is a critical factor that shapes immigrants' sense of belonging to the host society, the relations one keeps with one's home country are essential in shaping immigrants' sense of belonging there. Being able to retain home country citizenship (in the form of dual citizenship) affects immigrants' sense of belonging to the home society positively. Yang (1994, p. 458) found that having the opportunity to obtain home country dual citizenship has an instrumental correlation with naturalisation in the host country, since it allows immigrants to take advantage of citizenship in the new country without giving up full privileges and identity in the home country. Moreover, when both home and host country allow immigrants to keep dual citizenship, it positively affects immigrants' perceptions and decisions in relation to host country citizenship.

Scholars also found that immigrants' relations with their ethnic networks, such as immigrants' organisations in the host society, are related to their sense of belonging to the home country (Anderson, 1974; Ballard, 2001; Crisp, 1999; Haug, 2008; Ho, 2002; Orjuela, 2008; Plüss, 2005; Portes, Escobar, \& Radford, 2007; Portes \& Zhou, 2012; Wayland, 2004). Yang (1994) presented two competing hypotheses about how the size of the immigrant community in a host country affects immigrants' patriotic citizenship perceptions. According to the first hypothesis, the size of an immigrant community in the host country is inversely related to the probability of naturalisation. This is because a large immigrant community increases the likelihood of such communities "forming a self-contained ethnic network in which new immigrants can function well without citizenship" (Yang, 1994, p. 456). In such a case, Yang (p. 456) believes that "immigrants are less likely to use citizenship acquisition as a strategy for the purpose of self-protection and are less likely to identify themselves as [host country citizens]." The other hypothesis suggests a positive association between the size of the immigrant community and the probability of obtaining host country citizenship. That is, a large immigrant community may facilitate naturalisation by helping its members' integration and by providing information concerning the benefits of citizenship. As discussed earlier, Bloemraad (2006a) also believes that the existence of co-immigrants from the same country, and ethnic organisations, play a positive role in advancing immigrants' 
desire to become a host country citizen. When immigrants are surrounded by others from the same country, in a country that facilitates settlement and integration, they often generate positive perceptions about becoming host country citizens.

Zhou and Liu (2016) found that the nature of the bilateral relations between an immigrant's home and host country also affect their patriotic citizenship perceptions. Comparing Chinese immigrants in the United States and Singapore, they concluded that the latter tend to naturalise more than the former, due to the rivalry between China and the USA. Specifically, repeatedly hearing negative opinions about China, such as anti-Chinese speeches, reports, and news items, during their stay in the USA has disturbed Chinese immigrants' patriotic perceptions about citizenship acquisition there. Hence, becoming a citizen in a country that is a rival to their home country, China, is found to be an emotionally difficult decision. In contrast, warm relations between China and Singapore, and the long history of bilateralbusiness, have encouraged Chinese people in Singapore to have positive attitudes towards Singaporean citizenship.

As mentioned above, these two scenarios: 1) integration with the host society and 2) the type of relationship an immigrant keeps with their home country, critically affect immigrants' emotions. I argue that these emotions play a pivotal role in the generation of patriotic citizenship perceptions. These emotions include feelings of belonging and identification with a national collective or culture, feelings of loyalty, gratitude, and feelings of allegiance as a citizen (Ronkainen, 2011). To measure patriotic perceptions influenced by emotions, I employ Ronkainen's typology of thin and thick citizenship ties.

Ronkainen's typology is developed from Tilly's (1995) initial distinction between thin and thick citizenship, according to which "citizenship can ... range from thin to thick: thin where it entails few transactions, rights and obligations; thick where it occupies a significant share of all transactions, rights and obligations sustained by state agents and people living under their jurisdictions" (p.8). Ronkainen advanced Tilly's theory by connecting it to Hirschman's "voice, exit, loyalty theory" (described earlier in this chapter), making it easier to deconstruct and measure 
the thinness and the thickness of immigrants' citizenship perceptions. According to Hirschman, voice, exit and loyalty were the citizens' participation possibilities in relation to state. In addition to these typologies, Ronkainen added a further one roots - to examine how the ideal types of national belonging transfer to possible citizenship participation. Ronkainen's (p.258) four aspects of thin and thick citizenship ties are:

- Voice: voting or other types of political participation, such as having an opinion about the political and societal issues of the state, and the interest to follow those contemporary issues and concerns;

- Roots: feelings of belonging and identification with the national collective of society. Feelings of honouring family, kin, ethnicity, and other cultural backgrounds and roots;

- Loyalty: feelings of loyalty, gratitude, and solidarity towards the state. Feelings of allegiance and willingness to fulfil duties as a citizen;

- Exit: no notable use of citizenship tie, or the tie has been broken in practice.

As Ronkainen himself has acknowledged, this categorisation suffers from some limitations. On the one hand, some categories overlap, for example both roots and loyalty describe emotional attachments to citizenship. However, Ronkainen distinguishes roots and loyalty from each other as, with roots emphasising national or family cultures, whilst loyalty is directed more at the state and political community.

Yanasmayan (2015) who borrows from Ronkainen's typology as a guide to her research, states that Ronkainen does not provide a sound explanation as to how to operationalize the measurements of the thinness and thickness through his typology. For this reason, Yanasmayan uses a simple distinction to divide the two, employing the thin sense of citizenship to mean citizenship only as a legal status, aside from any emotional attachment, offering a utilitarian and statutory sense of citizenship that does not overlap with any emotive element. A thick sense of citizenship, on the other hand, is the emotional bonds towards the nation or the society. Thus, 
Yanasmayan uses roots as a sign of identity, and loyalty and voice as participatory dimensions.

My distinction of thin and thick citizenship is different from Yanasmayan's. Since I look at instrumental and patriotic perceptions separately, I investigate the utilitarian and statutory sense of citizenship under instrumental perceptions. Thus, in this study, thin does not mean a utilitarian and statutory sense of citizenship. Instead, I employ both thin and thick citizenship to understand and measure my participants' non-utilitarian views, such as senses of belonging, which I argue to be the stimulator for patriotic perceptions. Given their subjective, relative, and contextual nature, I do not group patriotic perceptions as either negative or positive. Thus, I hypothesize that participants' patriotic perceptions are on a spectrum: from thin to thick. Moreover, in measuring the thin to thick range of patriotic perceptions, I borrow the four aspects of Ronkainen's typology: voice, roots, loyalty, and exit. If a participant's patriotic perception is predominantly based on only one aspect (either voice, roots, or loyalty), I consider those perceptions to have a thin sense. If the perception is based on a combination of two or three aspects of voice, roots, and loyalty, I consider those perceptions to be thick patriotic. Even though I acknowledge the overlapping nature of these three aspects, I employ this typology because these overlaps do not affect my main aim - to identify how my participants' patriotic perceptions are shaped - in any significant way. Combining the thin to thick range with the arguments explained earlier about immigrants' integration in the host society, I hypothesize as follows:

Hypothesis 3: Both Sinhalese and Tamil participants' thin and thick patriotic perceptions towards their host country citizenship are the same, while their views towards home country citizenship are different.

In designing this hypothesis, I took into consideration the different types of attachments Sinhalese and the Tamil immigrants have with Sri Lanka due to their ethnic differences. I argue that based on those different attachments, Tamil participants have thin patriotism towards Sri Lankan citizenship, while Sinhalese participants have thick patriotism. 
3.6.3 Mixing both socio-economic and non socio-economic determinants

As I emphasised elsewhere, my effort in mapping how socio-economic factors influence instrumental perceptions while non socio-economic factors influence patriotic perceptions, should only be considered as an operational step in exploring immigrants' perceptions in-depth. This is because prior to finding the interrelationships between instrumental and patriotic perceptions, I assume that we should have a deep knowledge of each separate perception. However, in saying this, I do not deny the fact that immigrants' citizen ship perceptions are generally affected by a combination of both socio-economic and non socio-economic factors. As Yang (1994, p. 450) put it, these two types of traditions "are essentially noncontradictory; rather they complement each other." Therefore, while understanding each perception separately, I highlight the necessity of exploring the interrelationships between instrumental and patriotic perceptions to understand immigrants' citizenship meanings better.

There are many scholars who maintain that we do not necessarily have to analyse socio-economic and non socio-economic factors separately, since we can consider them as a mix. Foner (2001) brings up four main factors that affect migrants' views on citizenship, namely: familial; economic; political; and cultural. For Basch et al. (1994), there are six factors affecting immigrants' perceptions of citizenship: familial; economic; social; organisational; religious; and political. Levitt and Jaworsky (2007) point out five factors: economic; political; social; cultural; and religious. These categories overlap with each other. For example, religion can be viewed under the domain of culture, because distinguishing between culture and religion is not seamless (Levitt \& Jaworsky, 2007).

The findings of Mügge (2012), on Turkish immigrants' in the Netherlands perceptions of their home country citizenship, highlight how a combination of both socio-economic and non socio-economic factors affects immigrants. Mügge (2012) argues that the periods when the Netherlands allowed dual citizenship resulted in 
an increasing citizenship acquisition rate among Turks. When the Dutch naturalisation law reversed to the requirement of renunciation of former citizenship, it resulted in a decline in citizenship acquisition. According to Mügge (2012), there is an instrumental reason for this. Turks were afraid of losing their rights of inheritance in Turkey by becoming Dutch nationals, and that was the main reason for their reluctance to give up Turkish citizenship.

However, Yanasmayan (2015) counters this argument and finds that there were not only instrumental reasons, but also patriotic ones affecting dual citizenship acquisition. Yanasmayan focused on the Turkish Blue Card scheme introduced exclusively for their emigrants. This scheme gave certain rights, such as residence and inheritance, to Turkish emigrants. For example, if an immigrant is in a condition where their host country does not allow dual citizenship, they can obtain the Card. The Card helps them enjoy a set of instrumental benefits in Turkey even without Turkish citizenship. In this way, Yanasmayan countered Mügge's finding that Turkish migrants do not want to give up their Turkish citizenship because of the instrumental problems they have to face.

Another example is Pogonyi's (2019) study on how the acquisition of a passport from their host country passport affects immigrants' sense of belonging. Although some scholars have argued that immigrants' motivation for obtaining a passport from a Western democratic country is purely instrumental (Skulte-Ouaiss, 2013), Pogonyi (2019) found that for some, the passport is not only instrumental, but also has patriotic factors, as having a passport strengthens the holder's sense of belonging to a particular society. Therefore, Pogonyi argues that citizenship "is also ... a valuable symbolic asset which can be instrumentalized as means of social closure" (p.975).

Based on the arguments above, I assume that Sri Lankan immigrants' citizenship perceptions have been affected by a myriad of factors. Accordingly, my third hypothesis is as follows:

Hypothesis 4: Socio-economic factors affect immigrants' instrumental views as well as their patriotic views. 
In testing this hypothesis, I take both home and host country conditions into consideration. This means that I explore whether or not socio-economic factors of the home country have affected participants' host country citizenship perceptions, and vice versa.

\subsection{Conclusion}

This chapter discussed a range of theories relevant to immigrants' citizenship perceptions including traditional citizenship theory, which does not explain immigrants' multiple belongings - legally or sentimentally - and transnational citizenship theory, which recognises such multiple belongings. However, I argue that existing theories fail to fully explain immigrants' citizenship perceptions: specifically, how their comparative perceptions about costs and benefits of becoming citizens in their adoptive country, as well as retaining home country citizenship, shape their views.

Based on the case of Sri Lankan immigrants' in Australia and New Zealand, I argue that their perceptions about Australian or New Zealand citizenship are reversibly affected by their perceptions of Sri Lankan citizenship, and vice versa. However, I also argue that the way home country citizenship perceptions affect Sri Lankans' perceptions of adoptive country (and vice versa) is different forSinhalese and Tamil immigrants. This is because these two groups have had different home country experiences based on their ethnicity and majority-minority status, which have led them to hold different migratory objectives and motivations.

For this reason, I suggest that Sri Lankan immigrants cannot be considered a homogenous group, and their instrumental and patriotic citizenship perceptions are rather entangled. Hence, I argue that the socio-economic determinant model can explain not only immigrants' instrumental perceptions, but also patriotic ones. In investigating Sri Lankan immigrants' patriotic perceptions in-depth, I argue that 
Sinhalese and Tamil participants have different levels of thin and thick attachments to their Sri Lankan citizenship.

As I identified the strengths and weaknesses of the existing literature in this chapter, I present my findings about Sri Lankan immigrants' citizenship perceptions of their home and host states in Chapters Five to Seven, beginning with an exploration of my participants' instrumental perceptions in Chapter Five. 


\section{CHAPTER 4: Research methods}

\subsection{Introduction}

This chapter explains the research methods used in this study. The key objective of the study is to explore immigrants' perceptions of their host and home country citizenship. Perceptions refer to the collection, organisation, identification, and interpretation of information through which one makes sense of the world around them (Bennett, 1981; Schacter, Gilbert, Wegner, \& Hood, 2012). Thus, perceptions are highly subjective, contextual, and relative. The migration literature shows immigrants' perceptions to be affected by three main factors: their individual preferences, host country factors, and home country factors (Yang, 1994). These factors are further complicated by the influence of numerous socio-economic, political, and cultural conditions, suggesting that immigrants' perceptions are complex and multifaceted. This chapter discusses the methods adopted in this study to explore those complex perceptions and the numerous factors affecting them.

Because Sri Lankan immigrants' citizenship perceptions are inherently subjective, contextual and relative, for this research I employ a qualitative approach. Qualitative studies are aimed at understanding "complex world of human experience and behaviour from ... those involved in the situation of interest" (Krauss, 2005, p.764). Qualitative studies are generally empirical because they are conducted in natural settings (Toma, 2006). They therefore help us understand "individual diversity and the nuance of social context" (Stein \& Mankowski, 2004).

This chapter has three main sections: pre-field, field and post-field. The pre-field section discusses the design stage of the research, such as the reasons for selecting interviewing as the primary method of collecting data, participant recruitment, and planning the field. The field section examines the way interviews were conducted, as well as challenges and the lessons learnt during the field. The post-field section analyses the methods used in analysing data and writing up the findings. The conclusion contains a summary of the limitations of the methods used. 


\subsection{Pre-field}

Selecting appropriate methods to study subjective, contextual, and relative perceptions was challenging. Many of the previous studies examining this subject, such as Bueker (2005) and Yang (1994), as well as overlapping areas such as immigrants' naturalisation (Balistreri \& Van Hook, 2004; Bennour, 2020; Bueker, 2005; Evans, 1988; Forrest \& Dunn, 2006; Glover et al., 2001; Jones-Correa, 2001; Ronkainen, 2011; Simonsen, 2016,2017; Takeuchi et al., 2007), used quantitative methods, with a positivist and rational decision-making approach. Because my interest was to explore immigrants' perceptions, which go beyond a single reality, the positivist nature of many quantitative methods was not appropriate. Thus, for example, I avoided using surveys, because such a method would not let me find the plurality of immigrants' perceptions and novel themes that go beyond any structured points that I, the researcher, makes. Qualitative approaches, however, enable such nuance in the study.

I used interviews as the primary method of collecting data. Interviewing is the central resource for comprehending knowledge in social sciences (Atkinson \& Silverman, 1997) and is considered the primary method for researchers to collect rich and in-depth experiential data (Fontana \& Frey, 2005). According to Rapley (2011), interviews are social encounters within which respondents bring out their accounts or versions of the past, present, and future actions, experiences, feelings, and thoughts. As such, they are a crucial research method for receiving unknown information and to hear about people's experiences, feelings, and the beliefs that guide their behaviours (Holý \& Stuchlik, 1983).

There are two types of qualitative interviewing: 1) interview-data-as-resource; and 2) interview-data-as-topic. Seale (as cited in Rapley, 2011) described the first type as an exploration of data outside the interview. In other words, this type of data would reflect the interviewee's reality, in isolation from the interview. In contrast, the second type derives from the belief that the data collected in an interview is a 
reflection of the reality jointly constructed by the interviewee and the interviewer. Interviewing is an active process that leads to a "contextually bound and mutually created story" (Fontana \& Frey, 2005, p.696). This research considers interviews to be the second type, namely "interview-data-as-topic."

However, due to the interviewer's active involvement in the second type of interviewing, this method is criticised for possible biases. For example, if the interviewer gets too involved in the interview, and if this behaviour prevents the interviewee from sharing their real thinking, there is a risk that the researcher would not reach the pure truth. However, not being involved in the interview would not solve this issue. This is because knowledge is never value-free (Guba \& Lincoln, 1994). In other words, it is impossible for a researcher to remain an objective observer. The researcher, at some point, has to use their socially constructed knowledge, attitudes, beliefs, and experiences to consciously or subconsciously analyse data received during interviews. However, the researcher should try to be as unbiased as possible while explaining the process, and during data collection. One way to help prevent bias would be by recording and conveying related information about the researcher to the participant. Sunstein and Chiseri-Strater (2012) note that it would be deceptive if the researcher does not declare any relevant background information about themselves during the study. De Volo and Schatz (2004) also point out that recording and conveying such information increases the credibility of the study.

To make this a credible study, I hereby include background information about myself in three main areas: 1) fixed positions; 2) subjective positions; and 3) textual positions (Sunstein \& Chiseri-Strater, 2012). Fixed positions are personal facts such as my age, gender, class, nationality, ethnicity, and race, which might potentially influence the way the researcher sees and interprets the data. In my case, I am a Sri Lankan citizen; Sinhalese by ethnicity (part of the majority ethnic group of Sri Lanka); and a Buddhist by religion. I am a female in her early 30s, from a middleclass, suburban, family, and I have a daughter. I acknowledge that these fixed positions of mine have some impact on the way I saw my participants, and the way I interpreted and analysed my data. 
Subjective positions are the personalised life experiences that affect the researcher's views towards the study. In my case, I come from a migratory family background. Since I was two years old, my father worked and lived in Italy. Observing his behaviours and decisions regarding citizenship has influenced the way I see Sri Lankan immigrants' lives in their host countries and their relationship with the home country. Textual positions are the ways in which the researcher positions themself in the field with respect to the participants. Some participants are very open during the interview process, and some are not. These sorts of contextual reasons affect what kind of information can be gathered by the researcher. Throughout my fieldwork, I kept a fieldwork diary to record as much contextual information as possible. Recording this information helped me analyse and interpret my participants' data contextually.

\subsubsection{Semi-structured questions}

For this study I conducted semi-structured interviews. Since my aim was to study perceptions, structured interviews, which are generally rigid and centred around a limited set of response categories (Fontana \& Frey, 2005), were not suitable. Completely unstructured interviewing was also not appropriate, because too much flexibility would have blurred my focus and perhaps prevented me from collecting data related to my research questions (Rabionet, 2011). Semi-structured interviews, however, allowed me to ask the same set of questions to various people within a flexible framework (Dearnley, 2011). In addition to the main set of questions, I asked some spontaneous and follow-up questions depending on the interviewee responses. Semi-structured interviewing encouraged, and gave space for, the interviewee to elaborate on points of interest. This allowed the interaction between the interviewer and the interviewee to go deeper whenever necessary (Rabionet, 2011). Another advantage of using the semi-structured method was its ability to ask questions outside a defined order. This allowed me to navigate the questions based on keywords each answer. In this way, the conversations were more meaningful, 
clearer, and focused. Moreover, semi-structured questions encouraged my interviewees to express their views on citizenship freely, and allowed me to hear diverse and original answers from each person.

I designed a preliminary set of questions in July 2018. The questions were grouped into four themes: 1) perceptions about host country citizenship; 2) reasons for obtaining (or not) host country citizenship; 3) perceptions about home country citizenship; and 4) reasons for retaining (or not) home country citizenship. The interview started with the broad question: "what does your host country citizenship mean to you?" This beginning encouraged the participant to give an unbounded and broad answer. Broad questions such as this help break the ice between the interviewee and the interviewer by enabling the interviewee to express a range of different views before they go into details. According to Rapley (2011), it is only then the researcher can collect different or contrasting data that will be central to modifying theories. From this initial, broad, starting point, the rest of the conversation then navigated the other questions in a personalised way.

\subsubsection{Sampling and participant recruitment}

This study was based on forty-nine interviews, conducted in Australia and New Zealand. The richness of the data is the key to success of any qualitative study. Having access to a broad range of different opinions determines this richness. To help get a range of opinions, the researcher should have an adequate pool of participants. The existing literature provides different views about the ideal number of a sample for similar studies. Guest, Bunce, and Johnson (2006) suggest that one should continue sampling until one reaches data saturation - that is, reaching a point in the data collection process where new information no longer provides novel contributions (Morse, 1995). Bernard (as cited in Guest, Bunce and Johnson, 2006) observed that most qualitative studies similar to mine had between thirty to sixty participants. Morse (2000) agrees with the thirty to sixty range, arguing that this is 
an adequate sample to collect useable data when using semi-structured interviewing. The 49 interviews in my research enables its comparative nature.

I used purposive sampling to recruit participants. Due to the limitations of th is study, I decided not to use random sampling, despite its strengths as a sampling technique. Random sampling reduces biases and increases the ability for generalisations (Topp, Barker, \& Degenhardt, 2004). This sampling technique would have given each Sri Lankan immigrant in New Zealand and Australia an equal chance of being selected for the study. However, random sampling is not always feasible and efficient, especially if time and resources are limited. In addition, if the sample itself is diverse, random sampling will not do justice to the study.

The total number of Sri Lankan born immigrants is nearly 16,000 in New Zealand (Ministry of Foreign Affairs and Trade, 2019) and 109,853 in Australia (Australian Bureau of Statistics, 2016). As explained in Chapter Two, these communities are highly diverse. Therefore, if not chosen consciously, the sample may not represent the entire immigrant community. For example, because Tamils are the minority ethnic group in the Sri Lankan migrant community in Australia and New Zealand, there is a risk that their experiences will not get adequate attention in a random sample. This would mean that the majority Sinhalese ethnic immigrants' voice would dominate the sample. Even within each ethnic group, immigrants belong to various socio-economic and legal categories. For example, Sri Lankan immigrants range from professional migrants, skilled migrants, students, and those who migrate to re-unite with their family. These different categories possess various socioeconomic features. Also, there are Sri Lankan immigrants with refugee status in both New Zealand and Australia, whose views and experiences about citizenship may be different from those of the mainstream immigrants. With random sampling, there is a risk that this group will not be represented. Under these conditions, purposive sampling is recommended as a valid method (Tongco, 2007).

To ensure that my sample represents the diversity of the Sri Lankan immigrant community, I recruited participants carefully through purposive sampling. Also 
called judgement sampling, purposive sampling is a non-random technique of deliberately choosing informants based on a predetermined set of criteria set by the researcher, in line with the research objectives (Guest et al., 2006; Tongco, 2007). According to what needs to be found out, purposive sampling enablesthe researcher to select a diverse and fitting group of participants. These participants should have substantial knowledge and experience about the research topic and should be willing to share what they know with the researcher (Bernard, 2006). In this technique it is assumed that the research participants are reflective members of the related community (Bernard, 2006). In other words, a well selected purposive sample contains the ability to demonstrate the general features of the broader community.

To expand my participant network beyond those I initially knew, I used the snowballing method. That is, I sought my potential participants' assistance to connect to the people they know as other potential participants for my study. The snowballing technique has a couple of risks: that the researcher would meet only like-minded participants, or that the first participant will have a substantial impact on the sample, for example. To mitigate these constraints, I used multiple entry points to enter the Sri Lankan community. This gave me access to different types of Sri Lankan migrants. It also reduced the need to rely only on my first participant. My various entry points included the Sri Lankan Honorary Consul in New Zealand, leading Sri Lankan immigrant organisations such as the Sri Lanka German Technical Training Institute Old Boy's Association of Australia in Melbourne, the Sri Lanka Association of New South Wales in Sydney, the Sri Lankan Society of New Zealand in Auckland, and the United Sri Lanka Association in Wellington. I also used some personal contacts that I had made prior to starting my fieldwork. Since I was based in Wellington throughout this study, I attended numerous Sri Lankan events through which I could meet Sri Lankan immigrants from both Wellington and Auckland. I sought help from the people I met at these events who offered me assistance with connecting to the larger Sri Lankan immigrant community. As Merelo (2016) identified, if the researcher shares the same nationality as the research participants, attending national events and participating 
in the ethnic and cultural gatherings organised by embassies or community organisations is undoubtedly helpful to build up new contacts. Tongco (2007) also notes that asking for help from the community is useful in selecting a good sample. In the case of the Sri Lankan immigrant community, when I was recommended to them by someone else, most participants trusted and were comfortable to talk to me. I earned credibility as the researcher when an ethnic organisation or a participant who I had already interviewed approved of me. Gaining credibility was essential in getting participants to talk openly and freely with me.

During the pre-field period, I planned to conduct an even number of interviews (12 each) in the four cities. However, this was not possible. I conducted 49 interviews in total: 11 interviews in Melbourne, 12 in Sydney, 15 in Auckland, and 11 in Wellington. Of the 49 interviews, I conducted 39 interviews with Sinhalese participants and 10 with Tamil participants. This means that 79 percent of the data was collected from Sinhalese participants, and 21 percent from Tamil participants. This ethnic composition is similar to the composition of the Sinhalese and Tamils in the Sri Lankan population, as mentioned in Chapter Two.

A majority of my participants (33 people) were recruited purposively during the pre-field stage. The other 16 were recruited purposively during the field period. I All 11 participants in Wellington were recruited during the pre-field period. Because I was residing in Wellington during my $\mathrm{PhD}$ study I had a fairly extensive network within the Sri Lankan immigrants there, and I was flexible in terms of scheduling times and dates, therefore recruiting these participants was relatively straightforward. However, in the other cities, I had to schedule all the interviews during my short stay there. I also had to put extra effort into expanding my network to find potential participants. Seven interviews in Melbourne, eight in Sydney and seven in Auckland were with the participants I recruited purposively before conducting the field. The other 16 interviews in Melbourne, Sydney, and Auckland were with the participants I recruited during the fieldwork.

Six of these 16 participants were from former refugee backgrounds. Reaching out to such participants during the pre-field time, specifically, those who are Tamil 
immigrants who left Sri Lanka due to the civil war, was very challenging. My position as a Sinhalese Buddhist was a huge disadvantage. Until they saw and talked to me, former refugee participants did not seem to trust me. Having to share their citizenship perceptions, a sensitive topic for former refugee immigrants, also discouraged them from taking part in this research. The most successful way of recruiting them was going to the field, entering their community from somewhere they are familiar with, and being recommended by someone they trust. These 16 interviews are vital to making my data more diverse and interesting.

As I explained in Chapter One, my specific focus in this study is first-generation Sri Lankan immigrants. This is because studies have found that second-generation immigrants' perceptions about citizenship is shaped by their ambivalent "inbetweenness" experiences (Bartley \& Spoonley, 2008). This means that the factors (variables) that have shaped second-generation migrants' views of citizenship are different from those affecting the first-generation. Thus, I focused on firstgeneration migrants. Nonetheless, I recruited participants in different migratory statuses: host country citizens; dual-citizens (of both host and home country); permanent residents; and those in the host country with other visa statuses, such as student visas etc. This is because I wanted to explore the broader perceptions of Sri Lankan immigrants towards their host or home country citizenship, regardless of the legal status they carry. I also recruited participants from all ages, all genders, and who arrived in the host country from 1960s until 2017.

\subsection{Field}

As mentioned above, I conducted 49 interviews in total. Since I was based in Wellington during this research, I started interviewing participan ts from Wellington in November 2018. Even though I did not have a personal relationship with the participants I recruited there, I knew some of them before the interview. Others I met face to face for the first time at the interview. While interviews in the other three cities were tightly scheduled in shorter periods (e.g. a week), meetings in 
Wellington took place across one month, and since I was residing there, I let my participants decide on times and dates at their convenience. Although it was not purposefully planned, scheduling interviews with time lapses in between became very fruitful later. Since I was overwhelmed by my first set of interview data in Wellington, I started transcribing interviews after each interview. Sunstein and Chiseri-Strater (2012) suggest starting transcribing as soon as possible after interviews, before the researcher's memory of the interview starts fading. Otherwise, there is a possibility that the researcher forgets aspects of the interview. I initially began transcribing interviews word for word. I used parentheses and brackets to indicate pauses, laughing, and interruptions that happened during the interview. Since I transcribed the interviews in Wellington soon after each one, I had the memory of the contextual factors as well and entered them into my fieldwork diary.

Initially, I started transcribing because of my eagerness to listen to the interviews again and again. This helped me make necessary changes to the way I conducted interviews in the other locations. During the Wellington leg of the fieldwork, I reflected on each interview thoroughly while transcribing the data. This made me revisit the various aspects of the interviewing practices I used, such as the way I constructed the conversation, the way I framed questions, the sequence and flow of the questions, and the tone and rhythm of the conversation. I also tried to map how the questions I asked and the responses I received helped me revise the main research questions of the study. Being able to keep stepping in and out of the field, and having adequate time to transcribe and reflect on these interviews enabled me to effectively change some of the interview process in the other legs of the fieldwork.

After the interviews in Wellington, I went to Auckland in December 2018. I spent one week there. As mentioned above, I had recruited seven participants for the interviews in advance, and eight participants were recruited during the fieldwork. This is because reaching some participants; specifically, Tamil participants, was difficult. Once in the field, however, after experiencing the interview and thus knowing its content, some Tamil participants offered to connect me to some of their 
Tamil friends. I grasped these opportunities whenever they fit with my purpose and the fieldwork schedule.

After the field in Auckland, I left for Australia in January 2019. By the time I started the Australian fieldwork, I had transcribed all the interviews from New Zealand. I spent one week in Melbourne and another week in Sydney. If it were not for the limitations of time and financial resources, I would have preferred to have a break between these two fields. Conducting back to back semi-structured interviews for two weeks continuously, with nearly 23 participants, was challenging.

To make the most of the fieldwork, I scheduled interviews with people in close locations to one another. Even though the average time of an interview was 30 minutes, together with the initial preparation talks and post-interview wrap-ups, the total time of each meeting was around one hour. Many participants were excited to talk with me because my research topic resonated with them. I too wanted to generously explain things to them, and talk with them outside the interview time; during this I could learn more things about my participants, their perceptions, and lives as Sri Lankan immigrants. However, this was tiring, and not always possible.

\subsubsection{Interviewing, protocols, choices and lengths}

I needed to earn the trust of each of my participants to get them to talk to me freely. I attempted to gain the credibility of my participants by following the protocols and procedures recommended by the Ethics Committee of my university - Victoria University of Wellington. At the beginning of every interview, I handed over two documents to each participant. One was an information sheet about my research. It contained information about the project, and contact details for myself and my supervisors, as well as recording the approval of the Victoria University of Wellington Human Ethics Committee. Before starting the interview, I conveyed to my participants their rights, such as the right to ask any questions at any point, the right to remain silent without answering any question they felt uncomfortable with, and the right to ask me to stop the interview at any point. As stated in the 
information sheet, I assured participants that whatever they said in the interview would be used without identifying them. I also assured them that their real names would not be used in the analysis - thus all names in this thesis are pseudonyms. Any information that could potentially lead to the recognition of the participant was not revealed in the analysis. The second document was a consent form. All the participants included in this thesis signed the consent form and gave me their contact details and information such as whether they wish to read this research in the future.

When participants gave me consent to hold the interview, I took some background information from them, such as their ethnicity, profession, age, the year they arrived in their host country, the year they obtained citizenship there, and whether they had home country dual citizenship. I decided to collect this background information for two reasons. First, it was important to get these details to understand the participant contextually. Second, getting the participant to provide such background information acted as an effective ice breaker. Different participants responded to these background questions differently. While some participants gave short, direct answers, some gave more elaborative explanations (for example, some people shared their migratory stories with me at this stage). Thus, asking this set of short questions rendered both the participant and me ready and focused for the interview.

I conducted all the interviews in quiet, comfortable, and safe places chosen by my participants. I believe that giving this choice to the participant provides some agency over the interview. Some participants invited me to their house, while others suggested public places, such as coffee shops and parks. Whenever the interview was outside, I was concerned about the atmosphere and the surrounding noise. Interviewing in peoples' homes was also challenging. When I visited a house, in most cases, all the family members tended to welcome me and share their ideas. In such cases, it was not easy to ask the recruited participant to move to a quiet section of the house to conduct the interview individually.

The language used in the interview became another challenge. In the pre-field phase, I planned to conduct all the interviews in English. This is because, even 
though I could speak Sinhalese, I could not speak Tamil. I thought that if I talk in the mother tongue with one group of the participants (Sinhalese) but not with the others (Tamils), my data would be biased. However, once in the field, many Sinhalese participants said they were more comfortable speaking Sinhalese with me, especially after they learned that I am from their ethnic group. I could not refuse this request. Hence, I conducted some interviews with Sinhalese participants in Sinhalese. Since I do not know the Tamil language, I could not give the same opportunity to my Tamil participants. Some Tamil participants, specifically those from a former refugee background, could not speak English fluently. This may have limited some of the data collected from these interviews, and therefore, this study might have been affected by this language limitation.

\subsection{Post-field}

Even though I have divided the research methods I used in this study into three clear phases - pre-field, field and post-field - some of the tasks overlapped these phases. For example, as I described earlier, transcribing was completed during the field as well as in the post-field phases. After transcribing all the interviews, I started analysing data. Analysing qualitative data is labour intensive (Hoonaard, 2012). I used the constructivist approach (viewing data as constructed, acknowledging the notion of multiple realities, and emphasising reflexivity) to view and analyse data. According to this approach, data is not merely out there in the world, waiting to be discovered (Silverman, 2011), rather conducting research (data itself, data collection and data interpretation) flows from individual views and values. It is therefore not neutral by any means.

Therefore, in analysing data, constructivism notes that the researcher should locate themself within the inquiry (Chamaz, 2014). Constructivist theorists do not believe that it is possible for a researcher to remain a neutral observer outside the data. As Silverman (2011) suggests, by locating themselves inside the inquiry, qualitative researchers can get much closer to the data and the studied phenomena. 
Constructivist researchers can get an in-depth understanding of the participants' meanings and actions and how those meanings and action s are connected with the larger social structures and discourses of which those participants may be unaware. I used thematic analy sis to analyse the data. According to Roulston (2010), thematic analysis is one of the most commonly used approaches for qualitative data. Themes can be generated in multiple ways. Through sorting data firstly into codes, secondly into categories, and then into themes, this approach helps to reorganise the data into a thematic representation of findings (Roulston, 2010). After transcribing all the interviews, I started open coding (Chamaz, 2014; Hoonaard, 2012). In the first round of reading all the transcripts together (I read the transcriptions four times), I read each line-by-line, generating hundreds of codes from my data. I attempted to have an open mind in this initial stage. I believed that if I tried to look at data as the only material to answer my research questions, I may miss some in-depth nuances of data.

I then organised codes into categories. I firstly took the dynamic interrelationship of those codes into consideration. After many rounds of back and forth reading, coding, and categorisation, I then organised the categories into three key themes. This analysis was all conducted manually, however, I used NVivo to store the data. I wanted to ensure that I would not lose nuances and subtle inter-relationships existing in the data, and manual analysis gave me complete authority over assessing this, rather than relying on a computerised system. However, the convenience of storing the data in NVivo is undeniable: using this software made it easier for me to access sets of data whenever I wanted to track the codes, categories, and themes. Although I identified many themes and categories, after four months of juggling with, and trying to make sense of, a massive set of rich data, I was not completely confident with my interpretations of the data. However, I started writing up the analysis, although I did not, at this time, have a clear structure in mind. However, writing became a useful tool for analy sis, and helped me clarify my own arguments, recognise commonalities and exceptions in the data, and identify the inter-relations of the data sets. Finally, I was able to organise my arguments into three key themes, 
which are presented in the three empirical chapters of this thesis (Chapters Five, Six, and Seven).

\title{
4.5 Conclusion
}

This chapter discussed the research methods I used throughout this study and the reasons for selecting those methods. The chapter focused on three separate phases of my research: pre-field, field, and post field. In the pre-field section, I explained why I employed qualitative research methods, such as semi-structured interviews, how I recruited participants, and the selection of my sample. In the field section, I discussed how I conducted the interviews, the challenges and limitations I faced, and what I learned. In the post-field section, I described the methods I used to analyse the data. I also elaborated on the challenges and the lessons learned during this phase of the research. Some of the broader limitations of the study were also presented in this chapter. In the next three chapters, I present my findings about Sri Lankan immigrants' citizenship perceptions of their home and host states, beginning with my participants' instrumental perceptions, in Chapter Five.

\section{CHAPTER 5: Sri Lankan immigrants' instrumental perceptions about the host country citizenship}

\author{
5.1 Introduction
}


In this chapter, I explore the reversibility hypothesis presented by Portes and Rumbaut (2006) through my participants' data, specifically through their instrumental views. According to Portes and Rumbaut, if a migrant has more favourable conditions in her adoptive country than in her home country, this will increase her positive thoughts about citizenship of the adoptive country. To test this hypothesis, I divide this chapter in two sections.

First, I analyse how socio-economic factors have affected my participants' way of thinking about citizenship. My findings show that my Sinhalese participants' views about host country citizenship are more influenced by socio-economic factors than my Tamil participants. Sinhalese participants from both Australia and New Zealand shared fairly similar positive thoughts about the travel and career benefits offered by naturalisation, while participants from Australia also mentioned educational benefits as a factor affecting their instrumental perceptions.

Second, I analyse how political factors have affected my participants' citizenship views. My findings show that Tamil participants' views are more affected by political factors than Sinhalese ones. This is because my Tamil participants' main reason for migrating to Australia and New Zealand was political: for the majority of those Iinterviewed, the ethnic discrimination they experienced in their homeland led them to emigrate to Australia or New Zealand as refugees, asylum seekers, or economic migrants. Thus, Tamil participants revealed that safety and receiving equal rights were their main concerns as citizens in the host country. Therefore, despite the fact that all the people I interviewed have positive thoughts about their New Zealand or Australian citizenship, I explain in this chapter that it is important to consider them as a heterogeneous community.

Even though the central focus of this chapter is on participants' instrumental perceptions towards their host country citizenship, to understand those better, I explore their instrumental perceptions towards the home country citizenship as well. The data shows that all my participants considered the material benefits offered by home country citizenship to be negative. The perceptions of my Sinhalese participants were based on the potential socio-economic rights and 
benefits provided by Sri Lankan citizenship, while those of my Tamil participants were based on poor political rights and benefits. These negative perceptions show a close link with their positive thoughts about host country citizenship. Thus, the instrumental perceptions presented in this chapter support Portes's and Rumbaut's reversibility hypothesis.

\subsection{Instrumental perceptions based on socio-economic reasons}

In his pioneering work on immigrants' perceptions of host country citizenship acquisition, Bernard (1936) identified the "socio-economic determinant" as a critical component affecting immigrants' naturalisation decisions. He argued that if immigrants have better socio-economic conditions in the host country than in the country they came from, their propensity to acquire citizenship is higher. Yang (1994) stated that immigrants' decisions are affected not only by the actual socioeconomic conditions in the host country, but also by their perceptions of the cost and benefits of these socio-economic conditions in comparison to their home country.

Introducing the reversibility hypothesis, Portes and Rumbaut (2006) argued that these comparisons of home and host country conditions occur mainly when the immigrant moves from the Global South to the Global North. They noted that if the home country provides immigrants with unfavourable socio-economic conditions and the host country provides them with better ones, the propensity of host citizenship acquisition is higher.

My research data, specifically that on participants' instrumental perceptions, support the reversibility hypothesis, since it demonstrates that the majority of Sinhalese participants' assess the socio-economic benefits of the host country positively in comparison to the lower socio-economic conditions they received as home country citizens. 
Sinhalese participants were more interested in the socio-economic benefits of the host country citizenship than Tamil immigrants in two regards. On the one hand, a majority of the Sinhalese participants were economic migrants looking for better socio-economic opportunities, such as travel benefits, career prospects, and educational opportunities. On the other hand, Sinhalese immigrants also revealed that their assessment of these benefits was made by comparing them with the lower quality of such benefits in their home country. However, as I explain in the next section, socio-economic factors were not the determinant aspects of Tamil participants' citizenship perceptions; rather, political factors were central to their choices. Therefore, I argue that participants' positive instrumental perceptions about host country citizenship are influenced by their negative instrumental views about citizenship of their home country. These negative perceptions were mainly expressed based on three socio-economic factors: poor travel benefits, poor career prospects, and limited educational opportunities. Let me analyse these factors more in detail.

\subsubsection{Travel benefits}

The majority of Sinhalese participants from both Australia and New Zealand repeatedly mentioned that receiving a passport from their host country makes travelling easier than on their home country passport (Sri Lankan). They view the former as some of the world's most powerful passports, while they perceived the latter as having poor international recognition.

Many academics have found that immigrants from less-developed countries have instrumental interest in receiving a passport from a Western, developed, host country (Amit, 2014; Ong, 1999; Pogonyi, 2019); with some arguing that this is an economic asset (Altan-olcay \& Balta, 2016; Ferraris \& Davies, 2013; Pogonyi, 2019). Amit (2014) stated that host country passports offer specific career and educational options for immigrants. As Pogonyi (2019) and Ferraris and Davies (2013) found, a passport is also an object that assures one's social status as an 
individual in world-wide travel; this was supported by Altan-Olcay \& Balta (2016) who report that a passport increases one's cultural and social capital, elevating its holder's class status.

The research I conducted verified many of these findings ${ }^{8}$ Obtaining a passport was one of the main materialistic incentives for citizenship for many of my Sinhalese participants, because it grants them the ability to travel to a wide range of countries without any visa issues. Travelling is essential for the careers of some participants, while others believed their children's future is assured by obtaining a passport from a wealthy, developed, country. Finally, some participants viewed having the capability to travel whenever they want to as a symbol of independence, allowing them to fulfil travel-related aspirations.

Referring to his fellow Sri Lankan Tamil immigrant friends in Sydney, Raj said that many of them "... do not want to get the citizenship in the host country. They take it basically for the passport." According to Raj, obtaining the passport was one of the main reasons why Sri Lankan immigrants in Australia obtain citizenship. Many participants from New Zealand shared the same opinion. For example, Kamal, a Sinhalese participant from Auckland who arrived in New Zealand as a skilled migrant, stated: "we primarily came to get the passport. [With it] it's easier to go anywhere." Jayasiri, another Sinhalese participant from Auckland, who has been a New Zealand citizen since 2000, saw the New Zealand passport as “... a road to any other country without any hassle."

Shehan, a Sinhalese citizen of Australian, who lives in Melbourne, told me that he has to travel a lot because of his work. He said that when travelling “... [on my] Sri Lankan passport [people] gave me a hard time. Specially travelling to China. They questioned me a lot for my Sri Lankan passport. So, I realised ... getting the [Australian] passport was important.”Now, holding an Australian passport, Shehan is able to pass through immigration checks easily. Dinindu (Sinhalese), shared the same experience. In our interview he mentioned that obtaining an Australian

\footnotetext{
${ }^{8}$ In addition, as discussed in Chapter Six, it also shows that holding a passport from the host country has a patriotic meaning too.
} 
passport, instead of just keeping his Sri Lankan passport, helped simplify preparing documents for visa requirements. Malathi, a Sinhalese resident in New Zealand, who expected to become a New Zealand citizen, said that she thinks that internationally there are negative perceptions of the Sri Lankan passport. Whenever she had to show her Sri Lankan passport in travelling, she commented that "they [immigration officers at airports] just say oh.., bloody Asians... I don't like that attitude [and] the way they look at us [because of our passport]."

Anusha, a dual citizen of New Zealand and Sri Lanka, is another example. Even though she decided to permanently settle in New Zealand as soon as she arrived in 2002, she did not have any particular reason to become a New Zealand citizen except for the passport. She said "it made it easy to travel to Sri Lanka ... via Australia without visa. To be honest, that was one of the main reasons." Anusha is Sinahlese and flies to Sri Lanka at least once a year. From Wellington, the shortest, easiest, and the cheapest way to fly to Sri Lanka is via Australia. However, each time a Sri Lankan passport holder has to transit in Australia, she must obtain an Australian transit visa. No such visa is needed for New Zealand passport holders. Therefore, obtaining a New Zealand passport made Anusha's travels to Sri Lanka much easier.

For Padma, a Sinhalese Australian citizen, having a host country passport made her family travels easy. Although other members of her family obtained Australian citizenship early on, Padma did not become a citizen for many years. As a result, when travelling as a family, Padma had to pay the price for carrying the Sri Lankan passport. While her family members, with their Australian passports, were quickly accepted, she always had to wait in long queues in airports. Eventually, family trips, and specifically airport times became stressful for her. Her children cracked jokes, asking her to come on a different flight, because they often had to use separate queues, and had to wait for their mother at the airports. Padma said it is purely for this reason that she decided to apply for citizenship and obtain an Australian passport. She reported that her travels with her family are now very easy. 
Some participants perceived a host country passport as a tool to assure their own, and their children's, futures. As Pogonyi (2019) argues, for someone from the Global South, a passport from a wealthy developed country provides life-insurance. Samanthi, a Sinhalese mother of two children, believed Australian citizenship would bring her children many opportunities. She said: “... we only travel to Sri Lanka. With these little kids, we can't travel all around the world [now]." According to her, even though the Australian passport does not bring many benefits to them at this moment, Samanthi thinks that it will be an investment for her children in the future, and enable educational opportunities in other countries.

Supun, a permanent resident in New Zealand who is Sinhalese, shared the same thought. Even though he is not yet a father, he believed that having a New Zealand passport would bring enormous benefits for his children one day. Dharshi, a stayat-home mother in Melbourne, is Sinhalese and an Australian citizen. One of the primary motivations for her naturalisation was getting a passport. Even though she is not currently working, Dharshi thought that when she resumes her career, an Australian passport will make her travel far more convenient.

All the above-discussed participants perceived that their host country passport was an instrumental assurance to improve their own, and their children's, future lives. For other participants, an Australian or New Zealand passport was also the key to access their lifetime passions. Aloka, who lives in Sydney, is currently on a temporary resident visa, and stated that his "passion is travelling." Although Sinhalese, he thought that carrying "a Sri Lankan passport is the biggest barrier" he has in travelling around the world. Therefore, the main objective of his stay in Australia was to obtain an Australian passport. He believed that obtaining an Australian passport would enable him to "go to [my] dreams."

Even after nine years of residing in Australia, Aloka was still not a permanent resident or citizen. Sharing his migratory story with me, Aloka said that he came to Australia as a student with the hope of becoming a permanent resident, and then a citizen, after his studies. Due to some personal issues however, he could not finish his studies. Because he did not finish his study, he could not renew his visa and had 
to return to Sri Lanka. Meanwhile, his partner also came to Australia for her studies. Aloka returned to Australia on a dependent's visa. Both Aloka and his partner have struggled to find proper jobs, hence becoming a permanent resident or a citizen has not been possible. He said that he had "sacrificed a lot of things [in order] to get the [Australian passport]." Obtaining Australian citizenship and a passport was very important for Aloka; they were essential instruments to access his dreams.

\subsubsection{Career benefits}

The majority of my participants expressed positive opinions about the career benefits they receive in New Zealand and Australia, even during the period when they held residency status. This is because both New Zealand and Australia offer a considerable number of career opportunities for temporary and permanent residents. However, to be eligible to work for some of the government agencies (such as the Ministry of Foreign Affairs and Trade in New Zealand (New Zealand Foreign Affairs and Trade, 2019), the Department of Foreign Affairs and Trade in Australia (DFAT, 1999), or the Australian federal police (Australian Federal Police, 2019; Australian Government, 2019a)), citizenship is mandatory. Therefore, participants interested in working in the areas mentioned above wanted to obtain host country citizenship.

One example is Priyadarshani. She is Sinhalese, and has been a permanent resident in New Zealand for seven years, and who works in the Information Technology sector. Recently, she has been planning on changing her career. In our interview, Priyadarshani stated "actually, I am looking for a career change. So, if I am going for the defence ... military forces[or] intelligence ... I need New Zealand citizenship." Priyadarshani said that for the time being, her desire to change her career was the only reason pushing her to obtain citizenship. Similarly, Viru (Tamil) said becoming a citizen of New Zealand has allowed him to gain employment in any sector without restriction. He said "when my kids grow up ... they might want to [work] in the government sector, this might be a barrier if they are not citizens. 
So now we all are citizens." For both Priyadarshani and Viru, host country citizenship is a pathway to the jobs they wish to do.

Some participants considered that if one has citizenship, one is in a better position to get a job, even though many did not specifically mention seeking employment in the areas where it is mandatory. Instead, their view was that in any sector, one will get priority if she has host country citizenship. For example, Nilmini, a Sinhalese citizen of New Zealand, said:

... getting a job here is not that easy. Well, you can go and do an odd job, but finding a job that you are groomed for since your childhood is not easy... there is a thing in employment here that if you are a citizen, you are in a better position to get it.

Dinindu, had the same view, but with regard to Australia. "I worked for the Australian film industry for a while... I thought to have full citizenship [makes it] easier to work in [that] area," he stated. Even though having citizenship is not mandatory to work in the Australian film industry, Dinindu thought that having it would increase his probability of being selected. Such career-related positive instrumental perceptions have increased participants' likelihood of obtaining citizenship of their host country.

As mentioned by many Sinhalese participants, their desire to achieve economic prosperity through better career opportunities was in line with their migratory objectives, namely to find economic security. Yang (1994) found that when the economic status in the host society is better than the home one, immigrants have positive attitudes towards being a citizen, as the perceived benefits of naturalisation were better than if they returned home, or retained only home country citizenship. The data of this study support Yang's finding. Participants in both Australia and New Zealand mentioned that their lower economic and career statuses in Sri Lanka reversibly influenced their career-related positive perceptions of their host country citizenship. Explicitly, those who are from Sri Lankan middle-class families expressed their dissatisfaction with their financial and career status in Sri Lanka as opposed to their satisfaction about both in their host country. 
Sri Lanka is identified by the World Bank (2019) as a lower-middle-income country. After its independence from Britain in 1948, Sri Lanka was a closed economy until 1977. Since then, the Sri Lankan economy has been liberalised and has opened for international competition. However, the economy struggled during the 30-year civil war (1983-2009). After the end of the civil war in 2009, Sri Lanka's economy grew at an average of 5.8 percent, until 2017 (The World Bank, 2019). By 2017, the GDP per capita was USD 4,073 (The World Bank, 2019). However, the Central Bank of Sri Lanka (2018) reported that in the year 2018 the Sri Lankan economy became more vulnerable to global and domestic disturbances. The GDP growth in that year was reported as 3.2 per cent (Central Bank of Sri Lanka, 2018). It is worth noting that the majority of Sri Lankan immigrants in New Zealand and Australia, other than asylum seekers and refugees, belong to high or middle-class families. This is clear when we examine the pathways through which they arrived in Australia or New Zealand. Many of them came as skilled migrants with years of professional experience in Sri Lanka. Others arrived as students, and decided to settle. To enter Australia or New Zealand as a student one has to pay a significant amount of international tuition fees; costs that only those from high or middle-class families in Sri Lanka can afford.

\subsubsection{Educational benefits}

Access to education through citizenship was another key instrumental interest for many participants, particularly those in Australia. In the Australian case, some student loans such as HECS-HELP (a loan that can be obtained to continue studies in the Commonwealth), require Australian citizenship (Australian Government, 2018a). Under this loan, the total cost of the study is split between the Australian Government and the student (Australian Government, 2018). Due to participants' positive views about the Australian education system, in comparison to their negative perceptions about the Sri Lankan education system, participants viewed educational benefits such as this as "privileges." 
While some participants expected to receive those educational benefits for themselves, others wanted to secure them for their children. Kaushi (Sinhalese), a permanent resident in Australia, said the main reason she wished to become a citizen was the educational benefits her child would be able to access. She said “...for children, higher education is free [in Australia] and they can get a loan... I actually tried to become a citizen here [because then] my child can get education here one day." Although Kaushi thought that citizenship is mandatory to get free education in Australia, factually, permanent residency status is adequate to be eligible for free primary and secondary education. Australian citizenship is only mandatory to get loans such as HECS-HELP. Udari, a Sinhalese Australian citizen in Sydney with a teenage son, supported this view, stating "children who are the citizens can get the government loan and they can pay it when they start working. But permanent residents, I don't think they get that. Citizens have a priority." The perceived superiority of the Australian education system over Sri Lanka's was one of the main reasons for Darshi - a mother of two children - and her family to become Australian citizens. Hence, Kaushi, Udari, and Darshi thought that the educational benefits offered by the Australian citizenship were instrumentally positive in giving their children a better future.

Some other participants viewed the educational benefits offered by Australian citizenship as instrumental for their personal development. Talking about his wife, Gopal, a Tamil Australian permanent resident, said “... my wife applied for the citizenship for her higher studies, [so that] it will be [cheaper]. She can [also] get the loan to study and then she can pay it back."

For other participants, the educational benefits of Australian citizenship came as a result of their decision to permanently settle down there. When an immigrant decides to permanently settle in a host country, the desire to receive full benefits from the host country citizenship increases. An example is Suneth, a Sinhalese Australian citizen in Sydney. He said his reason for obtaining Australian citizenship was to maximise his ability to access all its associated benefits:

The day we came here, we decided to live in this country... to give education to our children... that is the main reason we came here... As a permanent resident, 
you will get minimal things from the Government... If you want to study, there are no grants or anything... When you become a citizen of this country, you are entitled to many things.

Another example is Shehan (Sinahlese), who lives in Melbourne. Even though he wanted to return to Sri Lanka one day, his children would never be able to settle there on a permanent basis. Thus, he decided to obtain Australian citizenship for his family to make sure his children can freely study there. He told me that he was influenced by another reason too: “... I heard here [in Australia], the citizenship rules are going to be very [restrictive] in the future. That day I decided, for my kids, I will get citizenship here. There is no other reason, but only for my kids' future.” All the above participants considered Australian education to be high in quality. For them, the ability to access it is a "privilege." They thought that their Sri Lankan citizenship did not allow them to enjoy a similar standard of education.

Relative to other South Asian countries, Sri Lanka has achieved high standards of education: in the World Bank ranking of social indicators, including education, it is ranked as the highest in South Asia (The World Bank, 2019) and has achieved universal primary education. Nearly 100 percent of children complete grade five (Taniguchi, 2017). The country introduced free education in 1945, enabling every child above the age of five and not more than sixteen entitle to free education (United Nations Development Programme, 2016). However, in contemporary times, the Sri Lankan education field is facing numerous challenges, and there are serious problems with the quality and relevance of Sri Lankan education (Taniguchi, 2017). Many participants thus conveyed their dissatisfaction regarding education in Sri Lanka.

To conclude, as mentioned above, Sinhalese participants viewed their Australian and New Zealand citizenship positively for the socio-economic benefits it provides in relation to travel, career prospects, and educational opportunities. Thus, they see instrumental benefits to citizenship. In terms of the travel and career benefits, Sinhalese participants in both Australia and New Zealand had similar positive thoughts. Participants from Australia in particular mentioned the educational 
benefits as a reason for pursuing citizenship. This is because, to be eligible for certain scholarships in Australia, citizenship is mandatory. The next section explains the critical political factors that determined Tamil participants' citizenship perceptions.

\subsection{Instrumental perceptions based on political factors}

According to pioneering work by Bernard (1936), if the host country provides its immigrants with better political conditions than at home, the propensity for those immigrants to naturalise in the host country is higher. Yang (1994) said it is not only the actual political conditions of the host country that matters, but immigrants' perceptions about the quality of those political conditions in the host country in comparison to the home country. For example, immigrants who are from countries where politics is corrupt or authoritarian of ten do not return. In addition, if their host countries provide them with greater political freedom than their home country, such immigrants are more likely to naturalise. This can also be due to pressure from relatives back home. Finally, those who arrived in the host country as refugees or asylum seekers due to civil wars, ethnic persecution, or other political disruption, are more likely to naturalise because they do not wish to go back to such suffering again (Yang, 1994). In their reversibility hypothesis, Portes and Rumbaut (2006) also argued that immigrants measure their host country's political conditions in comparison to those of their home country. Hence, if the home country has worse political conditions than the host country, immigrants will grow positive instrumental perceptions about host country citizenship.

The data from my participants, especially those who are Tamil, supports all the above findings. While the majority of Sinhalese participants mentioned socioeconomic factors such as travel, career prospects, and educational opportunities, a significant number of Tamil participants revealed that their instrumental perceptions about citizenship were more influenced by political factors in both their home and host country. That is, because they are a minority group, Tamils 
considered citizenship of their host country to offer them better safety and protection as equal citizens than that of their home country. Such perceptions have improved my Tamil participants' positive instrumental views about host country citizenship, and increased their propensity to naturalise.

\subsubsection{Safety benefits}

Safety was repeatedly mentioned by all the Tamil participants as a critical concern, strongly shaping their perceptions of host country citizenship. Safety was also a concern for some of the Sinhalese participants. Among the safety-related benefits of host country citizenship identified by Tamil (and some Sinhalese) participants, four were identified as especially important: 1) that they cannot be deported;2) that they receive protection from consular services while abroad; 3 ) that they have the right to freely enter and live in the host country; and 4) that they are protected from racism and anti-immigrant sentiments in the host society.

\subsubsection{Deportation}

Shivakumar emigrated to Australia in 1988 because of the safety risks he experienced in Sri Lanka. A Tamil citizen of Australia, he has no intention of returning to Sri Lanka to live on a permanent basis. Shivakumar believed that when he emigrated, the Sri Lankan government treated Tamils differently to Sinhalese. He stated “... that is why I became a citizen here [in Australia, because of] the safety... You need to feel safe." Shivakumar is still suspicious about the safety of Tamils in Sri Lanka. As a result, he wants to avoid deportation to Sri Lanka. Throughout the interview, Shivakumar repeatedly used the term safety. He believed that the authority to protect safety in Sri Lanka should be with the Government. However, as a victim of the Sri Lankan government's racist and discriminatory actions, Shivakumar viewed Sri Lankan citizenship as instrumentally negative, while viewing Australian citizenship as instrumentally positive. He thought that in 
opposition to his home country, democracy, law, and order are in place in his host country.

For Shivakumar, obtaining Australian citizenship prevented any potential of deportation to Sri Lanka. Unless citizenship is found to have been gained illegally, neither New Zealand nor Australia can deport its citizens. They can, however, deport permanent residents, and Australia can deport New Zealand citizens in the event of certain criminal cases, or if they are considered a threat to security (Dalley \& Bozovik, 2015; Makela, 2018)). As well as protecting him from deportation, Shivakumar also thought that continuing to be a Sri Lankan citizen may prevent him from claiming full protection from Australia. He recollected a similar case: "there was a case recently for a Lebanese girl here. [Australia wanted to deporther]. Because she did not have the Lebanese citizenship [but] only Australian citizenship, Australia could not deport her." This is because it is against international law to render a person stateless (United Nations High Commissioner for Refugees, 2019). Since Shivakumar has no plan to return to his home country on a permanent basis, he thus wanted to make sure he is completely secure in his chosen country.

\subsubsection{Protection from consular services while abroad}

Another safety-related aspect of citizenship participants mentioned was the protection their host country can provide them when travelling abroad. Via their diplomatic missions, both Australia and New Zealand provide consular assistance to citizens while abroad for any mishaps, accidents or injuries experienced (Australian Government, 2018b, New Zealand Foreign Affairs and Trade, 2019a). Permanent residents, however, are not eligible to receive such services.

Shivakumar, the Tamil Australian citizen mentioned above, stated that "if you have citizenship in Australia ...[Australia] will have protection over you." Shivakumar thought obtaining Sri Lankan dual citizenship would be detrimental to accessing Australian consular services while abroad, considering Sri Lankan citizenship "an unnecessary risk" in this regard, which would reduce his ability to enjoy full 
protection by Australia in an emergency. For example, he thought that if he is caught for some reason in Sri Lanka while he is travelling there, as a dual citizen, the Australian Government will not have the leverage to protect him solely as an Australian citizen. He stated:

a lot of [Sri Lankan immigrants] take Sri Lankan dual citizenship for very small things. For example, if you are not a Sri Lankan dual citizen, when you go to [tourist destinations in] Sri Lanka, [you have to buy] tickets for [tourists which] are expensive, but if you are a Sri Lankan citizen, it is cheaper. It is very silly. I don't think in that way. For me, my security is more important. I don't mind paying that little money [every time I visit a tourist place in Sri Lanka] than obtaining the Sri Lankan dual citizenship.

As well as Tamil participants, a few Sinhalese participants also had safety concerns. One example is Sarath, who has been a New Zealand citizen for the last twenty years. He decided not to become a dual citizen for similar reasons to Shivakumar. Sarath thought New Zealand could provide him with better protection, specifically when he is travelling in Sri Lanka. If he had dual citizenship with Sri Lanka and if for some reason he happened to be arrested there during political unrest, he said:

the Sri Lankan government can take [me] in to custody and put [me] in prison... because [I am] a Sri Lankan. Then New Zealand may not have the same level of access to [me] ... because they [Sri Lanka] would argue, that [I am] a Sri Lankan citizen, so [I] can be penalized under Sri Lankan law. So, I felt that it [Sri Lankan dual citizenship] is probably a dangerous thing to have, not that I will go there and get into trouble, but [just in a case].

Sarath's statement shows the insecurity and the distrust he has towards citizens' political rights in Sri Lanka. Sarath believes that even without a reason, the Sri Lankan government could take him into custody when he is in Sri Lanka. If such a thing happened, the Sri Lankan Government would not let the New Zealand Government check on him even though he is a New Zealand citizen. Sarath thinks that being or remaining a Sri Lankan citizen is "dangerous," while becoming a New Zealand citizen is "safe;" carrying New Zealand citizenship provides some protection for travel in Sri Lanka. 


\subsubsection{Right to freely enter and live in the host country}

Former refugee participants' perceptions about host country citizenship were mainly affected by their unwillingness or inability to return home. For them, the economic and social benefits of citizenship were not of primary concern, since more important for them is the political situation and the security factor associated with being able to live in the host country indefinitely without being required to leave. Factually, these participants could live in the host country indefinitely even as permanent residents, but they perceived that becoming a citizen would assure their ability to live there permanently. For example, Nethra, a Tamil, and from a former refugee family, said that her main reason for obtaining Australian citizenship is to make sure that she can live in Australia indefinitely. She said "Sri Lanka is our mother country, but with the war [in Sri Lanka], it's really unsafe. But here, we can be safe." Thiru, a Tamil former refugee from Wellington who does not want to return to Sri Lanka and is determined to live in New Zealand permanently, also considered the acquisition of citizenship as critically important because of this. $\mathrm{He}$ said:

most of them [in Sri Lanka], even the government forces, the police [and] the army, they always want money. If you give them money, they will do anything. Even the area that was under the LTTE, they [the LTTE] pay money to the armed forces to bring things to that area.... When we compare that with here, for example the police there with the police here, we are very happy we are here. Here everything happens lawfully, according to the system.

A problem that some refugees face is that they do not have a sufficient level of education to allow them to know the rights they would have as citizens. This problem finds confirmation in the literature; Portes and Rumbaut (2014) pointed out that those with poorer education levels do not know much about the benefits citizenship could offer them. Participants of this study from former refugee 
backgrounds strongly support Portes and Rumbaut's conclusions. They were not able to outline the differences in benefits and rights between residents or citizens. Instead, their citizenship acquisition was driven by their desire to settle somewhere permanently, and their unwillingness to return to the home country.

Another significant safety-related element of citizenship for other non-refugee Tamil and Sinhalese participants, was that it allowed them to live outside the host country and then re-enter the host country at any time they wish, without any problem (Australian Government, 2019a; New Zealand Immigration, 2019a). In both Australia and New Zealand holders of a permanent resident visa may travel and live outside those countries for up to five-years but must return after that, otherwise the visa will expire (Australian Government, 2019b; New Zealand Immigration, 2019b). According to some participants, this is one of the main differences between being a citizen and a permanent resident in Australia and New Zealand: permanent residents have to renew their residency status if they wish to live outside, and must pay attention to expiry dates, whereas citizens can enter the host country at any time, and have no restrictions on living in another country for as long as they want to (Australian Government, 2019a; New Zealand Immigration, 2019a).

This is the incentive for Rashmi, who is Sinhalese and currently a permanent resident of Australia, to become a citizen. As stated by her: “... if we go to Sri Lanka for some time, I want to make sure that I can [arrive in Australia], whenever I wanted." Through obtaining Australian citizenship, Rashmi wanted to make sure that she could live in Sri Lanka for longer periods and come back to Australia whenever she wants to. She said “... we want to make sure that we can live in both countries as we wish."

Sachini, a Sinhalese permanent resident of New Zealand, expressed her keen interest to become a citizen for the same reason: "[as permanent residents] we can't go outside the country [for long periods] ... [We] are like still somewhat trapped. If you are a citizen, [there is no restriction like that]." Thus, being able to live outside the host country indefinitely, and being able to enter at any time, is another 
instrumental right that participants viewed positively in terms of host country citizenship.

5.3.5 Protection from racism and anti-immigrant sentiment in the host society

A few participants from Australia mentioned that it is safer to live in Australia as a citizen than otherwise. Such a perception, however, was not mentioned by any participant from New Zealand. For example, Raj, who is Tamil and a permanent resident, expressed this as his primary reason for desiring citizenship. Raj stated "there is ... a very strong anti-immigrant wave [in Australia]. For [Australians], an immigrant means a person who does not have Australian citizenship."

According to Raj, many Australians view immigrants as people who are involved in "crimes or illegal activities." Raj stated "... to be frank, Australians have become racist... We can feel it everywhere... So, a new immigrant would love to go for citizenship, for the sake of saving themselves, not to feel them as immigrants [who are perceived to be associated with] crimes or illegal activities." Raj's comment suggests that in his case, his interest in becoming a citizen is primarily influenced by anti-immigration attitudes that exist in Australian society.

Many other participants also talked negatively about racist attitudes and the antiimmigration rhetoric in Australian society, stressing how having Australian citizenship could help in this regard. A further elaboration on this is included in Chapter Six.

\subsubsection{Voting rights}

The voting rights obtained were another reason for participants' to seek citizenship. As Bloemraad (2006) states, the level of political voice an immigrant can get is a key political factor affecting citizenship perceptions. Participants from Australia 
specifically mentioned that receiving voting rights was one of their reasons to become a citizen. Gopal, a Tamil permanent resident, stated that "you should have some freedom of expression right. That is one way you can show what you like. You can choose who you want. That is why I wanted it [the Australian citizenship]." Nimal, a Sinhalese permanent resident, also stressed the importance of obtaining voting rights: "[if you have voting rights] you can contribute to making the policies, and can select people to govern Australia, where you live. That's a good opportunity to select the person who is coming for the next era."

Australia offers voting rights only for citizens (Australian Electoral Commission, 2019). However, this is not the case in New Zealand, since this country is one of only five states in the world where permanent residents can vote in both local and national polls after the completion of one year's permanent residence (Barker \& McMillan, 2016; McMillan, 2017). ${ }^{9}$ Moreover, New Zealand is the only western democracy to allow non-citizens to vote in both local and national elections without any discrimination (Earnest, 2003).

Interestingly, no participant from either Australia or New Zealand - two countries where citizenship is mandatory to run for any political office - expressed any interest to take up citizenship to contest any local or national elections. Expressing his idea about Sri Lankan immigrants' lack of interest in running for elections, Sarath, a Sinhalese citizen of New Zealand stated that:

... most of the people who want to migrate, especially to New Zealand and Australia, they have many things to deal with at first. That takes precedence over everything. So, you don't have the time required to be a politician... But then the second generation, they have all the resources for that, they understand the process. Now, without knowing the environment, it is not easy to become a politician.

This suggests that it takes a long time for first-generation immigrants to settle, integrate, and achieve their migratory objectives. As a consequence, the time and

\footnotetext{
${ }^{9}$ The other countries are Mala wi, Chile, Ecuador, and Uruguay.
} 
resources they have to be actively involved in politics, other than voting, is significantly limited.

In summary, Tamil participants of this study provided more political motivations for becoming an Australian or New Zealand citizen than Sinhalese participants. As mentioned above, Tamil participants had four main safety related reasons that encouraged citizenship acquisition in their host country: 1) to prevent deportation;

2) to receive protection from consular services while abroad; 3) having the right to freely enter and live outside the host country; and 4) receiving protection from racism and anti-immigrant sentiment in the host society. Some Tamil and Sinhalese participants also wanted to obtain voting rights through host country citizenship.

\subsection{Conclusion}

In this chapter, I demonstrated that all participants share positive instrumental perceptions about their host country citizenship, and I outlined the various socioeconomic and political factors shaping such perceptions. The data suggests that participants did not arrive at positive perceptions about the host country citizenship based only on absolute qualities of socio-economic and political conditions, rather they assessed the quality of those factors relative to their home country experiences.

Thus, my study supports Portes's and Rumbaut's reversibility hypothesis that if home country citizenship provides migrants less favourable socio-economic and political conditions in comparison to the host country, migrants' perceptions about host country citizenship are more positive. However, this study stresses the importance of considering the heterogeneity of the migrant community. Even though all my participants were from Sri Lanka, their ethnic and class affiliations in the home country affected their perceptions about citizenship in the host country. For example, for the majority of Sinhalese participants - the majority ethnic group in Sri Lanka - host citizenship was primarily about its socio-economic benefits. Many of these participants come from high or middle-class families, and share common middle-class socio-economic grievances about living in Sri Lanka, a 
lower-income country. Relative to their home country citizenship, they perceive that of their host country to offer more favourable socio-economic conditions in terms of travel, career prospects and, especially for Australian participants, educational opportunities.

On the contrary, for Tamil participants - the minority ethnic group in Sri Lanka host citizenship means safety. Tamil participants have often faced ethnic discrimination over the years, and thus revealed that they have mainly political instrumental expectations from citizenship, such as safety and security. For Tamil participants who left Sri Lanka due to the ethnic conflict, host country citizenship gave protection and safety even in their home country. Most of this group did not show any interest in returning home. Therefore, for them, deciding on naturalisation is notbased on what benefits they receive as permanent residents or citizens. Rather, it is about finding a permanent alternative to their home country.

That said, it is essential to note that distinguishing socio-economic and political factors from each other was not easy, since these two factors are of ten interconnected. Nonetheless, I illustrated how it is possible to find a list of specific instrumental factors at the base of immigrants' instrumental perceptions about host country citizenship. I also demonstrated the significant difference between Tamil and Sinhalese immigrants regarding the factors deemed most important. In the next chapter, I discuss participants' patriotic perceptions of their adoptive country citizenship. 


\section{CHAPTER 6: Sri Lankan immigrants' patriotic perceptions about the adoptive country citizenship}

\subsection{Introduction}

This chapter explores participants' patriotic perceptions about their adoptive country citizenship, and the factors affecting these perceptions. To explore, and measure, patriotic perceptions, I borrow Ronkainen's (2011) typology of thin and thick citizenship ties. As previously outlined, he presented four elements in his typology: voice, roots, loyalty, and exit through which he tested thinness and thickness of multinationals' citizenship ties. Out of these four components, I use voice, roots, and loyalty as the factors that affect Sri Lankan immigrants' patriotic perceptions.

My data shows that participants' perceptions about their Australian or New Zealand citizenship can vary from thinly to thickly positive. I begin the chapter by presenting participants' first form of patriotic perceptions; a sense of gratitude, which I call thin patriotism. Participants develop this sense of gratitude, an aspect of loyaltyas in Ronkainen's typology - when they are satisfied with the socio-economic and political instrumental rights and benefits they receive via citizenship of their host country. I argue that the development of thin patriotism is critically important in generating thick patriotism towards the host country at a later time. The data demonstrates Sinhalese and Tamil participants' sense of gratitude to be affected by different instrumental inputs. In the Sinhalese participants' case, these instrumental inputs were mainly socio-economic; while in the Tamil's case, they were political. This difference was consistent throughout Australia's and New Zealand's datasets.

After discussing these aspects, I illustrate the participants' transition from thin to thick forms of patriotism. I introduce two factors that critically affect this transition: their length of residence in, and overall reception by, the host society. A longer period in the host country, with a satisfactory level of reception, while being able to access the level of socio-economic and political instrumental rights and benefits 
that led them to establish thin patriotism, she is more likely to generate thick patriotism towards the host society. These two factors - length of the stay and the reception of the host society - transform immigrants' initial sense of gratitude (a thin form of patriotism) in to a sense of belonging (a thick form of patriotism). Participants who develop this feeling imagine themselves as equal parts of the host country society. In Ronkainen's (2011) typology, such feelings represent the patriotic aspects of roots and voice. The development of a sense of belonging resulting from the length of stay, was similar for participants from both Australia and New Zealand. However, the interviews showed that they were affected differently by the second factor, the reception of the host society. This is because features of racism at the societal and institutional levels were perceived as disturbances in their transition from thin to thick patriotism by participants from Australia; this happened to a lesser extent to participants from New Zealand.

\subsection{Thin patriotic perceptions}

The data shows that the first form of patriotism manifested as a sense of gratitude. This was largely based on participants' positive instrumental perceptions of citizenship in the host country. All the participants of this study expressed satisfaction with the socio-economic and political instrumental rights and benefits they received, or expected to receive, by becoming citizens in their host country. This satisfaction in turn engendered gratitude. Many of them perceived host country citizenship as the tool enabling them to enjoy these rights and benefits. Therefore, I suggest that there is a causal relationship between immigrants' instrumental and patriotic perceptions towards host country citizenship.

However, this study also found that Sinhalese and Tamil participants' sense of gratitude were affected by different instrumental inputs. Sinhalese participants were largely influenced by the socio-economic rights and benefits. For example, many Sinhalese participants expressed gratitude towards their host society for offering them an internationally recognised passport and better employment 
opportunities. In contrast, Tamil participants' sense of gratitude was largely influenced by being granted political rights and benefits, rights such as receiving equal recognition as citizens, democratic rights, and a safe space to live in.

In this section, I argue that a sense of gratitude can be understood as thin patriotism, because it represents only one aspect of Ronkainen's (2011) typology; loyalty. According to Ronkainen, loyalty comprises feelings of solidarity towards society, community, feelings of allegiance, and willingness to fulfil citizens' duties. Unlike roots, which emphasises the meaning of national or family culture, loyalty is directed towards the state. The following section discusses the Sinhalese and Tamil participants' thin patriotic perceptions, and the different instrumental factors affecting those perceptions.

\subsubsection{Sinhalese participants}

As explained in Chapter Four, the majority of Sinhalese immigrants to Australia or New Zealand had socio-economic expectations - such as receiving travel benefits (from holding the host country passport), improved career prospects, and educational opportunities connected to their new citizenship. Participants revealed that they felt satisfied when they met these initial instrumental expectations. Many participants stated they feel "grateful" towards their host country because they believe that if they were in Sri Lanka, they would not receive such benefits. Thus the satisfaction of fulfilling these expectations, was followed by a sense of gratitude towards the host society.

Sarath is a New Zealand citizen who has been living in the country for twenty years. He states that he is very satisfied with the socio-economic rights and benefits he has achieved in New Zealand. At first, no patriotic reasoning influenced Sarath's decision to become a New Zealand citizen, it was "... mainly motivated by the benefits associated with [New Zealand] citizen ship, primarily about travel." Once he received his New Zealand passport, Sarath says he felt satisfied and grateful to the country for giving him and his family a better life. 
Jayasiri shares many of Sarath's thoughts. Jayasiri came to New Zealand in 1997 as a skilled migrant, and obtained New Zealand citizenship in 2001 . He is very satisfied with the instrumental benefits citizenship offers. He mentioned "the major benefit" he wanted from his host country citizenship was "the passport." $\mathrm{He}$ is also happy, however, about the socio-economic conditions he is able to reach in New Zealand: "I love New Zealand for the high standards of life it offers me. It is fantastic being here." Revealing his sense of gratitude towards the host country, Jayasiri says he always wants to pay New Zealand back by being a dutiful and a loyal citizen, and he never wants to "exceed the boundaries given [to me] by the host country." As a dutiful citizen, Jayasiri believes that he needs to try his best to live a lawful and obedient life in the host society. Jayasiri's statement clearly showed that his first form of patriotism towards his host country citizenship is "loyalty."

Romesh, a permanent resident of New Zealand from Auckland, also shows a sense of gratitude for the socio-economic rights and benefits he receives. He came to New Zealand in 2013, but struggled to find jobs and manage his finances in his first few years. However, he eventually found a good job, and now he is more satisfied with his life than he was initially. He said "this is the country that I live in with my wife and my daughter, where I earn. We use good vehicles. We eat well here. We earn well, and we save well... [so] I love [this] country." In the interview, he mentioned that he would not be able to have an equally comfortable life if he was in Sri Lanka. These statements suggests that he is satisfied with the life he is leading because he has reached his socio-economic expectations. Thus, Romesh has positive patriotic perceptions based on his gratitude to the host country for giving him a good life. The cases of Sarath, Jayasiri, and Romesh suggest that these three participants' sense of gratitude towards the host society is influenced by their satisfaction with the travel and economic benefits they receive by being a citizen in the host country. Some other participants report that they feel grateful towards the host country for offering them better employment opportunities and better working conditions than they would have in Sri Lanka. For example Dinesh, a Sinhalese citizen of New Zealand, views his new citizenship positively and patriotically because according 
to him, New Zealand has recognised his professional skills equally to other citizens. Dinesh first arrived in New Zealand in 2010 as a skilled migrant - he is a professional pastry chef. He believes that his citizenship allowed him to work in a society where his work is better appreciated and valued than in his home country. He stated that "... Sri Lanka did not give me the place I deserved as a pastry chef. But in here, I was given my deserved place." Due to this, Dinesh has a tremendous sense of gratitude towards his host society. His positive patriotic views have led him to stand up for the people in need in New Zealand: "I feel that I need to do something for this country... I have helped kiwis a lot." According to Dinesh, he helps people as payback for what he received. This suggests that Dinesh's positive instrumental perceptions about having a better job and better professional recognition triggered a robust patriotic feeling towards his host society.

Madavi and Anura, two Sinhalese participants from Australia, similarly convey thin, positive, patriotic perceptions about being Australian citizens. Those thin patriotic perceptions are based on their positive instrumental perceptions about the working conditions of the host country. Madavi believes that working in Australia is more relaxing than working in Sri Lanka, because, she thinks employees' rights are better protected in Australia than in Sri Lanka. Anura says he feels grateful to work in a country where he is "entitled" to his work-related rights: "In Sri Lanka," he stated, "getting leave from the workplace is very difficult ... [My] boss will ask [a lot of questions such as] why, what happened, why you are not coming, if you do not come, how can we do this etc. But here, if you want sick leave, you are entitled. It is your right. No one can ask questions about it." Thus, both Madavi's and Anura's sense of gratitude towards the host society is influenced by their positive perceptions about employment conditions in comparison to their home nation.

In the specific cases of Praveena and Anusha, their sense of gratitude is largely based on the health benefits they are offered in the host country. Praveena, who is Sinhalese and New Zealand permanent resident, shared positive patriotic views about the health benefits received by being a citizen. At some point in her past, she had an accident and was immobile for seven months. In our interview, she noted 
that “... the government paid all my medical bills. Even the taxi [bills were] paid. I know that kind of a support system would never be there in Sri Lanka." Based on the medical treatments and other support she received (instrumental benefits), she said her experience related to her accident increased her "gratefulness" towards New Zealand society. Anusha, who I introduced previously, views the country's health benefits patriotically, as well as instrumentally, positively. Anushahas a 7year-old daughter with autism. Having quality medical treatments for free has given Anusha a feeling of security about the future of her only child. This has increased her sense of gratitude (loyalty) to New Zealand.

This sense of gratitude has also increased Anusha's thick patriotism. ${ }^{10}$ Anusha has thought of ways to re-pay her gratitude towards New Zealand, including organising fund-raising programs supporting various medical programs. This is because Anusha's sense of belonging (roots) and her sensitivity to the co-members of the host society has increased. Anusha said “... I should give credit to my child, because of her medical condition, I am more involved with the systems ... in the society. So that helped me a lot, to be integrated. And also, to think about how we can contribute to New Zealand. That is why I'm doing fundraising programs." She invited some of her friends to cook food at home and then to sell it among themselves. Part of the money collected was sent to a cancer prevention program in New Zealand.

Bloemraad (2012) found that health benefits are prominent in improving citizens' belonging to society. Referring to the data of Focus Canada, 2010/EnviThirucs Institute, Bloemraad stated that 80 percent of the participants of that study reported that health care is strongly associated with the construction of their Canadian identity and their sense of belonging to Canada. Supporting Bloemraad's explanation, the data of this study shows that health benefits not only lead immigrants to have positive instrumental perceptions but also thin and thick patriotic perceptions. Anusha's example also shows the overlapping nature of loyalty and roots, and the practical difficulty in teasing them apart clearly.

\footnotetext{
${ }^{10}$ Aspects of thick patriotic perceptions a re thoroughly discussed in the next section. Nonetheless, how Anusha's sense of gratitude (an a spect of thin patriotism) has improved her thick patriotism is presented here to illustrate the overlapping nature of those two aspects.
} 
Participants who did not receive a satisfactory amount of instrumental opportunities, however, show less patriotic feelings about being host country citizens. One example is Padma's husband.Padma is a Sinhalese Australian citizen, who is a professor in a renowned university in Melbourne. Even though she is delighted about the instrumental opportunities she received in Australia, she does not think her husband is similarly satisfied. The main reason, according to Padma, is that her husband could not find appropriate job opportunities. Padma says that her husband was in a "higher-up position" professionally in Sri Lanka, but he could never find a similar or a closer position in Australia. Padma thinks it is due to the dissatisfaction of not getting suitable employment that her husband does not feel any allegiance (a form of loyalty) towards the host society. Instead, he still maintains close relations with his home country. Padma says that her husband is always very up-to-date about information regarding his home country, but not about his host country. This suggests that Padma's husband has not built any notable citizenship attachment with Australia, even though he decided to live there as a legal citizen. He thus fits under the exit aspect of Ronkainen's (2011) typology. Therefore, I argue that if an immigrant is dissatisfied with the socio-economic and political rights and benefits she has received in the host society, she does not develop any form of patriotic perception, be it thin or thick.

Another similar example is Nadie. Nadie, a Sinhalese permanent resident of Australia, arrived as a skilled migrant (a translator) in 2014. However, after coming to Australia, she found it challenging to find a suitable job for her qualifications. She took up a cleaning job at a sociology department in a renowned university in Melbourne, but that job did not make her feel happy or satisfied, even though she could earn. "I often thought "what I am doing here? I am someone who is supposed to be either studying or working in this department. [I should] not waste time in cleaning this department." After two years, she could still not find a suitable job other than her cleaning job. She hence felt undervalued by her host society. Nadie did not develop any sense of gratitude (loyalty) or belonging (roots) towards the host society, primarily because of this dissatisfaction. Instead, she decided to go back to Sri Lanka. The decision to return to her home country signals her broken 
ties with the host country (exit). Even though she went back to Sri Lanka, because she had completed the two-year in country requirement, she could extend her permanent residency for another five years. Nadie's example demonstrates how the inability to find a job that suited her qualifications (a negative instrumental experience) and the ensuing dissatisfaction, hindered any possible development of thin or thick patriotism towards her host country citizenship.

The findings above show that many Sinhalese participants' patriotic perceptions begin as a thin form of patriotism, particularly guided by loyalty - which resulted from their sense of gratitude towards the host country. This thin form of patriotism is based on their satisfaction about the socio-economic rights and benefits they receive from citizenship. These include travel rights and benefits, economic conditions, employment conditions, and medical provision. Sinhalese participants who are dissatisfied with the socio-economic rights and benefits received in the host society found it challenging to develop patriotic perceptions.

\subsubsection{Tamil participants}

As explained in Chapter Five, many Tamil participants' instrumental motivations for obtaining host country citizenship were political - they had objectives such as enjoying democratic rights, and being safe as host country citizens. Tamil participants showed that once they get access to those instrumental expectations to a satisfactory level, they develop a sense of gratitude towards the host society.

Thiru, a Tamil participant who is now a citizen, first arrived in New Zealand as a refugee in 2012. Because he was welcomed and offered refugee status, Thiru expressed extreme gratitude to the country. When in Sri Lanka, Thiru lived in Vavuniya, a city in the northern part of the country. Vavuniya was severely affected by the Sri Lankan civil war. Thiru decided to flee Sri Lanka in 2008 when he felt that continuing to live there was life-threatening; "[My] sister was killed. That is the point I decided to leave Sri Lanka." He fled to Bangkok and lived as an illegal 
immigrant there for four years, while applying for refugee status in New Zealand. Finally, his application was approved.

According to Thiru, arriving in New Zealand is a "dream came true" for him and a life stabiliser after years of vulnerable life conditions. While in Bangkok, he was alone, but when he received refugee status in New Zealand, his wife and two children could join him. Throughout our interview, he repeatedly mentioned how grateful he is towards New Zealand and its people, for letting him and his family enter a peaceful country and have ordinary lives as citizens.

Thiru said:

I am very thankful to the [New Zealand] government. I had a tough time in Bangkok for four years. I lived without a visa. But when we came here, we experienced the fullest peace. Because I did not have a visa, in Bangkok, I always had to hide from the police... So I am very, very thankful to this country.

Thiru's case shows that he developed thin patriotism related to his sense of gratitude, fitting Ronkainen's (2011) concept of loyalty. In contrast to my Sinhalese participants, this sense of gratitude is directly shaped by the political privileges (such as the refugee status) he received.

Within the Sri Lankan former refugee community in Australia and New Zealand, two types of refugees can be found. One is those who were directly affected by the Sri Lankan civil war, who had been living in areas where the civil war took place. Thiru and Sri both belonged to this category. The other type was those who did not live in places where the civil war took place, and thus were not directly affected by it, but who were indirectly affected because of their ethnic identity (Tamil). Because of the prevailing ethnic divisions between the majority Sinhalese and the minority Tamil communities, these people claimed refugee status because they feared living in Sri Lanka.

These two categories of former refugees exhibited different class and caste features. Many of those directly affected by the civil war (category one) were from lower classes and castes. Many Tamils from higher classes and castes (category two) who were living in the areas where the civil war was being fought, migrated to other 
places in Sri Lanka or to other countries, at the beginning of the war. Tamils from lower classes and castes did not have the financial resources or networks needed to migrate. Thus, the Sri Lankan civil war impacted Tamils from different classes and castes differently. For example, the level of education of the Tamils who lived in the areas of the war was lower than the Tamils who lived elsewhere. These internal dynamics meant that my Tamil participants had different perceptions of citizenship.

Saranya is a former refugee participant who was from the second category. She was not directly affected by the war, however, she claimed refugee status in New Zealand on the grounds that she was afraid she would be persecuted in Sri Lanka because of her ethnicity. She is Tamil. She now lives in Auckland with her two children. Like many others in my study, she listed safety as a primary motivation for seeking citizenship in New Zealand. She says she feels grateful for her citizenship because she trusts that "if something happens to [me], where ever [I] go, the country [New Zealand] will be responsible for [me]."

Like Thiru, Saranya is not only grateful because of the safety factor. She is also thankful for the socio-economic instrumental opportunities New Zealand citizenship has offered her and her family. Her level of education is higher than Thiru's, and she commented: "[this is] a very good country, very good for the children and whoever is looking for prospects in their lives. It is for the betterment of the children." Saranya's case suggests that due to her background (from a higher class and a caste), even though safety was a primary concern, in seeking citizenship she did not only look for safety and other political benefits, she also sought other socio-economic rights and benefits.

Many scholars argue that citizenship acquisition is higher among immigrants with higher levels of education (Bloemraad, 2002; Bueker, 2005; Constant et al., 2009; Miller \& Barry, 2009; Yang, 1994). Yang (1994) asserts that this is because immigrants with higher levels of education understand the rights and privileges offered by host country citizenship better than those with lower levels of education. Miller and Barry (2009) report that since there are increased job opportunities for citizens, immigrants with higher levels of schooling perceive this as an economic incentive for naturalisation. The data of this research show that in the case of Sri 
Lankan immigrants in Australia and New Zealand, even the immigrants with lower educational levels, specifically those who were from former refugee backgrounds, showed a greater sense of interest in citizenship acquisition. Although my participants with lower levels of education did not know the specif ic rights and privileges available by being a citizen, as found by previously mentioned scholars, all participants from former refugee backgrounds perceived obtaining citizenship to be beneficial.

Similarly to the cases discussed in the previous chapter, some Tamil participants, appreciated citizenship, and felt grateful to the host country for political, as well as other instrumental, reasons. For Shivakumar, for example, being offered a passport was not only about socio-economic benefits, but also about benefits such as being given equal recognition as a citizen. Shivakumar (70), is a Sri Lankan Tamil immigrant in Melbourne who arrived in Australia in 1988, and has been living there for the last thirty-two years. He decided to leave Sri Lanka because of the ethnic riots during the 1970s. He says he feels "privileged" to be an Australian citizen and feels proud to travel as an equal member of that society. Consequently, he reports a true allegiance to Australia, as opposed to Sri Lanka:

... I was not comfortable to travel around [the world] with a Sri Lankan passport, where I didn't feel safe, as a Tamil.... But as an Australian citizen, I feel privileged, and people respect that passport....

The above examples from both Sinhalese and Tamil participants show that their sense of gratitude towards the host country citizenship is caused by their positive instrumental perceptions, i.e., their satisfaction towards the socio-economic and political rights and benefits they receive through citizenship of the host country. The instrumental satisfaction of Sinhalese participants is predominantly affected by the socio-economic rights and benefits they receive (or expected to receive), while the instrumental satisfaction of Tamil participants, specifically those who were former refugees, is mainly affected by the political and safety-related rights and benefits they receive (or expected to receive) as a citizen. For some other Tamil participants (economic immigrants or former refugees from higher classes or 
castes), their thin patriotism is shaped as a result of their satisfaction of both political and socio-economic rights and benefits.

Based on these findings of both Sinhalese and Tamil participants' perceptions, I argue that there is a causal relationship between participants' instrumental and patriotic views. Participants' first form of patriotism (a sense of gratitude) is caused by their positive instrumental perceptions, such as their satisfaction with the socioeconomic and political opportunities they receive through host country citizenship. In terms of perceptions regarding host country citizenship, no participant expressed positive patriotic views while simultaneously holding negative instrumental views. Instead, if a participant holds positive patriotic perceptions, she already had positive instrumental perceptions. Instrumental views were as leading to patriotic views. Therefore, it can be suggested that Sri Lankan immigrants' instrumental and patriotic views are not mutually distinct, instead, instrumental views triggered patriotic perceptions.

\subsection{Thick patriotic perceptions}

This section discusses my participants' transition from thin to thick patriotism. It is essential to notice that in all the cases examined in this section, thick patriotic perceptions occur on top of (or sometimes simultaneously with) pre-existing thin patriotic perceptions. Since I have covered the functioning and modulating factors of thin patriotic perceptions at length in the previous section, I will not discuss them again here. It may be assumed that all the participants featuring in this section have experienced thin patriotism, based on a sense of gratitude and hence on loyalty.

According to the findings of this study, two key factors have critically affected participants' conversion from thin to thick patriotism: their length of the stay, and the reception they receive in the host society. Both these factors (simultaneously or on top of the sense of gratitude - loyalty) have led participants to develop a sense of belonging in the host society, in addition to their sense of gratitude. Some participants' sense of belonging (roots) was limited to an emotional affiliation. 
They identified themselves as a part of the collective in the host society and honoured its culture. Because of their sense of belonging, other participants revealed their interest in actively participating in the affairs of the country, such as voting (voice). Because at this level, participants' patriotic perceptions had two or more aspects of Ronkainen's (2011) typology, loyalty, roots, and voice, I call it as thick patriotism.

To explore this, I first explain how the length of stay of an immigrant in the host society affects her sense of belonging - demonstrating how the longer the stay of a participant in a particular country, the higher the tendency to feel belonging to that society. Following this, I explain how the reception of the host society affects participants' sense of belonging. According to my data, when the response from the host country, at both the state and societal level, is positive and welcoming, participants tend to feel they belong. However, the conversion from thin to thick patriotism takes place differently in the cases of Australia and New Zealand. This is because participants perceive the receptions they receive from Australia and New Zealand differently. Specifically, participants from Australia see racism in Australian society to be a disturbance that delays their conversion from thin to thick patriotism.

\subsubsection{Length of stay}

As previously stated, the results of my study found that the longer an immigrant's stay is, the higher the tendency to feel a sense of belonging to the host society. A longer time in the host country provides greater opportunities to learn the culture and values, and to create memories with co-members of the host society.

Jayasiri, a dual citizen of New Zealand and Sri Lanka, has been living in Auckland for twenty years. When he first obtained New Zealand citizenship, he wanted it only for instrumental reasons, primarily to receive a passport. However, he now feels a great sense of belonging to the society, and believes that the main reason for his improved patriotism is his long stay, during which he has had many positive 
experiences. Like those mentioned in the previous section, the instrumental benefits he received because of his long time in the country led to a sense of gratitude and loyalty to New Zealand (thin patriotism). He also had positive relations with the people/society, the land, and the culture, which has led him to feeling a sense of belonging (thick patriotism). As a result, he now feels that he "is a part of" New Zealand. Answering a hypothetical question about whether he would he have applied for citizenship at this point of his life if he had initially had instrumental reasons in the years after emigrating, he says he would. He notes that "... if a person wants to be a full part of the host country, he or she needs to become a citizen. It does not make sense to me to see a person living in a country for so long, without being a citizen."

As stated in Chapter Five Sarath (a New Zealand resident of 32 years, who has held citizenship for 20), first developed gratitude because of the instrumental (mainly travel) benefits he received. This sense of gratitude (loyalty) has encouraged him to think of the ways he can payback New Zealand. One of these ways, is voting for the Labour party: “... since 1988, we were able to come here and settle because of the labour government policies... I was a strong supporter of Labour for a long time. I voted and followed David Lange." Sarath's example suggests that his sense of gratitude (loyalty) directed him to participate in political matters in the host society by voting (voice in Ronkainen's (2011) typology). Sarath's example, shows the overlapping nature of the aspects of Ronkainen's typology - although representing two different aspects, loyalty and voice in this example had a causal relationship - loyalty caused voice.

Throughout his time in New Zealand, Sarath has also collected many living experiences that enabled him to feel belonging (roots). He explained to me an experience with the Ombudsman some time ago, and was impressed that, under the Official Information Act (1962), New Zealand citizens can request information directly from the Ombudsman. "I just lodged a complaint," Sambath said, "and everything was taken care of. It did not cost me. There was a comprehensive report I got at the end." For him, this first-hand experience is "unbelievable," and "is not something that I can ever expect from Sri Lanka.” These experiences led him to 
identify himself as a valued equal citizen in the host country. Such identifications have increased Sarath's sense of belonging - a feature of Ronkainen's (2011) roots - towards New Zealand. Thus, Sarath's example clearly shows the role of his thin patriotism, that was based on loyalty, in improving his thick patriotism: his political participation (voice) and sense of belonging (roots).

Supun is a Sinhalese New Zealand permanent resident who wishes to become a New Zealand citizen. He has been living in Wellington for four years. He believes that it is still "too early" for him to belong to the host society, and that for a person to be a patriotic citizen, she should have "attachments" with the people, the land, and the culture of a society. While discussing the issue with me, he commented that “...I spent twenty-nine years there [in Sri Lanka]. That's where I grew older. So probably, if I spent twenty-nine years here in New Zealand [instead Sri Lanka], things [views] might have changed." He believes that when he learns more about the New Zealand society, he would be "a part of it," and that he will belong to his host society in the future. ".... four years is not enough. We still have a sort of culture shock. It's new. The [New Zealand] culture is alien to us yet. We will feel homely in the future when we start laughing at their jokes; when we start understanding why they do the things they do."

Participants who found better job opportunities during their stay report that their work environment is one of the critical platforms encouraging their belonging. Anusha (introduced above: a Sinahelese dual citizen), stated that her job positively affected her sense of belonging to New Zealand. “... I'm an accountant. I have to know what the tax system is, how the tax benefits are flowing into the economy... So, I had to know what the policies of different parties are ... and I think it also accelerated my integration to the society." At first, she searched for that information only because of her career, however, now it has extended beyond this"

...[In] those days I felt I was still a Sri Lankan citizen who was living in New Zealand. But now I feel I'm more integrated to New Zealand Society. I want to know what is happening in politics and the environment and how we can contribute... And also as a professional, I'm concerned as to how I can contribute more to society. 
She reports being conscious of the "politics and environment" and also thinks about "how [she] can contribute ... to the [host] society." Partly due to her satisfaction at her level of job, not only Anusha's sense of gratitude (loyalty) but also her sense of belonging (roots), and her political participation (voice), has improved, converting her thin patriotism into thick patriotism.

Padma too views her job as a tool that increased her sense of belonging to Australian society during her lengthy stay. Padma (also discussed in Chapter Five), is Sinhalese and a dual citizen, who experiences a sense of thick patriotism. As previously mentioned, she is a professor at a university in Melbourne, and says that she feels blessed to have the opportunity to work where she does. Because of her job, she thinks she receives opportunities to learn more about Australia daily. Because of this, she feels closer to the host society than she was before, and her feelings of belonging (roots) has been deepened.

\subsubsection{Reception of the host society}

The other critical factor that affects participants' conversion from thin to thick patriotism is the way they perceive the level of reception from their host society. According to the data, when participants experience a positive response from the host society, it improves their sense of belonging to the host society. When the response from the host society is negative, participants find it harder to develop a sense of belonging. Reception here means the day to day societal reception participants experience from fellow host society members, as well as the institutional and policy support from the state. These aspects (institutional and policy factors) have been noted by many scholars as affecting immigrants' sense of belonging, as well as the level of support people feel (Bloemraad, 2006a; Cho, 1999; Ersanilli \& Koopmans, 2010; Garcia, 1981; Lister, Smith, Middleton, \& Cox, 2003; Ramakrishnan \& Espenshade, 2001; Rosenstone \& Hansen, 1993; Uhlaner, Cain, \& Kiewiet, 1989). For example, Simonsen (2016), argues that immigrants' 
belonging is more a matter of informal and subtle everyday interactions between immigrants and the host society.

As previously stated, participants from Australia and New Zealand have different perceptions regarding their reception. Many of those from Australia perceiveracism in both institutional and day-to-day societal levels, which limits or prevents their feelings of belonging to Australian society. This is perceived by them as a barrier in their conversion from thin to thick patriotism. In comparison, participants from New Zealand have fewer negative perceptions regarding this matter. None viewed racism at an institutional level, however, according to a few participants, there was some at the societal level. As with those in Australia, those who did experience some form of racism felt a barrier in the development of their sense of belonging to New Zealand society. Regardless of this, the majority of participants from New Zealand were more easily able to move from thin to thick patriotism than those from Australia. In what follows, I compare cases from Australia and New Zealand.

Let us return to Sarath. Sarath (a New Zealand citizen for twenty years), views the New Zealand government's reception of immigrants positively. Specifically, he perceives the voting rights given to non-citizens a progressive feature, indicative of the government's reception towards immigrants. As discussed in Chapter Two, New Zealand is one of the five countries, and the only Western democratic country that offers voting rights to their non-citizens (McMillan, 2017). Sarath compared the voting rights received by immigrants (when they become residents) in New Zealand with Australia, commenting that "... in Australia, residents have no voting rights. But here, we are privileged that New Zealand residents can vote. New Zealand residents are considered as a part of the electoral matters. So, they have a say." Sarath believes the offer of voting rights soon after people become residents encourages belonging and helps immigrants to become an equal part of the host society.

However, Romesh (introduced in the discussion of socio-economic and patriotic aspects of citizenship), views people in some specific areas of New Zealand to be racist. Following his arrival in 2013, Romesh stayed and worked in Auckland. 
However, he then got a better job opportunity in Invercargill, a city in the South Island. Expecting to obtain better socio-economic benefits, he moved to Invercargill, with the expectation of settling there. However, he struggled in Invercargill:

I have never felt racism [in New Zealand, well... in] only one city here, in Invercargill... There are only white people there. I could only stay there for two weeks. Then I came back to Auckland. [Auckland] is a multicultural place; I am very much used to be here.

Romesh left Invercargill because the prevailing societal racism made him feel unwelcome there. As Romesh had already experienced Auckland, a more "multicultural" city where he feels like an equal citizen, he decided to return and settle in Auckland. Six years after arrival in New Zealand, Romesh is now a citizen, and feels like he belongs. Romesh's case suggests that when the host society reception is positive and more multicultural, it helps immigrants to belong faster, thus to develop thick patriotic perceptions sooner.

Charith, a participant who had lived in both New Zealand and Australia, provided a useful comparative case study. He described how the reception he received in each country affected his sense of belonging to each. Charith (Sinhalese), is a New Zealand citizen who is now settled in Melbourne, Australia. He first arrived in New Zealand from Sri Lanka in 1999. In 2009, after becoming a New Zealand citizen, he decided to move to Australia with his family. The main reason he gave for the move was that he thought his son and the daughter would get better educational opportunities in Australia than in New Zealand. Despite this, he has decided not to become an Australian citizen, but to keep his New Zealand citizenship.

This is because Charith reports having a greater sense of belonging to New Zealand. At first, Charith obtained New Zealand citizenship for socio-economic (instrumental) purposes. However, during his 10 year stay in New Zealand, he developed gratitude, and a sense of belonging (first thin and then thick patriotism) towards New Zealand. These resulted specifically because of the positive experiences he received in his everyday interactions with New Zealand society. The negative experiences he received in everyday interactions in Australia, on the other 
hand, has prevented him feeling like he belongs to Australian society, and thus prevented his desire to naturlise. Commenting on this, Charith stated:

[New Zealand citizenship means] a lot to me... New Zealand is a very peaceful country... it's clean, green ... [and] people are very decent. They respect each other, trust each other... They are friendly... In Australia, you can't get things done over the phone, but in New Zealand, you just call them, you can get services connected, people trust you, they don't ask for your identification. But in Australia, you have to prove yourself. You don't trust them; they don't trust you... [In New Zealand] you don't hear a horn sound. I think it's because it is a clean and a green country, so people are happy there. So New Zealand citizenship is very, very valuable to me. Hence, I didn't even choose to get Australian citizenship, even though there are benefits for me. Here if you get Australian citizenship, you will get government benefits if you lose your job; none of my family members is entitled to it now. Even my children don't have many benefits, such as student loans. Yet I chose not to become an Australian citizen. Because I like the New Zealand passport, I want to say that I am a New Zealand citizen very proudly.

As can be seen, Charith's sense of belonging to New Zealand is more profound than that of Australia. I argue that the critical factor affecting his feelings of belonging in New Zealand but not Australia, is the different receptions he received in these two societies. He has a thick patriotism towards his New Zealand citizenship because he feels belonging to New Zealand society. His patriotism towards Australia, however, remains thin.

Charith was not the only participant to identify racism: many other participants from Australia also reported this as a negative factor limiting the development of their sense of belonging as Australian citizens. As a result, many participants from Australia hold thin patriotic perceptions towards their Australian citizenship for a long time, without them becoming thick patriotic perceptions. Racism was perceived at both societal and state levels. As Simonsen (2016) found, immigrants' sense of belonging for a host society is dependent on how that host society imagines its community. In this sense, understanding the level of racism in a host society (at both societal and governmental levels) is important because it shows the host society's imagination about their society, including their view on immigrants. 
Rasika (Sinhalese), an Australian permanent resident, believes that he could not find a suitable job in Australia because of racism. This negative perception has prevented him from feeling he belongs to, and is a part of, Australian society: “... they [Australians] say there is no discrimination... [but] if an immigrant goes to a job interview, there is always discrimination..." Rasika explains his frustration as follows:

When I came [to Australia], I was a banker back then. Although we have the experience, they [Australians] don't give us jobs. To be honest, if someone is new to the country, they might not have Australian experience, right? You can't keep on asking people to have Australian experience if they are new. If you keep on asking for this, even after two years [without giving them a chance], there won't be any people to work in those industries.

Rasika, claims that Australia requests "too many things" from immigrants without providing them the necessary assistance. According to him, only after Australian society improves, and racism towards immigrants reduces, should integration and loyalty be assessed;i.e. there should be a two-way relationship between immigrants and Australian society. He believes immigrants' have a right to be in a place where there is no racism, and Australia should work towards this, instead of only expecting immigrants to be loyal to Australia.

Some other participants perceived certain government policies regarding immigrants in Australia to be reflections of racism. For example, in comparing the Australian policies in the late 1980s and present, Shivakumar (70), a Tamil, Australian citizen for 29 years, perceives contemporary measures, such as the citizenship test, to be a result of the government's discriminatory approach towards immigrants. In the 1980s, he said that the government encouraged immigrants to be citizens, welcoming them with open arms. It was "very easy" to obtain Australian citizenship then; he received a letter from the government, inviting him to become a citizen at the end of his two-year residency period. For him, the current citizenship test is nothing but an effort to cut down the numbers of Asian immigrants becoming citizens. He claims that the government is racist and implements quick, simplistic, measures for complicated issues: 
The current Labour government; they are very racist. They are very racist. There are a lot of Europeans [in Australia], and they don't want to be citizens. Because they hold their countries' passports, and they don't want to become citizens. [On the other hand] there are a lot of Indians coming in ... now they [white Australians] feel threatened. They want to reduce that [Asian] population coming in. So that is the reason...very, very simple politics they are playing.

Shivakumar does not believe that the citizenship test genuinely intends to measure immigrants' knowledge about Australian history, values, and culture. Pointing to the nature of questions, he claims that the test is purely intended to make it harder for Asian migrants to become citizens. He questions “... how many runs Bradman got in his cricket; if I know that statistic, [how it is] going to make me love Australia?... if you ask [those questions] from white people, even they do not know the answers. As I said before, it is just to reduce the numbers."

Other participants from Australia also express negative perceptions about the Australian citizenship test. They question the ability of the citizenship test to assess loyalty and belonging. Padma criticised the nature of the questions asked, commenting that:

[The citizenship test asks] questions, the most ridiculous ones [such as] when did Phar Lap [the horse] die? ... Along with that, I think the English test asks for seven out of 10 IELTS, which is what we ask at [our university] for a student doing a $\mathrm{PhD}$. How much of that English does an immigrant [really] need to know [to live in Australia]?

She also says when a test is compulsory, people would not learn things because they love the country but only to pass the test; so it neither increases one's loyalty or belonging. Instead, she believes, if an immigrant wishes to settle in Australia and are given adequate space to "learn ... and understand the ethos, the spirit of the country [organically]" that is a "much better way for them to learn than doing a test." Padma thinks the nature of these assessments encourages assimilation, not integration.

The institutional policies of host countries critically affect immigrants' feelings about that society (Avc1, 2006). Avc1 (2006) argues that host countries with more 
assimilationist policies do not help immigrants to have positive attitudes, or patriotic senses of belonging, towards that society. The examples above show that many participants from Australia perceive the reception they received in Australian society (both at the societal and institutional and policy level) to have racist features. As a result, they find it more difficult to upgrade their thin patriotism to thick patriotism than the participants from New Zealand.

\subsection{Conclusion}

This chapter described participants' patriotic perceptions about host country citizenship, and the factors that have affected those perceptions. As discussed in section 6.2, participants showed an initial tendency to develop thin forms of patriotism towards their host country. In this chapter, I argued that this thin patriotism emerged out of sense of gratitude. Gratitude represents one category of Ronkainen's (2011) typology of thin-thick national citizenship ties: loyalty. When participants are satisfied with the socio-economic and political rights and benefits they receive through host country citizenship, they tend to be grateful about it. Thus, I suggest that participants' sense of gratitude is caused by their positive instrumental perceptions towards host country citizenship. This chapter also suggested that we should see a causal relationship between participants' instrumental and patriotic perceptions. Furthermore, the data showed that Sinhalese and Tamil participants' sense of gratitude have been affected by different in strumental factors. While socioeconomic instrumental perceptions influenced Sinhalese participants' sense of gratitude, the majority of Tamil participants' gratitude was affected by political perceptions.

Based on these findings, I argue that in the context of migration, immigrants' instrumental and patriotic perceptions should not be considered as diametrically opposed to each other. As explained in Chapter Three, in the literature citizens' instrumental and patriotic perceptions had been understood as two different extremes that are mutually exclusive. In contrast, at least in the case of Sri Lankan 
immigrants in Australia and New Zealand, their instrumental and patriotic perceptions are deeply related, with the latter growing out of the former. Thus, the key finding of this chapter challenges the way instrumental and patriotic perceptions have previously been theorised as two contrasting concepts.

Section 6.3 explained the participants' transition from thin to thick patriotism. The data showed that, along with the continuation of the factors affecting thin patriotism (a sense of belonging), two factors affected this transition: length of stay, and the reception of the host society. Participants who have had longer stays in Australia or New Zealand, and have had a positive reception from the host society, were found to have a greater sense of belonging (roots) towards the host society, creating increased interest in participating in societal matters, such as voting (voice). I called these perceptions thick patriotic perceptions, because they contained two or three aspects of Ronkainen's (2011) typology: loyalty, roots, and voice. However, in terms of the reception from the host country, participants from Australia and New Zealand reported different experiences. Participants from Australia thought the reception they had (from a societal, institutional, and policy level) contained more racist features than participants from New Zealand. As a result, thin patriotism had transformed into thick patriotism for fewer participants from Australia than from New Zealand.

The previous two chapters together discussed participants' instrumental and patriotic perceptions of their adoptive country citizenship. In the next chapter, I move the discussion to citizenship perceptions of participants' home country citizenship. 


\section{CHAPTER 7: Sri Lankan immigrants' instrumental and patriotic perceptions about home country citizenship}

\subsection{Introduction}

In this chapter, I identify what value my participants saw in having Sri Lankan citizenship, both in terms of the material benefits they would gain, and its expression of a sense of loyalty and belonging to Sri Lanka. Overall, I found that two main factors explained their thoughts: 1) their pre-emigration experiences and perceptions as Sri Lankan citizens living in Sri Lanka; and 2) the factors guiding their decisions about whether to retain or re-apply for Sri Lankan dual citizenship after emigrating. As I elaborated in Chapter Five, the first aspect is influenced commonly by participants' socio-economic and political experiences in Sri Lanka. In this chapter, I specifically detail my participants' views of the second aspect; their decision to become dual-citizens of Sri Lankan and Australia or New Zealand which, I argue, demonstrates the meaning of Sri Lankan citizenship to those who maintain it. It is essential to note here that my aim is not to distinguish between citizenship and dual citizenship theoretically or policy-wise. Instead, I explore the salient features of participants' meanings of home country citizenship through their decision to become (or not) dual citizens in their home country.

My data shows that both Sinhalese and Tamil participants had negative instrumental perceptions, but positive patriotic perceptions - thin or thick - towards Sri Lankan citizenship. The majority of Sinhalese participants had thick patriotic perceptions, while Tamil participants had thin patriotic perceptions. I consider the majority of Sinhalese participants' perceptions thick because they contained two or three aspects of Ronkainen's (2011) typology: voice, roots, and loyalty. The majority of Tamil participants' patriotic perceptions only contained roots, hence, I describe them as thinly patriotic. 
Interestingly, my findings demonstrate that participants can hold negative impressions about Sri Lankan citizenship in terms of the poor materialistic benefits and rights it offers, while simultaneously holding positive aspects in terms of being loyal and belonging to Sri Lankan society as citizens. This suggests a different pattern in participants' instrumental and patriotic perceptions towards home and host country citizenship, as outlined in Chapters Five and Six. I found a positive relationship between my participants' views of the instrumental benefits associated with acquiring citizenship and their likelihood of seeing citizenship as an expression of patriotism.

In this chapter, I show that these two views can be mutually ex clusive and one does not necessarily affect the other. I argue that this different way of viewing home and host country citizenship is the result of the different positioning of my participants as home and host country citizens. Many positioned themselves as native citizens when reviewing Sri Lankan citizenship, and as immigrants in thinking about Australian or New Zealand citizenship. I argue that regardless of whether her migratory expectations (that are mostly social, economic, and political) are met, when a person positions herself as an immigrant, this shapes her patriotic attachment to the society. However, when a person positions herself as a native citizen, in a society that she has memories of, and sentimental attachments to, people, places, and culture, she can value that citizenship patriotically positively (ranging from thin to thick), without it being affected by any instrumental thoughts.

I divide this chapter into two main sections. First, I discuss participants' instrumental perceptions of Sri Lankan citizenship. Second, I describe their patriotic meanings related to dual citizenship. As I mentioned previously, there are differences between Sinhalese and Tamil participants' patriotic perceptions. Therefore, I present the perceptions of these two ethnic groups separately.

\subsection{Instrumental reasons}


As discussed in Chapter Five, both Sinhalese and Tamils emigrated to Australia or New Zealand because they were not satisfied with the materialistic benefits and rights they received as Sri Lankan citizens in Sri Lanka. According to my data, whereas a majority of Sinhalese participants' negative instrumental views regarding Sri Lankan citizenship were based on poor socio-economic factors in the home country, the majority of Tamil participants' negative instrumentalviews were based on poor political factors.

In deciding whether they should retain or resume their Sri Lankan citizenship after naturalising in Australia or New Zealand, the majority of my participants had patriotic interests, although a few also had instrumental interests. I divide participants' instrumental reasons in to two groups: direct and indirect instrumental reasons. Direct instrumental reasons are those relating to owning and managing property, businesses, or investments, while those such as securing travel rights, are indirect. Those who had direct instrumental interests obtained dual citizenship primarily for materialistic reasons as explained below. Those with indirect instrumental interests, obtained dual citizenship due to a combination of patriotic and instrumental aspirations; for example, wanting to assure travel rights (an instrumental interest), while also wanting to continue their relations with, and sense of belong to, Sri Lanka (a patriotic interest).

\subsubsection{Direct instrumental reasons}

Five out of the forty-nine participants had direct instrumental reasons for obtaining Sri Lankan dual citizenship, related to managing property, investing, or doing businesses. However, it is essential to note that these five participants concurrently had patriotic reasons that backed up their decision to obtain dual citizenship. Therefore, it cannot be concluded that they obtained it purely for instrumental reasons. Instead, for them, Sri Lankan dual citizenship acquisition was motivated by a combination of instrumental and patriotic goals. 
Two out of these five participants said they need dual citizenship because they have land and/or property in Sri Lanka. They consider that the legal rights obtained through dual citizenship makes it easier to manage land/property. Saranya (a Tamil New Zealand citizen), is a good example. She came to New Zealand as a visitor in 2008 and then claimed refugee status. She said, "[I have] my husband's properties ... in Sri Lanka." After her husband's death, Saranya had to look after and manage those properties.

Saranya obtained Sri Lankan dual citizenship for this reason. However, she also wanted to become a dual citizen because "Sri Lanka is our motherland. You can't forget your mother, your mother tongue, the people, everything." Hence, Saranya's case suggests that her decision to become a Sri Lankan dual citizen is a combination of both instrumental (to manage her property) and patriotic (because of a sense of belonging).

The other three participants' direct instrumental reasons for obtaining dual citizenship was because it would provide them with the administrative and legal ability to get things done in Sri Lanka. For example, Sachini (Sinhalese) - a permanent resident of New Zealand who runs a business in Sri Lanka - said that being a dual citizen gives her the same business rights as that of a Sri Lankan full citizen. However, she mentioned that her sense of belonging is important as well: "my father lived in Italy for 25 years but never obtained Italian citizenship ... he used to tell me when I was small [that I can never change] where I come from... So, I do not want to change [where I was born.]"Hence, Sachini's case also proves that her decision to become a dual citizen was not only influenced by instrumental reasons, but also by her patriotic interests.

\subsubsection{Indirect instrumental reasons}

As opposed to these direct aspects, many participants had indirect instrumental reasons for obtaining dual citizenship, of which the main one was travel rights. Having dual citizenship provides the right to travel back and forth to Sri Lanka at 
any given time, and to stay in the country as long as they wish, without needing a visa. I call this an indirect, because many participants' interest in securing the travel rights was so that they could visit and stay in Sri Lanka where they have a strong sense of belonging (a patriotic reason). The majority of participants said that they wanted to visit Sri Lanka often, and stay there as long as they wish, because of their sense of belonging to the people, the land, and the culture.

This sense of belonging was mostly related to people they personally know in Sri Lanka; the most recurrent reason to keep visiting Sri Lanka was to maintain relationships with immediate family, as well as other relatives, neighbours, and friends. Except for a few, most of my participants still had parents and siblings living in Sri Lanka. To maintain these relationships, participants thought visiting Sri Lanka frequently is needed. Priyadarshani (40), a Sinhalese New Zealand permanent resident, said “... my parents are living [in Sri Lanka, so] I have commitments [there.]" Priyadarshani thought that having Sri Lankan citizenship would ensure her legal right to travel there at any time and to stay as long as she desires.

Tamil participants who wanted to obtain dual citizenship considered travelling to Sri Lanka often to see family and friends, essential. Shiva (60), said "from my young age, all my friends and family friends ... my family, my wife's parents, brothers ... relations are there [in Sri Lanka] and I have to go to the place where I was born." Shiva, who is a Tamil New Zealand citizen, also expected to go back to Sri Lanka to settle, so this was also a factor in his interest in dual citizenship.

It is essential to stress that travelling to Sri Lanka on an Australian or a New Zealand passport is not difficult. Both passport holders can get a visitor's visa on-arrival to Sri Lanka, enabling them to stay up to 30 days (Department of Immigration and Emigration Sri Lanka, 2019). Many participants who are (and want to be) Australian or New Zealand citizens knew of the on-arrival visa. Nonetheless, a majority of them noted that 30 days is not long enough for their needs; they want no restriction. Moreover, some of them also expressed their dislike of entering Sri Lanka, their home country, on a foreign passport. 
Pathum, a Sinhalese immigrant in New Zealand who has lodged a refugee application, is one example. Since his visa application is still in the process in New Zealand, he cannot go to Sri Lanka any time soon. ${ }^{11}$ Thinking about the future, he said that shortly after he becomes eligible to visit his home country, he would immediately want to obtain dual citizenship. This is to make sure that he can visit anytime and stay as long as he wants. Pathum has an extended family and after having lived for such a long period abroad, he thinks that 30 days will not be enough to meet his family members properly: "I have a lot of relatives there. I need a lot of time there."

As explained above, only a small number of participants had direct instrumental interests in obtaining dual citizenship. The limited instrumental reasons participants shared were economic (managing properties, investing, or doing businesses). Other participants had indirect instrumental interests, such as obtaining travel rights to visit and stay longer in Sri Lanka. No participant expressed any other form of instrumental interest such as political (having voting rights).

\subsection{Patriotic reasons}

While a small number of participants mentioned instrumental reasons for obtaining dual citizenship, the majority had patriotic reasons for continuing or regaining their Sri Lankan citizenship. However, the factors affecting participants' patriotism towards their home country are different from those affecting their patriotism towards their host country. As discussed in Chapter Six, with host country citizenship, a sense of gratitude is the prime factor causing patriotism; firstly, in a thin form and latterly in a thick form. It is also related to their positive instrumental perceptions and experiences of host country citizenship.

\footnotetext{
${ }^{11}$ He cannot go to Sri Lanka while his refugee a pplication is processing, and a ssumes that the soonest he will be able to visit Sri Lanka will be in a couple of years.
} 
In contrast, participants' patriotic perceptions towards home country citizenship did not show any relationship with their instrumental perceptions; their positive patriotic perceptions were not affected by negative instrumental perceptions. Instead, their patriotic perceptions were largely shaped by their sense of belonging towards the land, the people, and the culture of the home country (roots). For some participants, holding Sri Lankan citizenship was also a form of continuing their home country identity, showing solidarity with, and allegiance to, the home country (loyalty). Finally, some wanted to obtain citizenship so that they could participate in political affairs in the home country (voice), and many did not want to break their citizenship ties with Sri Lanka (exit).

My research underlined key differences between Sinhalese and Tamil participants' patriotic perceptions. My findings show that Sinhalese participants held more thick patriotic perceptions, while Tamil participants hold more thin patriotic perceptions. In the following section, I first discuss Sinhalese participants' patriotic perceptions towards Sri Lankan citizenship and the factors that have affected those. I then discuss the case of Tamil participants' patriotic perceptions towards Sri Lankan citizenship.

\subsubsection{Sinhalese participants}

Sinhalese participants in this study showed thick patriotism towards their Sri Lankan citizenship. Many of these perceptions combined two or three aspects of Ronkainen's (2011) typology, namely: voice, roots, and loyalty. They did not show Ronkainen's aspect of exit, or any intention to break their ties with Sri Lanka as citizens. In particular, roots, which represents the sense of belonging towards people, society, land and culture, as a strong emotional affiliation, could be prominently seen in Sinhalese participants' patriotic perceptions.

One reason for Sinhalese participants' thick patriotism is their decision to secure aforementioned travel rights. As I explained above, they want to travel in order to maintain their relationships with family and friends in the home country. However, 
some Sinhalese participants want to visit Sri Lanka, not only to visit their family and friends, but also because they have a sense of belonging (roots) and a sense of gratitude (loyalty) to other people that they do not know personally. That is, these participants want to visit their home society because they share many historical and cultural similarities with other co-members. For example, Darshi's sense of belonging and gratitude is not only a result of her close ties with the people she has direct contact with, but also because she has a strong sense of belonging and gratitude to other citizens in Sri Lanka, since she believes that she shares so many commonalities with the other co-members of her home society. A Sinhalese dual citizen of New Zealand and Sri Lanka, Darshi said:

If [I] walk in the street in Sri Lanka, [I] have the feeling that [I] know them, although [I] don't know them personally. [I] know that they are someone among us ... Sri Lankans... I don't know; there is no strange feeling in Sri Lanka because that is our country.

Darshi's statement shows that she had feelings of belonging to, and identification with, a national collective, suggesting the aspect of roots in Ronkainen's (2011) typology. These strong feelings of belonging towards being a Sri Lankan citizen also suggests that Darshi does not want to break ties with her home society (exit). Due to her sense of belonging (roots) and relationship with co-members of the Sri Lankan society, Darshi also shows that she has both feelings of solidarity towards the political community as well as strong feelings of allegiance (loyalty).

Darshi's example underlines the overlapping nature of roots and loyalty, and the difficulty in practically disentangling these aspects. Moreover, this case suggests a different pattern in participants' roots and loyalty sensitivities in their host and home country citizenship perceptions. As discussed in Chapter Six, when it comes to participants' patriotic perceptions towards host country citizenship, many participants develop roots (a sense of belonging) based on their loyalty (sense of gratitude). In contrast, in her patriotic perceptions towards her home country citizenship, Darshi develops her loyalty (sense of gratitude) based on her roots (sense of belonging). Hence, it can be seen that there is a different pattern in thin 
and thick patriotic perceptions and their relationship in host and home country citizenship.

Praveena, previously introduced in Chapter Six (Sinhalese, and a resident of New Zealand) shared similar sentiments, commenting that unlike when she is in New Zealand, in Sri Lanka she gets the feeling of living among people she knows: "[in Sri Lanka] there are people, you can hear them, you can feel them." Praveena did not talk about people she knows personally, but about other co-members of her home society. She thinks she shares many cultural similarities with them, therefore, becoming a dual citizen is a way to continue her sense of belonging to the people she shares many commonalities with, as well as her identity. Similar to Darshi, Praveena's patriotic perceptions towards home country citizenship represents the loyalty, roots, and exit categories of Ronkainen's (2011) typology. Thus, I consider Praveena's patriotic perception to be thickly patriotic.

For other Sinhalese participants, obtaining Sri Lankan dual citizenship is a means of continuing their strong emotional bond with the land where they were born and grew up. This sense of belonging towards the homeland overlaps with Sinhalese participants' positive sense of belonging towards the people and the culture of Sri Lanka. Darshi wanted to obtain dual citizenship because of her sense of belonging to the homeland. She said that Sri Lanka is "everything" to her because "... that is our country. That's where we grew up..." Likewise, the main reason for Udari, a Sinhalese Australian citizen, to obtain dual citizenship, was because "that is where we were born. That's our motherland. We do not want to lose the connection..." Although now a resident of New Zealand, Malathi also wanted to obtain Sri Lankan dual citizenship because she did not want to lose her relationship with where she was born. In her opinion, Sri Lankan citizenship is something bigger than a mere piece of paper, since being a Sri Lankan at heart is superior to being a Sri Lankan in a document. Answering a hypothetical question as to what she would do if she had to choose one citizenship at the expense of the other (Sri Lankan or New Zealand), Malathi decided to go for New Zealand citizenship. Nonetheless, she said: 
[Losing Sri Lankan citizenship would be] the saddest thing ever...[But] that's okay ... taking away my Sri Lankan citizenship is like just paperwork. But, from my heart, my body and everything, I [will be] a Sri Lankan... I will keep that identity - being a Sri Lankan, and a proud Sri Lankan ... because we have a long, 2,500year culture... I am very proud of my country and ... I think I am lucky to be a Sri Lankan.

In this case, Malathi showed her deep sense of belonging (roots) to Sri Lanka. She mentioned that if she encountered a situation where she could not obtain Sri Lankan dual citizenship, even though she prefers to preserve her SriLankan citizenship, she thinks it is alright otherwise, since her meaning of being a Sri Lankan citizen is deeply rooted in her heart. Hence, Malathi's words also reveal her feelings of allegiance and solidarity towards her Sri Lankan identity (loyalty). Even though she does not have the legal status of Sri Lankan dual citizenship at present, she does not believe that she has actually broken her ties (exit) with her home society. Thus, I suggest Malathi's patriotic perceptions towards Sri Lanka is a form of thick patriotism, because her thoughts contained aspects of both loyalty and roots.

Furthermore, Malathi's example demonstrates the strength of qualitative research in grasping the meaning of citizenship for different individuals. For example, if for some reason Malathi did not obtain Sri Lankan citizenship, it does not necessarily mean that she does not want it. Rather, it only means that her perception of citizenship is different; it is not only about having legal citizenship status but also an identity in her heart. Hence, in the case of Malathi, not obtaining a document of citizenship cannot be interpreted as her not wanting to obtain citizenship or as a possible breaking of citizenship ties. This example well represents the importance of exploring the emotive meaning of citizenship and the potential of qualitative research in such explorations

Anura, a Sinhalese citizen of Australian, also wants to obtain dual citizenship because of his sense of belonging to his homeland. Like the cases above, his expression of his sense of belonging had aspects of loyalty and roots. Aside from his own opinions, Anura attempted to generalise the factors affecting immigrants' patriotism towards their home country. In his opinion, immigrants' decisions to 
continue Sri Lankan citizen ship is due to their memories growing up, from which one cannot easily detach. For example, he said:

...if you are a Buddhist; you will go to the Ruwan Weli Maha Seya [a Buddhist temple in Sri Lanka], if you are a Christian, it's the Madu Church [a Christian church in Sri Lanka] ... Even a person who hates the home country for some reason ... there can be such attachments that he/she can't easily be detached from.

Anura's explanation also suggests that immigrants' patriotism to home country citizenship has a bottom-up approach. According to Anura, first-generation immigrants' belonging to their home society, and being a citizen of the state or political community (top-level) relates to their experiences and memories of people, places, and events in the home country (bottom level). In this case, immigrants' experiences and memories at the bottom level are causal factors affecting their meaning of citizenship at the top level.

In the case of Sinhalese participants' patriotic perceptions towards Sri Lankan citizenship, the common pattern seems to have a bottom-up approach. Many Sinhalese participants tended to establish patriotism as a Sri Lankan via their experiences and memories growing up with fellow members in the home society. This sense of belonging, then, leads them to perceive themselves as citizens in the political community in the state of Sri Lanka.

Asela obtained dual citizenship (of Australia and Sri Lanka) because he perceived losing his home country citizenship as "a big loss" in his life. Asela said "I ... did not obtain Australian citizenship [for a while] because of the fear that I would lose my Sri Lankan citizenship. I took [dual citizenship] because Sri Lanka is our bom country." Asela explained further: "even though [Sri Lanka] is a poor country, it created us, shaped us. The bond we have with [Sri Lanka] is immense. I did not want to lose it. The only reason is that I had a strong sense of belonging to Sri Lanka."

The above statements illustrate that Asela's patriotism towards Sri Lankan citizenship was thick because it has aspects of both loyalty - in the form of a sense of gratitude - and roots - in the form of a sense of belonging. Furthermore, he revealed his desire to actively participate in home country politics through 
becoming a Sri Lankan citizen, which had aspects of voice. Asela said he "need[s] the right ... to talk about [issues in Sri Lanka] as a full citizen." He used the term "right" to mean his ability to talk about Sri Lanka, since he perceives that his political opinions about Sri Lanka will be listened to and accepted by his Sri Lankan peers only insof ar as he is a dual citizen. Hence, dual citizenship is Asela's way of having legitimacy to share his opinions with fellow co-members of Sri Lankan society. He commented: "there is an opinion [in Sri Lanka] that, Sri Lankan people who have left Sri Lanka do not love Sri Lanka.” Obtaining Sri Lankan dual citizenship was Asela's counter strategy for such an opinion.

Amal and Supun, two Sinhalese immigrants based in Melbourne, also revealed thick patriotic perceptions towards their Sri Lankan citizenship, despite their negative instrumental perceptions. As discussed in Chapter Six, this is a different pattern than their instrumental and patriotic perceptions towards the host country citizenship, which are more entwined.

Amal said he wished to obtain dual citizenship because he does not "want to die in [Australia]." He wants to die in his motherland; Sri Lanka." Nonetheless, he expressed keen interest in the instrumental benefits becoming an Australian citizen would have for him, as well as for his children's education. This is because Amal considers the Australian system to be more advanced and better globally recognised than that of Sri Lanka. Amal's negative views about the education system in Sri Lanka has not curtailed his sense of belonging to his homeland: even though he expects to obtain Australian citizenship for the sake of his son's education (an instrumental reason), he said he always wants to go back to Sri Lanka because of feelings of gratitude and belonging.

Supun's perceptions about continuing to be a Sri Lankan citizen also contained aspects of loyalty and roots. He mentioned a sense of belonging to the home country as his reason for obtaining dual citizenship. He said "it's the place [I] grew up, that's [mine]... Sri Lanka has given me a lot... a way of life, the culture, and that's what I am and who I am..." He also said: "a bigger part of me is still there [in Sri Lanka] and I expect to go back at one point." Comparing home and host country citizenship, 
Supun commented that he is not satisfied with the instrumental rights and benefits he gets through his home country citizenship, so he wants to become a New Zealand citizen mainly for such reasons, such as the benefits for his children in the future.

Amal's, Supun's, and other participants' cases, prove that it is possible to simultaneously hold negative instrumental views and positive patriotic views. When it comes to home country citizenship, I thus argue that instrumental and patriotic perceptions are not entwined, but can be separated from each other. It can also be argued that this difference results from the different positioning of one's self as an immigrant or native citizen. My findings conf irm this; as I have shown, when a person positions herself as a native citizen, she can separate the instrumental and patriotic aspects of citizenship. However, when she positions herself as an immigrant, her patriotism is critically influenced by her instrumental experiences and perceptions of the host country.

Other people who expressed thick patriotism towards Sri Lankan citizenship included Anusha, a Sinhalese dual citizen of Sri Lanka and New Zealand, introduced in Chapter Six. For Anusha, her Sri Lankan identity was an important element of her life and obtaining Sri Lankan dual citizenship was thus a means to continue her home identity. Anusha visits Sri Lanka every year, and said that whenever she enters, she wants to enter as a Sri Lankan, not as a New Zealander. Anusha had to visit Sri Lanka once using her New Zealand passport - during a period shortly after obtaining New Zealand citizenship, when her Sri Lankan citizenship had been revoked, and she was waiting for her dual citizenship application to be approved. Recalling this experience, Anusha noted that she felt "guilty" about using New Zealand passport to arrive in Sri Lanka. In other words, Anusha's perception of her home citizenship was strongly shaped by her sense of gratitude and loyalty to the country, and obtaining dual citizenship is both about continuing her Sri Lankan identity, and an expression of her loyalty to Sri Lanka.

For other participants, especially those who had children, obtaining and keeping dual citizenship was a means to pass positive thoughts about their home country to 
their offspring. Two main thoughts shaped Nilmini's - a Sinhalese New Zealand citizen from Wellington - decision to obtain dual citizenship.

Firstly, it was because of her sense of belonging towards her home country and the desire to continue her home country identity. On reflection, Nilmini said that she always appreciated the values she received by being a Sri Lankan. She wants dual citizenship to show her gratitude for the cultural values that made her who she is today. “... [A]fter 25 years, I am still a typical Sri Lankan. [Sri Lankan culture] taught us to be ourselves, have a few good friends...etc. That is not the Kiwi [New Zealand] culture." She also said "... I love my country [Sri Lanka] and love the values, how we share things, how we go out of the way to help people." Nilmini thinks she "can never be a kiwi." She assumes the main rea son for her inability to become "a kiwi" is her inability to adapt to the host society culture, because of the continuing influence of her home country culture on her day to day life.

Secondly, Nilmini wanted to pass the identity and positive thoughts Sri Lankan culture to her children, and wanted them to continue their Sri Lankan dual citizenship. In this way, it will be easier for her to take her children to visit Sri Lanka, and to learn Sri Lankan values in more depth. As she stated:

[my children] have some values... But by taking them to Sri Lanka at least once a year, they would start loving [those values more] ... [and] they will pass our [Sri Lankan] roots ... to the next generation ... Through that, we can develop a bond between the younger generation and Sri Lanka. That is why I want dual citizenship.

Dinindu, a Sinhalese Australian citizen, and the father of two girls, shared similar thoughts to Nilmini. On the one hand, Dinindu wants to obtain Sri Lankan dual citizenship to continue his Sri Lankan identity. On the other hand, he wants to pass the Sri Lankan identity to his children. He said "I teach my children the Sinhalese language. [I also take them] to the temple. I value Sri Lankan citizenship as an honour. One day I would love to be retired and live [in Sri Lanka].” It was not only Nilmini and Dinindu; many other participants who are also parents thought that they must be committed to passing the Sri Lankan identity to their children because they live outside Sri Lanka. This is because they had thick patriotism towards Sri Lankan citizenship. 


\subsubsection{Tamil participants}

From my interviews, I noted that while the majority of Sinhalese participants had thick patriotic perceptions towards Sri Lankan citizenship, the majority of Tamil participants had thin patriotism. Sinhalese participants did not show any interest in breaking their citizenship ties - exit- with the home country, and their thick patriotic perceptions represented all the three key aspects of Ronkainen's typology (2011). On the contrary, Tamil participants' patriotic perceptions did not represent all those categories. Many showed feelings of belonging (roots) towards the Tamil community, the land, and the culture of Sri Lanka. However, many of them, specifically the participants from refugee backgrounds, did not have positive feelings or a sense of gratitude and allegiance to Sri Lanka (loyalty). As a result, some of these participants did not want to continue their legal ties with their home country (exit).

Many Tamil participants' negative patriotic perceptions were shaped by their experiences and perceptions of ethnic discrimination and the majority-minority problems in Sri Lanka. They viewed the Sri Lankan government as dominated by Sinhalese people who are "racist," "ethno-nationalistic," and "undemocratic." For example, Shivakumar, a Tamil citizen of Australia, thought Sinhalese people were "racist, very aggressive, and unable to stand other opinions." According to Shivakumar "[now the rivalry] is not only between Tamils and Sinhalese [but] between Sinhalese [themselves]. If there are two different [ideological] groups, they [Sinhalese] kill each other. They just do not think twice [about it]." Shivakumar thought Sinhalese people were not democratic, and did not respect other's opinions. He therefore did not exhibit feelings of solidarity towards his home country and the political community, or feelings of allegiance (loyalty). As a result, Shivakumar did not want to become a Sri Lankan dual citizen.

However, many Tamil participants have thin patriotism based on having a sense of belonging, that represent roots in Ronkainen's (2011) typology. Similarly to 
Sinhalese participants, these perceptions were associated in many ways with their birth and childhood memories in Sri Lanka. Some Tamil participants mentioned that they wanted to obtain dual citizenship because Sri Lanka is their "motherland." Even those who have had discriminatory experiences in Sri Lanka, use the term "motherland" with a robust patriotic meaning, despite the fact that they did not have the sense of gratitude (loyalty) towards their home country.

Niru is an example. Niru is a Tamil Australian citizen who was directly affected by the civil war in Sri Lanka. She came to Australia in 1995 as a refugee. In her interview, she mentioned that she could not live in her "own house," in her "own land," because of bombings and shooting. Because of these disruptive memories, Niru did not express feelings of gratitude (loyalty) towards her Sri Lankan citizenship. Even though this might suggest her entire view towards being a Sri Lankan citizen to be negative, she calls Sri Lanka her "moth er country," and expects to obtain dual citizenship because of her sense of belonging to that "mother country."

Niru does not appreciate the term "dual citizen," since she thinks the term dual citizen itself is not an accurate way to identify herself. She said “... when Sri Lanka asks us to have dual citizenship, it is very hard. It's a very painful thing for us... We are Sri Lankans. We are very happy to say that we are Sri Lankans." I argue that this is because, for her, the meaning of a dual citizen is some what lesser than a full citizen. Even though Niru did not show any sense of gratitude (loyalty), I suggest that she had a thin patriotism towards her Sri Lankan citizenship shaped by her sense of belonging to the homeland (roots), and by the fact that she did not want to break her ties with Sri Lanka (exit). Niru's case thus suggests a complexity of patriotic feelings, since she had negative patriotic perceptions of loyalty, but she also held positive patriotic perceptions of roots.

Another example is Saranya, a Tamil citizen of New Zealand who claimed refugee status there. She fled Sri Lanka with her two children because of the civil war. She expressed strong dislike towards the majority Sinhalese people, including the Sri Lankan government, for not securing Sri Lankan Tamil citizens' rights. She said during the civil war, Sinhalese people "accused ... Tamils" without evidence. These 
experiences created negative perceptions for Saranya about about her (specifically Sinhalese) co-members of home society. In our interview, she commented that Sinhalese people are intolerant - not only of the minority Tamil people, but even tolerate of the opposing views of other Sinhalese people. Referring to how Sinhalese politicians from different parties fight with each other because of their greed for power, Saranya said "now see what is happening. Their own thing [power], they [Sinhalese] are fighting [for]. Who is suffering?"

This suggests that Saranya has negative feelings of gratitude and allegiance (loyalty) towards the political community of her home country. Nonetheless, she holds a strong sense of belonging towards the land of Sri Lanka, her "motherland." “[Sri Lanka] is our motherland. you can't forget your mother, mother language, people, everything." The use of the term motherland is an expression of intense patriotism towards the home country. In South Asian culture, the mother is of the utmost importance, and children are always obliged to respect their mother.

For this reason, I suggest that Saranya has simultaneously thick patriotic perceptions shaped by a sense of belonging (roots) and negative patriotic perceptions shaped by gratitude (or lack thereof) (loyalty). Saranya's opposing views about Sinhalese people (negative perceptions) and the land (positive perceptions) also show the complexity of her perceptions about being a home country citizen. She has been able to hold contradictory feelings about these two aspects of the same society - continuing her positive patriotic attachment to the land of the home country while simultaneously continuing to dislike a group of comembers (the Sinhalese people).

Saranya's case also challenges the Sri Lankan popular anti-diaspora rhetoric which claims refugees who left Sri Lanka (specifically Tamil refugees) do not love Sri Lanka, and attempt to damage the image of Sri Lanka in their host countries or on the international platform because of this (George, 2011; Orjuela, 2008). However, Saranya's example shows that refugees' attachments with the home country are more complex than that. 
Finally, this case describes the complexity of belonging, since people develop this feeling based on different factors that are at times contradictory. Thus, it is important to understand one's sense of belonging to a society subjectively. For example, many Western democratic countries assume that when a refugee arrives in their country as a result of persecution or discrimination, those refugees have (or should) given up on every aspect of their home country. In the process of applying to be a refugee, the more a refugee can prove her disconnection with the home country, the more likely is the success of the application. In reality, however, a refugee's sense of belonging to the different aspects of their home countries (such as the society or the land) is more complex.

In sum, Tamil participants' patriotic perceptions towards their home country citizenship are more complicated than Sinhalese participants, since the former hold positive and negative patriotic perceptions towards their Sri Lankan citizenship simultaneously. Sinhalese participants' patriotic perceptions were thick and shaped by the aspects of Ronkainen's (2011) typology: voice, roots, and loyalty. They did not expect to exit. The majority of Tamil participants' patriotic perceptions, however, were thin; only being shaped by roots.

\subsection{Conclusion}

This chapter discussed the value and meanings my participants gave for their Sri Lankan citizenship. Since I discussed participants' negative thoughts about the materialistic value of Sri Lankan citizenship in Chapter Five, in this chapter, I focused on their reasons for obtaining (or not) dual citizenship. The study found that a majority of participants hold negative instrumental perceptions (for different social, economic, and political reasons) and positive patriotic perceptions (either thick or thin) simultaneously about home country citizenship. Positive patriotic perceptions were thick for Sinhalese participants and thin for Tamil participants. I consider Sinhalese participants' perceptions thick because they contained two or more Ronkainen's (2011) typology aspects, specifically: voice, roots, and loyalty. 
They did not include exit. I consider Tamil participants' perceptions as thin because they only contained one aspect of Ronkainen's (2011) typology: roots. Tamil participants patriotic perceptions were found to be more complicated than those of Sinhalese.

In addition to these findings, this chapter shows that there is a different pattern to the way participants view their Sri Lankan, versus their Australian or New Zealand citizenship. As suggested in Chapter Six, participants only had emotional affiliation, in the form of loyalty and a sense of belonging, to their Australian or New Zealand citizenship once they felt satisfied about achieving their migratory objectives, which were predominantly socio-economic or political. Therefore, I argued participants' patriotic value for the host country citizenship to be closely inter-twinned with their instrumental value. However, in evaluating the meaning of Sri Lankan citizenship, the findings show that participants' can hold contrasting instrumental and patriotic perceptions simultaneously. Therefore, I argue that participants' instrumental and patriotic perceptions of Sri Lankan citizenship are mutually exclusive from each other.

In the next chapter, I tie together all the arguments I made in Chapters Five, Six and Seven, and present my conclusion.

\section{CHAPTER 8: Conclusion}

8.1 Introduction 
This thesis explored Sri Lankan immigrants' perceptions of their adoptive country (Australia or New Zealand) and home country (Sri Lanka) citizenship. It also explored the factors that have affected those citizenship perceptions. The widely accepted dichotomy of citizenship perceptions, instrumental vs patriotism, and the interpretations given by Betts and Birrell (2007) and Fozdar and Spittles (2010), was deployed, while also testing Fozdar's and Spittles's argument about the interconnected nature of the two notions.

Through interviews with forty-nine Sri Lankan immigrants in Australia and New Zealand, this study found that participants view the material, political, and travel (or "instrumental") benefits associated with their citizenship in their host and home countries differently. They saw citizenship in Australia or New Zealand as providing them with significant instrumental benefits, while the instrumental benefits accruing from Sri Lankan citizenship were considered to be limited. Patriotic perceptions of host and home country citizenship are also significantly different from each other. This is because those perceptions are affected by a range of different factors. Patriotic perceptions of host country citizenship are largely affected by people's sense of gratitude for the instrumental opportunities they received there, among many other factors. In contrast, their patriotic perceptions of home country citizenship are primarily affected by their sense of belonging to the home society, among other socio-economic and political factors.

This conclusion ties the main arguments made in previous chapters, together. It also situates the key arguments of this study in the broader academic and policy debates of migration and citizenship scholarship. I present my key arguments in three main sections. The first section lays out the strengths and weaknesses of the reversibility hypothesis used to explain immigrants' instrumental and patriotic perceptions of host country citizenship. The second and third sections present the crux of this study: participants' patriotic perceptions of host and home country citizenship, an area that has not been adequately studied, but has had crucialinput to migration and citizenship policy-making. I argue that participants' different positioning of themselves in respect to each citizenship, i.e. as immigrants in their host country and native citizens in their home country, has resulted in different patriotic 
perceptions towards host and home country citizenship. I conclude the chapter by reemphasizing my finding's theoretical contribution, and relevance for policymaking, and by suggesting potential avenues for further research.

8.2 The limitations of the reversibility hypothesis

As explained in Chapter Three, the reversibility hypothesis of Portes and Rumbaut (2006) is a prominent argument that explains immigrants' perceptions of host country citizenship. This hypothesis suggests a reversible effect between immigrants' perceptions about home and host country citizenship. It asserts that if the economic, political, social, and cultural conditions of the home country are less favourable than those in the host country, immigrants would have positive thoughts towards their host country. This increases their probability of seeking citizenship in their host country citizenship.

This study's findings on participants' instrumental perceptions about the home and host country citizenship, as discussed in Chapters Five and Seven, strongly supports the reversibility hypothesis. I found that all my participants carried negative instrumental perceptions of their home country citizenship, while carrying positive instrumental perceptions of their host country citizenship. However, in the specific case of Sri Lankan immigrants, the way the socio-economic and political factors affect participants' instrumental perceptions is more nuanced, exhibiting ethnic diversity. This study found that Sinhalese participants' positive instrumental perceptions about host country citizenship were largely shaped by their negative instrumental perceptions of socio-economicfactors in Sri Lanka. Meanwhile, Tamil participants' positive instrumental perceptions about host country citizenship are due to their negative instrumental perceptions of the political factors in their home country. This is because, as explained in Chapter Two, Sinhalese and Tamil immigrants had different migratory push factors motivating their move from Sri Lanka to another country. For many Sinhalese participants, the decision to emigration from Sri Lanka were mostly related to socio-economic reasons, while 
for many of my Tamil participants, the decision was mostly related to their experiences of ethnic discrimination and civil war.

Thus, even though both Sinhalese and Tamil immigrants displayed positive instrumental perceptions about host country citizenship, this study found that those perceptions were influenced by different factors from the home country. These findings highlight the importance of understanding immigrants as a heterogeneous community (Glover et al., 2001). Due to many practical limitations, smaller immigrant communities, such as Sri Lankans, are not given adequate attention in migration-related academic or policy studies. As a result, such communities are often assumed to corroborate the findings of studies on other, larger, immigrant communities. However, Doorn, Scheepers and Dagevos (2013) found that smaller immigrant communities' experiences are different to larger communities. This study strongly supports this finding, and demonstrates that smaller immigrant communities, such as the Sri Lankan immigrants in Australia and New Zealand studied here, have unique and contextual realities that could not be explained by knowledge of other immigrant communities. Furthermore, this study found that even though Sri Lankan immigrants come from the same sending country, they are not homogenous in their perceptions or decision-making patterns. Their ethnicitybased experiences have led them to have different perceptions about host and home country citizenship. I therefore stress the importance of understanding smaller immigrant groups, such as Sri Lankan immigrants, contextually.

Returning to the discussion on the validity of the reversibility hypothesis, it helps us understand how immigrants' instrumental perceptions about host country citizenship are influenced and shaped by their instrumental perceptions about home country citizenship. Nonetheless, the reversibility hypothesis does not adequately explain immigrants' patriotic perceptions about host country citizenship.

Immigrants' patriotic perceptions (as will be discussed further in the next two sections) are more multifaceted and complex to study and measure than their instrumental perceptions. Patriotic perceptions are significantly under-studied in 
academia and policy reports. This study found immigrants' patriotic perceptions towards the host and home country citizenship to be different from each other and affected by different factors, such as their level of gratitude and sense of belonging. Patriotic perceptions towards home country citizenship does not show a potential reversibility effect towards host country citizenship; thus, it cannot be explained through the reversibility hypothesis. This inability to explain patriotic perceptions stands as one of the main drawbacks of the reversibility hypothesis. Therefore, I assert that the reversibility hypothesis is not a plausible explanation for understanding the entirety of immigrants' perceptions of host country citizenship. Rather, it can only explain their instrumental perceptions.

8.3 Participants' instrumental perceptions towards the host country citizenship have a causal effect on their patriotic perceptions

As discussed in Chapter Six, my research findings show that there is a close relationship between participants' instrumental and patriotic perceptions towards their host country citizenship: this study found that participants' patriotic perceptions depended on their instrumental perceptions. Instrumental perceptions often developed quickly, and before their patriotic perceptions, which grew gradually.

As I explained in Chapter Five, participants developed thin patriotism towards the host country citizenship first and then eventually, it transformed into thick patriotism. This transition from thin to thick, only occurred with the right conditions, such as living in the host society for a long period and experiencing a positive reception from the host society. Participants' instrumental perceptions played a critical role, firstly in the generation of their thin patriotism and latterly in the development of their thick patriotism. As per my findings, participants who had positive instrumental opinions about citizenship of the host country eventually begin to view the citizenship patriotically positively too. I therefore argue that there 
is a causal relationship between participants' instrumental and patriotic perceptions towards host country citizenship.

If participants were satisfied with the instrumental benefits and rights they received in the host country (hence having positive instrumental perceptions), they began to feel a sense of gratitude. This was their first sign of patriotism towards the host country. Amongst the four categories Ronkainen (2011) introduced (voice, roots, loyalty and exit) to measure immigrants' thin or thick attachment to the citizenship, this sense of gratitude fits in only one category, loyalty. In this first step of improving patriotic perceptions, participants did not show much interest in the other categories of Ronkainen's thin-thick measurement, such as having voice (i.e. political participation) or viewing any roots anchoring them (i.e. a sense of belonging) in the host country. Instead, some participants showed their need to exit from the host country (returning to their home country); another category of Ronkainen's typology. Since participants' patriotism related to being a host country citizen at this stage only contained loyalty (in the form of gratitude), I argue that immigrants' first stage of patriotic perceptions often starts with thin-patriotism.

As I explained in Chapter Five, this thin patriotism, however, turns into thick patriotism if immigrants live in the host country for a long period, experience a positive reception, and continue to receive satisfactory levels of instrumental rights, benefits, and opportunities to integrate into the host society. If immigrants experienced these conditions, they eventually started developing a feeling of belonging (roots) to the host society. Some participants who lived in the host country for more than 10 years reported that, depending on their sense of gratitude (loyalty), and their sense of belonging (roots), they also developed a desire to participate politically (voice) in the host society. The patriotic perceptions of such participants were transformed from their initially thin perceptions into thick patriotic perceptions.

Therefore, this study supports Bloemraad's (2006) findings regarding the importance of public funding and programmatic support for immigrants' integration into a host society, although for a different reason. As mentioned in Chapter Four, 
Bloemraad found that institutional arrangements related to immigrant integration in the country of settlement are an influential factor, which can increase immigrants' propensity to naturalise. No participant in this case study expressed concern with their level of integration to the host society at the time of naturalisation. As discussed in Chapter Five, the majority of my participants obtained Australian or New Zealand citizenship for instrumental reasons. Even though public funding and programmatic support for integration did not influence my participants' naturalisation decisions, it certainly helped them develop positive patriotic perceptions towards host country citizenship, transforming them from thin to thick.

In comparing Australia with New Zealand, this study found that even though participants went through the same journey in developing their patriotic perceptions in both countries, they differed in speed. I argue that this is because of the different reception people experienced in Australia and New Zealand. Participants from Australia had more negative perceptions about the institutional and societal reception they received than the participants from New Zealand did. The majority of participants from Australia said that the high level of racism in Australian society prevented them from feeling a full sense of belonging, i.e. it acted as a barrier to transitioning from thin to thick patriotism. In comparison, only a few participants from New Zealand reported that they experienced racism. They also had positive perceptions related to being granted access to more rights in New Zealand from the beginning of their migratory journey (for example, voting rights). These factors led to their thin patriotism transforming into thick-patriotism faster than that of participants from Australia. Thus, I argue that the institutional and societal reception immigrants receive is a crucial factor that affects the development of their patriotic perceptions towards that host country's citizenship.

This study also argues that understanding polarizing instrumental and patriotic perceptions as dialectically opposing views is misleading. As I explain further in the next section, as native citizens, participants separated their instrumental and patriotic perceptions of home country citizenship. However, as immigrants, they could not do the same for host country citizenship. My interviews also showed that the factors affecting my participants' host country citizenship perceptions are more 
complicated than the factors affecting those of their home country. This study highlights the importance of understanding instrumental and patriotic relationships to host country citizenship from an immigrant's point of view, rather than a native citizen's view.

As highlighted in this study, instrumental and patriotic perceptions are intertwined and inseperable for immigrants. This finding is important because it helps us avoid interpreting intrumental perceptions as merely "selfish" (Foner, 2001, p.29) while identifying patriotic perceptions as merely selfless (Betts, 2002). For example, according to Betts (2002), persons who view citizenship instrumentally do not have compassionate feelings for others in the society. Betts argued that they imagine the state without nation, and as a service station. In addition, she claimed that citizens with patriotic aspirations are the only people who will contribute to the collective identity, and to the common good, in a society. These arguments are demonstrated in her use of the terms "peoplehood" and "communitarianism" interchangeably to refer to patriotism (Betts, 2002, p.57). Foner (2001) too interpreted "instrumentalism" as "selfish" (p.29). She suggested that many immigrants only need to secure government benefits (and this need, according to her, is selfish) but do not pledge true allegiance to their host country. Unlike Betts' and Foner's arguments, this study found that in the formation and development of immigrants' patriotism towards host country citizenship, instrumental perceptions play a causal role. Hence, this study supports Fozdar's and Spittles' (2010) hypothesis on the intertwining of instrumental and patriotic perceptions. As I detail in the next section, citizenship in the context of migration has its own characteristics that need to be understood.

8.4 Participants' instrumental and patriotic views towards home country citizenship are separable

As discussed in Chapters Five and Seven, participants generally held negative instrumental perceptions about their home country citizenship, which is to say, they 
did not think there were a lot of material benefits to be gained from Sri Lankan citizenship. This is demonstrated by two key findings: 1) many participants emigrated from Sri Lanka because they were not satisfied with the poor social, economic, and political benefits they received as Sri Lankan citizens; 2) the majority of participants did not obtain dual citizenship because they had interests such as running a business or buying a property in the home country. Instead, many participants obtained dual citizenship as a symbol of their sense of belonging, and an expression of their loyalty towards their home country.

As explained in the second section of this chapter, participants' instrumental and patriotic perceptions about host country citizenship were inseparable from each other. In fact, there was a causal relationship between them. In contrast, this study found that participants simultaneously hold negative instrumental perceptions and positive patriotic perceptions towards their home country citizenship. This pattern of holding opposing instrumental (negative) and patriotic (positive) perceptions simultaneously makes participants' home country citizenship perceptions different from those of their host country.

Thus, this study suggests that there are different patterns in the development of patriotic perceptions towards host and home country citizenship. Participants' patriotic perceptions towards home country citizenship seemed to be governed more by roots than loyalty. Feeling of belonging to the national collective, and honouring their family and cultural backgrounds, took a primary place in these patriotic perceptions. Irrespective of the rights and benefits they received from the state, participants could belong to their home country as citizens because of their roots. I therefore argue that participants' patriotism towards Sri Lanka mainly grew from roots. Patriotic perceptions towards host country citizenship, however, as explained in Chapter Six, were primarily driven by loyalty. Participants developed loyalty because of their gratitude for the rights and benefits they are offered by the state. It is from that loyalty, that participants then developed other forms of patriotism such as roots. 
Returning to the discussion about participants' patriotic perceptions towards the home country citizenship, Tamil participants from former refugee backgrounds displayed an interesting pattern in their patriotism. As discussed in Chapter Seven, many of those participants had negative perceptions about the majority Sinhalese people in the home society, and about the Sri Lankan government, which is dominated by Sinhalese. As a result, Tamil participants did not have much loyalty to the home country. Nonetheless, despite the disruptive memories and experiences they had back home, many of them displayed some level of patriotism towards Sri Lanka, based on roots. They demonstrated a sense of belonging towards their families, their ethnic group, and the culture of the home country. Therefore, I argue that former refugees' perceptions about home country citizenship, and their sense of belonging to the home society, are more complex than others. They showed the ability to simultaneously hold negative (i.e., loyalty), and positive (i.e., roots), patriotic perceptions.

Understanding the complexity of refugees' patriotic perceptions towards their host and home country citizenship is critically important for policy making in both host and home countries. In making their refugee policies, many Western democratic countries expect refugees to prove their divorce from the home country in order to receive refugee status. This might be because host countries assume that refugees cut off their relationships with, and sense of belonging to, the home country entirely because they suffered persecution and discrimination there. However, this study shows that if that refugee is a first-generation immigrant, there is also the tendency that she would hold some level of emotional attachment, i.e., a sense of belonging to their families, ethnic groups, and/or culture (roots), of the home coutry. Therefore she might find it difficult to emotionally separate from the home country. In this case, host countries' refugee policy would put additional pressure on the refugee immigrant to prove something that does not actually exist.

In addition to its importance for host countries, understanding the complexity of refugees' perceptions towards home country citizenship is critically important for policy making there. Many countries that have produced a large number of refugee 
emigrants have skeptical approaches towards them. For example, many people in Sri Lanka believe that those who left as refugeesdo not carry any sense of belonging to the country. It is widely believed that all Tamil emigrants with former refugee backgrounds, who have now settled in Western democratic countries, intend to sabotage the image of Sri Lanka in the international space, simply because they all hate their home country. However, this study finds that, even though Tamil former refugees do have negative perceptions towards certain aspects of their home country, they also carry positive connections with certain aspects, such as their shared culture, the memories they made with family and friends, and the land they grew up on. Hence, I argue that the assumption that all Tamil former refugee firstgeneration emigrants have no sense of belonging or af filiation to Sri Lanka is highly over-simpified.

These findings also suggest an alternative explanation for the growing antiimmigrant rhetoric of many Western democratic host countries. The anti-immigrant sentiment generally comes from one reference point (native citizens) towards another referent point (immigrants). If native citizens in the host countries perceived their home country citizenship similar to the way my participants' do, they would be able to view the instrumental and patriotic aspects of citizenship separately. However, immigrants viewed the instrumental and patriotic aspects of host country citizenship conjointly. Since native citizens can separate their instrumental and patriotic perceptions, they would tend to think that the true spirit of becoming a citizen lies only in one's thick patriotism towards a political society. Consequently, they would consider that becoming a citizen for economic reasons (or more broadly, instrumental reasons) is a selfish act (Betts \& Birrell, 2007; Burns \& Gimpel, 2000; Foner, 2001). In contrast, immigrants would not view their instrumental interests as selfish motives. Instead, when immigrants hold more positive instrumental perceptions, the tendency for them to develop patriotic perceptions would be much higher. Thus, one can claim that the core of antiimmigrant rhetoric is this tension between incompatible and contrasting citizenship perceptions by native citizens and immigrants. 
However, further research is needed to verify this argument (that is native citizens' and immigrants' citizenship perceptions differ from each other). It should be noted that I make this argument on the premise that native citizens in the host countries perceive their home country citizenship in similar ways to the way my participants perceived their Sri Lankan citizenship. Nonetheless, given the socio-economic, political, cultural, and historical differences of countries, native citizens in different countries might perceive their own home country citizenship differently.

Not only the anti-immigrant rhetoric, but also naturalisation policies of many countries are designed based on the view of a native citizen. I argue that the need to prove an immigrant's patriotism in order to naturalise in a host society is entirely based on native-citizens' assumptions about citizenship. For example, in host countries such as Australia, immigrants are required to prove their loyalty or level of integration into the Australian society by successfully passing a citizen ship test, before they can naturalise. However, as explained in the second section of this chapter, immigrants cannot generate thin or thick patriotism overnight. This process takes time and is affected by many other factors. Given this, the effectiveness of such tests in measuring immigrants' loyalty and integration is highly problematic. I, therefore, suggest that understanding the differences between native citizens' and immigrants' perceptions of citizenship would improve naturalisation policymaking in host countries.

\subsection{Potential avanues for future research}

This study highlights the need to produce new knowledge about immigrants' citizenship perceptions. I suggest that discovering immigrants' thoughts and opinions about host and home country citizenship would assist policy makers in both locations to articulate more effective citizenship policies, such as naturalisation policies (in host countries) and dual citizenship policies (in home countries). As found in this study, immigrants' citizenship perceptions of both host and home countries are affected by numerous factors, and therefore, are subjective 
and contextual. Thus, to learn more about immigrants' citizenship perceptions, it is imperative to conduct more qualitative, micro-case research on immigrant communities.

As discussed earlier in this chapter, comparing immigrants' and native citizens' citizenship perceptions is a significant area that needs further exploration. This study suggested that there could be differences in the way immigrants and native citizens view citizenship in that country. By using qualitative methods, future research would be able to further this, by identifying more nuanced realities about specific cases in relation to citizenship of both home and host countries, as viewed by immingrants and native citizens. Such research may also find alternative explanations about the anti-immigrant rhetoric existing in many host countries.

Finally, this study highlights the need to explore different Sri Lankan immigrants' citizenship perceptions further. I suggest that exploring Sri Lankan Tamil immigrants' ways of imagining and understanding citizenship will help us to understand the nature of their relationship with Sri Lanka. Sri Lanka has a contentious relationship with Tamil former refugee emigrants, specifically in relation to the perception that these emigrants lobby international bodiesto pressure Sri Lanka over war crimes allegations (Orjuela, 2008). Meanwhile, Tamil emigrants - both former ref ugees and non-refugees - keep sending larger amounts of financial aid back for the development of northern Sri Lanka (Erdal, 2006; Sriskandarajah, 2002; Wayland, 2004). These dual behaviours of Tamil emigrants would be better understood by a deeper understanding of their opinions of what being (or not) Sri Lankan citizens legally and/or emotionally means to them. Such knowledge will allow us to generalise the findings to other cases, i.e., to theoretically identify salient features of similar contentious relations between refugee emigrants and their home countries. In the specific case of Sri Lanka, I conclude that knowing emigrants' citizenship perceptions will also assist policy-makers in Sri Lanka to craft more effective diaspora engagement policies, and ease the tension between the home government and former refugee (Tamil) emigrants. 


\section{References}

Adamson, F. B. (2019). Sending states and the making of intra-diasporic politics: Turkey and its Diaspora(s). International Migration Review, 53(1), 210-236. https://doi.org/10.1177/0197918318767665

Affleck, W., Thamotharampillai, U., Jeyakumar, J., \& Whitley, R. (2018). "If One Does Not Fulfil His Duties, He Must Not Be a Man”: Masculinity, Mental Health and Resilience Amongst Sri Lankan Tamil Refugee Men in Canada. Culture, Medicine, and Psychiatry, 42(4), 840-861. https://doi.org/10.1007/s11013-018-9592-9

Ager, A., \& Strang, A. (2008). Understanding integration: A conceptual framework. Journal of Refugee Studies, 21(2), 166-191. https://doi.org/10.1093/jrs/fen016

Altan-olcay, Ö., \& Balta, E. (2016). Class and Passports: Transnational Strategies of Distinction in Turkey. Sociology, 50(6), 1106-1122. https://doi.org/10.1177/0038038515591944

Amit, V. (2014). Inherited multiple citizenships: Opportunities, happenstances and improvisations among mobile young adults. Social Anthropology, 22(4), 396-409.

Anderson, B. (1991). Imagined communities: Reflections of the origins and spread of nationalism. London: Verso.

Anderson, G. M. (1974). Networks of contact: the Portuguese and Toronto. Waterloo, Ontario: Wilfrid Laurier University Press. Retrieved from https://ebookcentral.proquest.com/lib/vuw/reader.action?docID=3050220

Arkilic, Z. A. (2016). Between the homeland and host states: Turkey's diaspora policies and immigrant political participation in France and Germany. University of Texas, Austin.

Arunatilake, N., Jayasuriya, S., \& Kelegama, S. (2001). The economic cost of the 
war in Sri Lanka. World Development, 29(9), 1483-1500.

https://doi.org/10.1016/S0305-750X(01)00056-0

Arvizu, J. R., \& Garcia, F. C. (1996). Latino voting participation: explaining and differentiating Latino voting turnout. Hispanic Journal of Behavioral Sciences, 18(2), 104-128.

Athukorala, P., \& Jayasuriya, S. (2000). Trade policy reforms and industrial adjustment in Sri Lanka. The World Economy, 10(2), 387-404. https://doi.org/10.1111/1467-9701.00278

Atkinson, P., \& Silverman, D. (1997). Kundera's immortality: The interview society and the invention of the self. Qualitative Inquiry, 3(3), 304-325. https://doi.org/10.1177/107780049700300304

Australian Bureau of Statistics. (2016). 2016 Census Quickstats Country of Birth. Retrieved April 30, 2020, from https://quickstats.censusdata.abs.gov.au/census_services/getproduct/census/2 016/quickstat/7107_036

Australian Citizenship Act 2007 (2007). Canberra.

Australian Electoral Commission. (2019). Enrol to vote. Retrieved August 20, 2019, from https://www.aec.gov.au/enrol/

Australian Federal Police. (2019). Careers. Retrieved August 20, 2019, from https://www.afp.gov.au/careers

Australian Government. Public service act 1999 (1999). Attorney-General's Department, Canberra. Retrieved from https://www.legislation.gov.au/Details/C2009C00324

Australian Government. (2018a). Commonwealth and HECS-HELP. Australian Government Publishing Service. Retrieved from https://www.studyassist.gov.au/sites/studyassist/files/ed18-0137_hecshelp_booklet_acc.pdf

Australian Government. (2018b). Consular services charter. Retrieved August 20, 
2019, from https://smartraveller.gov.au/services/Pages/consular-servicescharter.aspx

Australian Government. (2018c). Fact Sheet - Abolition of the "White Australia" Policy. Retrieved June 27, 2018, from https://www.homeaffairs.gov.au/about/corporate/information/factsheets/08abolition

Australian Government. (2019a). Citizenship. Retrieved August 20, 2019, from https://www.defencejobs.gov.au/joining/can-i-join/citizenship

Australian Government. (2019b). Permanent resident. Retrieved August 20,2019, from https://immi.homeaffairs.gov.au/visas/permanent-resident/overseastravel

Avc1, G. (2006). Comparing integration policies and outcomes: Turks in the Netherlands and Germany. Turkish Studies, 7(1), 67-84. https://doi.org/10.1080/14683840500520592

Back, L., Keith, M., Khan, A., \& Shukra, K. (2002). New Labour's White Heart: Politics , Multiculturalism and the Return of Assimilation. The Political Quarterly, 73(4), 445-454. https://doi.org/10.5153/sro.719

Balistreri, K. S., \& Van Hook, J. Van. (2004). The more things change the more they stay the same: Mexican naturalization before and after welfare reform. International Migration Review, 38(1), 113-130.

Ballard, R. (2001). The impact of kinship on the economic dynamics of transnational networks: reflections on some South Asian developments (Transnational Communities Program).

Bandarage, A. (2008). The separatist conflict in Sri Lanka: Terrorism, ethnicity, political economy. Routledge.

Barker, F., \& McMillan, K. (2016). Access to electoral rights: New Zealand. Retrieved from http://cadmus.eui.eu/bitstream/handle/1814/42884/EUDO_CIT_ER_2016_05 
.pdf? sequence $=1 \&$ isAllowed $=\mathrm{y}$

Barker, F., \& McMillan, K. (2017). Factors influencing the electoral participation of Asian immigrants in New Zealand. Political Science, 69(2), 139-160. https://doi.org/10.1080/00323187.2017.1348236

Bartley, A., \& Spoonley, P. (2008). Intergenerational transnationalism: Asian migrants in New Zealand. International Migration, 46(4), 63-84.

Basch, L., Schiller, N. G., \& Blanc, C. S. (1994). Nations unbound: Transnational projects, postcolonial predicaments and deterritorialized nation-states. Gordon and Breach Science Publishers.

Baser, B. (2014). The awakening of a latent diaspora: The political mobilization of first and second generation Turkish migrants in Sweden. Ethnopolitics, 13(4), 355-376. https://doi.org/10.1080/17449057.2014.894175

Bauböck, R. (1994). Transnational citizenship: Membership and rights in international migration. Hants: Edward Elgar Publishing Limited.

Bauböck, Rainer. (2005). Expansive citizenship: Voting beyond territory and membership. PS: Political Science and Politics, 38(4), 683-687. https://doi.org/10.2307/30044350

Bedford, R. (2002). Contested Ground: The Politicisation of Immigration and Belonging. New Zealand Journal of Geography, 11(1), 8-16. https://doi.org/10.1111/j.0028-8292.2002.tb00833.x

Bedford, R. (2006). Skilled Migration in and out of New Zealand: Immigrants, Workers, Students, and Emigrants. In L. Hawthorne, B. Bireell, \& S. Richardson (Eds.), Evaluation of the General Skilled Migration Categories (pp. 224-251). Canberra: Commonwealth of Australia.

Beiser, M., Goodwill, A. M., Albanese, P., \& Mcshane, K. (2015). Predictors of the integration of Sri Lankan Tamil refugees in Canada: Pre-migration adversit, mental health, personal attributes and post-migration experience. International Journal of Migration, Health and Social Care, 11(1), 29-44. 
https://doi.org/10.1108/IJMHSC-02-2014-0008

Bellamy, R. (2008). Citizenship: A very short essay. New York: Oxford University Press.

Bennett, W. L. (1981). Perception and cognition. In The handbook of political behavior (pp. 69-193). Boston: Springer.

Bennour, S. (2020). Intention to become a citizen: Do subnational integration policies have an influence? Empirical evidence from Swiss cantons. Regional Studies, 1-11. https://doi.org/10.1080/00343404.2019.1699237

Bernard, H. R. (2006). Research methods in anthropology: Qualitative and quantitative approaches (4th ed.). Oxford: AltaMira Press. Retrieved from http://www.dphu.org/uploads/attachements/books/books_476_0.pdf

Bernard, W. S. (1936). Cultural determinants of naturalization. American Sociological Review, 1(6), 943-953. Retrieved from http://www.jstor.org/stable/2084619

Betts, K. (2002). Democracy and dual citizenship. People and Place, 10(1), 5770. Retrieved from http://researchbank.swinburne.edu.au/vital/access/services/Download/swin:2 123/SOURCE1

Betts, K., \& Birrell, B. (2007). Making Australian citizenship mean more. People and Place, 15(1), 45-61. Retrieved from http://tapri.org.au/wpcontent/uploads/2016/02/v15n1_5bettsbirrell1.pdf\%5Cnhttp://search.informit .com.au/documentSummary; $\mathrm{dn}=334995911274209 ;$ res=IELHSS

Bhatia, S. (2008). 9/11 and the Indian diaspora: Narratives of race, place and immigrant identity. Journal of Intercultural Studies, 29(1), 21-39. https://doi.org/10.1080/07256860701759923

Bhattacharya, G. (2008). The Indian diaspora in transnational context: Social relations and cultural identities of immigrants to New York city. Journal of Intercultural Studies, 29(1), 65-80. 
https://doi.org/10.1080/07256860701759949

Bloemraad, I. (2000). Citizen ship and immigration: a current review.

International Migration and Integration, 1(1), 9-37.

https://doi.org/10.1007/s12134-000-1006-4

Bloemraad, I. (2002). The North American naturalization gap: an institutional approach to citizenship acquisition in the United States and Canada. International Migration Review, 36(1), 193-228. https://doi.org/0198$9183 / 02 / 3601.0137$

Bloemraad, I. (2004). Who claims dual citizenship? the limits of postnationalism, the possibilities of transnationalism, and the persistence of traditional citizenship. International Migration Review, 38(2), 389-426. https://doi.org/10.1111/j.1747-7379.2004.tb00203.x

Bloemraad, I. (2006a). Becoming a citizen: Incorporating immigrants and refugees in the United States and Canada. Berkeley: University of California Press.

Bloemraad, I. (2006b). Becoming a citizen in the United States and Canada: Structured mobilization and immigrant political incorporation. Social Forces, 85(2), 667-695. Retrieved from https://academic.oup.com/sf/articleabstract/85/2/667/2235091

Bloemraad, I., Korteweg, A., \& Yurdakul, G. (2008). Citizenship and Immigration: Multiculturalism, Assimilation, and Challenges to the NationState. Annual Review of Sociology, 34(1), 153-179. https://doi.org/10.1146/annurev.soc.34.040507.134608

Brown, B. E. (2014). From Guru Gama to Punchi Italia: changing dreams of Sri Lankan transnational youth. Contemporary South Asia, 22(4), 335-349. https://doi.org/10.1080/09584935.2014.963514

Brown, D. (1999). Are there good and bad nationalisms? Nations and Nationalism, 5(2), 281-302. https://doi.org/10.1111/j.13545078.1999.00281.x 
Brubaker, R. (1992). Citizenship and nationhood in France and Germany. Harvard University Press.

Brun, C., \& Van Hear, N. (2012). Between the local and the diasporic: The shifting centre of gravity in war-torn Sri Lanka's transnational politics. Contemporary South Asia, 20(1), 61-75.

Brysk, A., \& Shafir, G. (Eds.). (2004). People out of place: Globalization, human rights and the citizenship gap. Routledge.

Bueker, C. S. (2005). Political incorparation among immigrants from ten areas of origin: The persistence of source country effects. International Migration Review, 39(1), 103-140.

Burgio, G. (2016). When Interculturality faces a Diaspora. The Transnational Tamil Identity. Encyclopaideia, (44), 106-128.

https://doi.org/10.6092/issn.1825-8670/5992

Burns, P., \& Gimpel, J. G. (2000). Economic insecurity, prejudicial stereotypes, and public opinion on immigration policy. Political Science Quarterly, 115(2), 201-225. https://doi.org/10.2307/2657900

Butcher, A., Spoonley, P., \& Trlin, A. D. (2006). Being accepted: the experience of discrimination and social exclusion by immigrants and refugees in New Zealand. Occasional Publication 1 (Vol. 1). Palmerston North. Retrieved from http://newsettlers.massey.ac.nz/publications_pdfs/Butcher, Spoonley and Trlin OP No. 13.pdf

Carens, J. (1987). Aliens and citizens: The case for open borders. The Review of Politics, 49(2), 251-273.

Cassim, S. (2017). Oceans away: Sri Lankan migrants in New Zealand. The University of Waikato.

Cassim, S., Hodgetts, D., \& Stolte, O. (2015). Cultural consideration and mixed methods for psychological research: A Sri Lankan perspective. In Ethnographies in Pan Pacific research:tensions and positionings (pp. 111- 
121). Routledge.

Castles, S. (1997). Globalisation and the ambiguities of national citizen ships. In Stephen Castles \& P. Spoonley (Eds.), Migration and Citizenship. Albany: Massey University.

Castles, Stephen. (2004). The factors that make and unmake migration policies. International Migration Review, 38(3), 852-884.

Central Bank of Sri Lanka. (2018). Annual Report 2018. Retrieved from https://www.cbsl.gov.lk/sites/default/files/cbslweb_documents/publications/a nnual_report/2018/en/5_Chapter_01.pdf

Chamaz, K. (2014). Constructing grounded theory (2nd ed.). Sage.

Cheran, R. (2003). Diaspora circulation and transnationalism as agents for change in the post-conflict zones of Sri Lanka. Berghof Foundation for Conflict Management.

Cho, W. K. T. (1999). Naturalization, socialization, participation: Immigrants and (non-) voting. The Journal of Politics, 61(4), 1140-1155.

Clayton, A. (2016). A great Wall?: Migration, political socialisation and political participation among Chinese in New Zealand. Victoria University of Wellington.

Cohen, R. (1996). Diasporas and the Nation-State : From Victims to Challengers. International Affairs, 72(3), 507-520. Retrieved from http://www.jstor.org/stable/2625554

Cohen, R. (2008). Classical notions of diaspora: Transcending the Jewish tradition. In Global diasporas: An introduction (pp. 1-29). Taylor and Francis.

Collins, J. (2007). The landmark of Cronulla. In J. Jupp, J. Nieuwenhuysen, \& E. Dawson (Eds.), Social cohesion in Australia (pp. 61-69). New York: Cambridge University Press. 
Collyer, M., Wimalasena, P., Ansar, N., \& Ali Khan, M. (2009). Return migrants in Sri Lanka.

Conover, P. J., Crewe, I. M., \& Searing, D. D. (1991). The nature of citizenship in the United States and Great Britain: Empirical comments on theoretical themes. The Journal of Politics, 53(3), 800-832.

https://doi.org/10.2307/2131580

Constant, A. F., Gataullina, L., \& Zimmermann, K. F. (2009). Ethnosizing immigrants. Journal of Economic Behavior and Organization, 69, 274-287. https://doi.org/10.1016/j.jebo.2008.10.005

Conway, D. (2000). Notions unbounded: A critical (re)read of transnationalism suggests that US-Caribbean circuits tell the story better. In B. Agozino (Ed.), Theoretical and methodological issues in migration research: interdisciplinary, intergenerational and international perspectives (pp. 203226). Ashgate: Aldershot.

Conway, Dennis, Potter, R. B., \& St Bernard, G. (2008). Dual citizenship or dual identity? Does "transnationalism” supplant "nationalism” among returning Trinidadians? Global Networks, 8(4), 373-397. https://doi.org/10.1111/j.1471-0374.2008.00230.x

Crisp, J. (1999). Policy challenges of the new diasporas: Migrant networks and their impact on asylum flows and regimes. WPTC-99-05. Geneva.

Dalley, S., \& Bozovik, M. (2015). Criminal offending and deportation liability.

David, A. (2011, February 27). Strict new criteria for dual citizenship. Sunday Times. Retrieved from http://www.sundaytimes.lk/110227/News/nws_01.html

de Volo, L. B., \& Schatz, E. (2004). From the inside out: Ethnographic models in political research. PS: Political Science and Politics, 37(2), 267-271.

Dearnley, C. (2011). A reflection on the use of semi-structured interviews. Nurse Researcher., 14(2), 24-31. 
Department of Census and Statistics. (2012). Population and Houses Census, Sri Lanka: 2012.

Department of Home Affairs Australia. (2014). Australian Citizenship: Our common bond. Department of Home Affairs.

Department of Immigration and Emigration Sri Lanka. (2018). Dual citizenship. Retrieved October 20, 2018, from http://www.immigration.gov.lk/web/index.php?option=com_content\&view= article $\& \mathrm{id}=299 \&$ Itemid $=59 \&$ lang=en

Department of Immigration and Emigration Sri Lanka. (2019). Implementing free visa scheme for designated countries. Retrieved October 23, 2019, from http://www.immigration.gov.lk/web/index.php?option=com_content\&view= article \&id=332\%3Aimplementing-the-free-visa-scheme-for-selectedcountries $\&$ catid $=48 \% 3$ Aentry - visa $\&$ lang $=$ en

Department of Internal Affairs New Zealand. (2014). Choice: The New Zealand citizenship story. Wellington.

DeVotta, N. (2007). Sinhalese Buddhist nationalist ideology: Implications for politics and conflict resolution in Sri Lanka. Policy Studies, 40, 1-64.

Dias, M., \& Jayasundere, R. (2002). Sri Lanka: Good practices to prevent women workers from going into exploitative forms of labour (GENPROM Working Paper No. 9). Geneva.

Dias, M., \& Jayasundere, R. (2004). Sri Lanka: The anxieties and opportunities of out-migration. In P.-S. Ahn (Ed.), Migrant workers and human rights: Outmigration from South Asia (pp. 153-192). International Labour Organization.

Doorn, M. Van, Scheepers, P., \& Dagevos, J. (2013). Explaining the integration paradox among small immigrant groups in the Netherlands, 14(2), 381-400. https://doi.org/10.1007/s12134-012-0244-6

Dunand, J. (2004). From traitors to heroes: 100 years of Mexican migration policies. Migration Policy Institute. 
Earnest, D. C. (2003). Voting rights for resident aliens: a comparison of 25 democracies. In Annual meeting of the Northeast Political Science Association. International Studies Association - Northeast.

Economou, N. (2007). Measuring social cohesion in a diverse society. In J. Jupp, J. Nieuwenhuysen, \& E. Dawson (Eds.), Social cohesion in Australia (pp. 33-44). New York: Cambridge University Press.

Erdal, M. B. (2006). Contributing to development? Transnational activities among members of the Tamil diaspora in Norway. University of Oslo.

Ersanilli, E., \& Koopmans, R. (2010). Rewarding integration? Citizenship regulations and the socio-cultural integration of immigrants in the Netherlands, France and Germany. Journal of Ethnic and Migration Studies, 36(5), 773-791. https://doi.org/10.1080/13691831003764318

Escobar, C. (2006). Dual citizenship and political participation: Migrants in the interplay of United States and Colombian politics. In S. Oboler (Ed.), Latinos and citizenship: the dilemma of belonging. New York: Palgrave Macmillan.

Evans, M. R. R. (1988). Choosing to be a citizen: The time-path of citizenship in Australia. International Migration Review, 22(2), 243-264.

Faist, T. (2000). The volume and dynamics of international migration and transnational social spaces. Oxford: Oxford University Press.

Faist, T. (2007). The fixed and porous boundaries of dual citizenship. In T. Faist (Ed.), Dual citizenship in Europe: From nationhood to societal integration (pp. 1-27). Aldershot: Ashgate.

Faist, T. (2010). Diapora and transnationalism: What kind of dance partners? In Rainer Bauböck \& T. Faist (Eds.), Diaspora and Transnationalism (pp. 934). Amsterdam University Press. Retrieved from http://www.jstor.org/stable/j.ctt46mz31.4

Faist, T., Gerdes, J., \& Rieple, B. (2004). Dual citizenship as a path-dependent process. International Migration Review, 38(3), 913-944. 
https://doi.org/10.2307/27645421

Farrag, M. (1997). Managing international migration in developing countries. International Migration, 35(315-336).

Faulks, K. (2000). Citizenship. London: Routledge.

Ferraris, M., \& Davies, R. (2013). Documentality: Why it is necessary to leave traces. New York: Fordham University Press.

Fleras, A., \& Spoonley, P. (1999). Recalling Aotearoa. New York: Oxford University Press.

Flores, J. (2005). The diaspora strikes back: Reflections on cultural remittances. NACLA Report on the Americas, 39(3), 21-26. https://doi.org/10.1080/10714839.2005.11725320

Foner, N. (2001). Immigrant commitment to America, then and now: myths and realities. Citizenship Studies, 5(1), 27-40. https://doi.org/10.1080/13621020020025178

Fontana, A., \& Frey, J. H. (2005). The interview: From a neutral stance to political involvement. In N. K. Denzin \& Y. S. Lincoln (Eds.), The SAGE handbook of qualitative research (pp. 695-728). London: Sage.

Forrest, J., \& Dunn, K. (2006). 'Core' culture hegemony and multiculturalism. Ethnicities, 6(2), 203-230.https://doi.org/10.1177/1468796806063753

Forsyth, I. (2013). Immigration: I feel like I dont belong. Retrieved May 31, 2018, from http://www.stuff.co.nz/stuff-nation/assignments/welcome-to-newzealand/8824976/Immigration-I-feel-like-I-don-t-belong

Fozdar, F. (2013). Belonging in the nation-state: civic and ethno-belonging among recent refugees to Australia (No.13-12). Retrieved from http://www.mmg.mpg.de/fileadmin/user_upload/documents/wp/WP_1212_Annotated-

Bibliography_MEDDIV.pdf\%5Cnhttp://fabriziogilardi.org/resources/papers/ Gilardi-4-Theses-Diffusion.pdf 
Fozdar, F., \& Spittles, B. (2009). The Australian citizenship test: Process and rhetoric. Australian Journal of Politics and History, 55(4), 496-512. https://doi.org/10.1111/j.1467-8497.2009.01529.x

Fozdar, F., \& Spittles, B. (2010). Patriotic vs. proceduralist citizenship: Australian representations. Nations and Nationalism, 16(1), 127-147. https://doi.org/10.1111/j.1469-8129.2010.00396.x

Galligan, B. (2017). Australian citizenship in a changing nation and world. In Citizenship in transnational perspective: Australia, Canada and New Zealand (pp. 79-96). Palgrave Macmillan.

Galligan, B., Boese, M., \& Phillips, M. (2014). Becoming Australian. Melbourne: Melbourne University Publishing.

Galligan, B., \& Roberts, W. (2003). Australian multiculturalism: Its rise and demise. In Australasian Political Studies Association Conference. Hobart: University of Tasmania.

Gamage, S. (1998). Curtains of culture, ethnicity and class: The changing composition of the Sri Lankan community in Australia. Journal of Intercultural Studies, 19(1), 37-56. https://doi.org/https://doi.org/10.1080/07256868.1998.9963454

Gamage, S. (2002). Adaptation experiences of Sri Lankan immigrants and their children in Australia in the context of multiculturalism and Angloconformity. In A. Richardson, M. Wyness, \& E. A. Halvorsen (Eds.), Exploring Cultural Perspectives: Integration and Globalization (pp.3-29). Edmonton: International Cultural Research Network Press.

Gamage, S. (2015). Dual citizenship as a moral act and a vehicle for mutual benefit. Retrieved May 24, 2018, from https://www.colombotelegraph.com/index.php/dual-citizenship-as-a-moralact-a-vehicle-for-mutual-benefit/

Ganeshathasan, L., \& Welikala, A. (2017). Report on citizenship law: Sri Lanka. Badia Fiesolana. 
Garcia, J. A. (1981). Political integration of Mexican immigrants: explorations into the naturalization process. International Migration Review, 15(4), 608625. https://doi.org/10.2307/2545515

George, G. (2011). The Canadian Tamil diaspora and the politics of multiculturalism. Identities: Global Studies in Culture and Power, 18, 459480. https://doi.org/10.1080/1070289X.2011.670610

Glover, S., Gott, C., Loizillon, A., Portes, J., Price, R., Spencer, S., ... Willis, C. (2001). Migration: An economic and social analysis. RDS occasional paper. Retrieved from https://mpra.ub.unimuenchen.de/75900/1/MPRA_paper_75900.pdf\%0Ahttp://www.lse.ac.uk/cg i-bin/goto.pl?http://www.homeoffice.gov.uk/rds/pdfs/occ67-migration.pdf

Government of Sri Lanka. Citizenship (Amendment) Act (1987). Parliament of Sri Lanka.

Government of Sri Lanka. Citizenship Act no. 45 of 1987 (1987).

Government of Sri Lanka. Sri Lankan constitution, 19th amendment (2015). Colombo. https://doi.org/10.1017/CBO9781107415324.004

Grassby, A. J. (1973). A multi-cultural society for the future. Australian Government Publishing Service. Canberra: Australian Government Publishing Service.

Guba, E. G., \& Lincoln, Y. S. (1994). Competing paradigms in qualitative research. In Y. S. Denzin, N.K., Lincoln (Ed.), Handbook of Qualitative Research (pp. 105-117). Sage. Retrieved from https://www.sfu.ca/cmns/courses/2012/801/1Readings/Guba_Lincoln_CompetingParadigms.pdf

Guest, G., Bunce, A., \& Johnson, L. (2006). How many interviews are enough? an experiment with data saturation and variability. Field Methods, 18(1), 59-82. https://doi.org/10.1177/1525822X05279903

Habermas, J. (1994). Struggles for recognition in the democratic constitutional 
state. In Multiculturalism: Examining the Politics of Recognition (pp. 107147). Princeton: Princeton University Press.

Hammersley, R. (2015). Concepts of citizenship in France during the long eighteenth century. European Review of History, 22(3), 468-485. https://doi.org/10.1080/13507486.2015.1036231

Harris, J. (1999). State social work and social citizenship in Britain: From clientelism to consumerism. The British Journal of Social Work, 29(6), 915937.

Haug, S. (2008). Migration networks and migration decision-making. Journal of Ethnic and Migration Studies, 34(4), 585-605. https://doi.org/10.1080/13691830801961605

Heater, D. (1990). Citizenship: The civic ideal in world history, politics and education. Harlow: Longman Group UK Limited.

Heater, D. (1999). What is citizenship? Cambridge: Polity Press.

Henayaka-Lochbihler, R., \& Lambusta, M. (2004). The Sri Lankan diaspora in Italy: an explorative mapping. Berlin.

Ho, E. (2015). The changing face of Asian peoples in New Zealand. New Zealand Population Review, 41, 95-118. Retrieved from http://www.ecald.com/Portals/49/Docs/Publications/Changing Face Asian PP NZ.pdf

Ho, E. S. (2002). Multi-local Residence, Transnational Networks: Chinese 'Astronaut' Families in New Zealand *. Asian and Pacific Migration Journal, 11(1), 145-164.

Hoffmann, B. (2010). Bringing Hirschman back in: Exit, voice, and loyalty in the politics of transnational migration. The Latin Americanist, 54(2), 57-73.

Holý, L., \& Stuchlik, M. (1983). Actions, norms and representations: foundations of anthropological inquiry. 
Hoonaard, D. K. (2012). Qualitative research in action: A canadian primer. Ontario: Oxford University Press.

Hoonaard, W. C. Van Den, \& Hoonaard, D. K. Van Den. (2010). Creative integration: Persian Bahá'í newcomers in New Brunswick. Journal of New Brunswick Studies, 1(1), 143-155.

Howard, M. M. (2005). Variation in dual citizenship policies in the countries of the EU. International Migration Review, 39(3), 697-720. https://doi.org/0197-9183/05/3903.0151

Howie, E. (2013). Sri Lankan boat migration to Australia: motivations and dilemmas. Economic and Political Weekly, 48(35), 97-104.

Hugo, G., \& Dissanayake, L. (2017). The process of Sri Lankan migration to Australia focusing on irregular migrants seeking asylum. In M. McAuliffe \& K. Koser (Eds.), A long way to go: Irregular migration patterns, processes, drivers and decision-making (pp. 197-226). ANU Press. https://doi.org/dx.doi.org/10.22459/LWG.12.2017.08

Hugo, G., \& Ukwatta, S. (2010). Sri Lankan female domestic workers overseas the impact on their children. Asian and Pacific Migration Journal, 19(2), 237-263.

International Crisis Group. (2010). The Sri Lankan Tamil diaspora after the LTTE. Retrieved May 16, 2018, from https://d2071 andvip0wj.cloudfront.net/186-the-sri-lankan-tamil-diasporaafter-the-ltte.pdf

Janardhanam, V. (2013). Political participation of the Indial diaspora in the USA. Journal of International and Global Studies, 5(1), 16-33.

Janoski, T. (1998). Citizenship and civil society: A framework of rights and obligations in liberal, traditional, and social democratic regimes. Cambridge University Press.

Jayanath, A. (2015). The 19 Amendement and dual citizenship. Retrieved May 24, 
2018, from https://www.colombotelegraph.com/index.php/the-19amendment-dual-citizenship/

Jayasuriya, D., \& McAuliffe, M. (2013). Placing recent Sri Lankan maritime arrivals in a broader mig ration context (Irregular Migration Research Program Occasional Paper Series).

Jayawardena, P. (2020). Sri Lankan Out-Migration : Five Key Waves Since Independence. University of Colombo Review (Series III), 1(1), 101-118.

Johnson, C. (2009). The dilemmas of ethnic privilege: a comparison of constructions of 'British, "English" and "Anglo-Celtic" identity in contemporary British and Australian political discourse. Ethnicities, 2(2), 163-188. https://doi.org/10.1177/1468796802002002655

Jones-Correa, M. (2001). Under two flags: dual nationality in Latin America and its consequences for naturalization in the United States. International Migration Review, 35(4), 997-1029. https://doi.org/0198-9 183/0 $1 / 3504.0136$

Jones, D. (2016). Being Tamil, being Hindu: Tamil migrants' nego tiations of the absence of Tamil Hindu spaces in the West Midlands and South West of England. Religion, 46(1), 53-74. https://doi.org/10.1080/0048721X.2015.1027968

Joppke, C. (2004). The retreat of multiculturalism in the liberal state: Theory and policy. British Journal of Sociology, 55(2), 237-257. https://doi.org/10.1111/j.1468-4446.2004.00017.x

Joppke, C. (2008). Comparative citizenship : A restrictive turn in Europe? Law and Ethics of Human Rights, 2(1), 1-41.

Jordens, A.-M. (1997). Alien to citizen: Settling migrants in Australia, 1945-1975. Allen \& Unwin.

Kivisto, P., \& Faist, T. (2010). Beyond a border: The causes and consequences of contemporary immigration. London: Sage. 
Kivisto, Peter. (2010). Theorizing transnational immigration : a critical review of current efforts. Ethnic and Racial Studies, 24(4), 549-577. https://doi.org/10.1080/0141987012004978

Koenig-Archibugi, M. (2012). Fuzzy citizenship in global society. Journal of Political Philosophy, 20(4), 456-480. https://doi.org/10.1111/j.14679760.2011.00405.x

Koleth, E. (2010). Multiculturalism: A review of Australian policy statements and recent debates in Australia and overseas. Canberra: Department of Partliamentary Services.

Krauss, S. E. (2005). Research paradigms and meaning making: a primer. The Qualitative Report, 10(4), 758-770.

Kymlicka, W. (1995). Multicultural citizenship: A liberal theory of minority rights. Oxford University Press.

Kymlicka, W. (2003). Immigration , Citizenship, Multiculturalism: Exploring the Links. The Political Quarterly, 74, 195-208. https://doi.org/10.1111/j.1467923X.2003.00590.x

Kymlicka, W., \& Norman, W. (1994). Return of the citizen: a survey of recent work on citizenship theory. Ethics, 104, 352-381.

Leitner, H., \& Ehrkamp, P. (2006). Transnationalism and migrants' imaginings of citizenship. Environment and Planning A, 38, 1615-1632. https://doi.org/10.1068/a37409

Levitt, P., \& Glick Schiller, N. (2004). Conceptualizing simultaneity: A transnational social field perspective on society. International Migration Review, 38(3), 1002-1039. https://doi.org/10.1111/j.17477379.2004.tb00227.x

Levitt, P., \& Jaworsky, B. N. (2007). Transnational migration studies: Past developments and future trends. Annual Review of Sociology, 33(1), 129156. https://doi.org/10.1146/annurev.soc.33.040406.131816 
Levitt, P., \& Nyberg-Sørensen, N. (2004). The transnational turn in migration studies (No. 6). Global migration perspectives.

Lister, R., Smith, N., Middleton, S., \& Cox, L. (2003). Young people talk about citizenship: Empirical perspectives on theoretical and political debates. Citizenship Studies, 7(2), 235-254. https://doi.org/10.1080/1362102032000065991

Makela, M. (2018). Deportation and removal from Australia.

Mann, J. (2017). The search for a new national identity: The rise of multiculturalism in Canada and Australia, 1890s-1970s. New York: Peter Lung Publishing, Inc.

Marshall, T. H. (1981). The right to welfare. London: Heinemann Educational Books.

Martínez-Saldaña, J. (2003). Los Olvidados become heroes: The evolution of Mexico's policies towards citizens abroad. International Migration and Sending Countries, 33-56.

McDowell, C. (1996). A Tamil asylum diaspora: Sri Lankan migration, settlement and politics in Switzerland. Providence; Berghahn Books.

McMillan, K. (2017). From “the Commonwealth's most dutiful daughter” to “young multicultural nation": Non-citizen voting rights and New Zealand's citizenship regime. In J. Mann (Ed.), Citizenship in transnational perspective: Australia, Canada and New Zealand (pp. 117-138). Palgrave Macmillan.

Merelo, G. (2016). Not from around here: The political acculturation of Mexican migrants in New Zealand. University of Auckland.

Miller, P., \& Barry, C. (2009). Citizenship in the United States: The Roles of Immigrant Characteristics and Country of Origin. Research in Labor Economics (Vol. 29). Elsevier. https://doi.org/10.1108/S01479121(2009)0000029007 
Ministry of Business Innovation \& Employment. (2015). Migration trends 2015/2016. Retrieved from http://www.mbie.govt.nz/publicationsresearch/research/migrants---monitoring/migration-trends-and-outlook-201516.pdf

Ministry of Foreign Affairs and Trade. (2019). Sri Lanka. Retrieved from https://www.mfat.govt.nz/en/countries-and-regions/south-asia/sri-lanka/

Morse, J. M. (1995). The significance of saturation. Qualitative Health Research, 5(2), 147-149.

Morse, Janice M. (2000). Determining sample size. Qualitative Health Research, 10(3). https://doi.org/10.1177/104973200129118183

Mügge, L. (2012). Dual nationality and transnational politics. Journal of Ethnic and Migration Studies, 38(1), 1-19. https://doi.org/10.1080/1369183X.2012.640003

Nagel, C. R., \& Staeheli, L. A. (2004). Citizenship, identity and transnational migration: Arab immigrants to the United States. Space and Polity, 8(1), 323. https://doi.org/10.1080/13562570410001678860

New Zealand Foreign Affairs and Trade. (2019). Work with us. Retrieved August 19, 2019, from https://www.mfat.govt.nz/en/about-us/work-with-us/

New Zealand Immigration. (2018). New Zealand refugee quota program.

Retrieved May 5, 2018, from https://www.immigration.govt.nz/aboutus/what-we-do/our-strategies-and-projects/supporting-refugees-and-asylumseekers/refugee-and-protection-unit/new-zealand-refugee-quota-programme

New Zealand Immigration. (2019a). Citizenship. Retrieved August 20, 2019, from https://www.newzealandnow.govt.nz/move-to-nz/new-zealandvisa/citizenship

New Zealand Immigration. (2019b). Will I lose my New Zealand residence status if I travel abroad. Retrieved August 20, 2019, from https://www.immigration.govt.nz/knowledgebase/kb-question/kb-question- 
Ong, A. (1999). Flexible citizenship: The cultural logics of transnationality. Duke University Press.

Orjuela, C. (2008). Distant warriors, distant peace workers?: Multiple diaspora roles in Sri Lanka's violent conflict. Global Networks, 8(4), 436-452. https://doi.org/10.1111/j.1471-0374.2008.00233.x

Orjuela, C. (2011). Violence at the margins: Street gangs, globalized conflict and Sri Lankan Tamil battlefields in London, Toronto, and Paris. International Studies, 48(2), 113-137. https://doi.org/10.1177/0020881712469457

Østergaard-Nielsen, E. (2001). The politics of migrants' transnational political practices. In Transnational Migration: Comparative Perspectives. Princeton University. https://doi.org/10.1111/j.1747-7379.2003.tb00157.x

Paquet, M. (2012). Beyond appearances: Citizenship tests in Canada and the UK. Journal of International Migration and Integration, 13(2), 243-260. https://doi.org/10.1007/s12134-011-0233-1

Perera, N. (2020). Tamil weekends: Intergenerational perspectives on belonging. In A Sense of Viidu: The (Re)creation of Home by the Sri Lankan Tamil Diaspora in Australia (pp. 137-154). Singapore: Palgrave Pivot.

Perera, Nirukshi. (2015). The maintenance of Sri Lankan languages in Australia comparing the experience of the Sinhalese and Tamils in the homeland. Journal of Multilingual and Multicultural Development, 36(3), 297-312. https://doi.org/10.1080/01434632.2014.921185

Phalet, K., \& Swyngedouw, M. (2002). National identities and representations of citizenship. Ethnicities, 2(1), 5-30.

Pingama, A. (2016). Reasons for youth migration in Sri Lanka with emphasis on regular and irregular youth migrants. In $2 n d$ International Conference on the Humanities. University of Kelaniya, Sri Lanka.

Pinnawala, S. K. (1984). Sri Lankans in Melbourne: Factors influencing patterns 
of ethnicity. Australian National University.

Plüss, C. (2005). Constructing globalized ethnicity: Migrants from India in Hong Kong. International Sociology, 20(2), 201-224.

https://doi.org/10.1177/0268580905052369

Pogonyi, S. (2019). The passport as means of identity man agement: Making and unmaking ethnic boundaries through citizenship. Journal of Ethnic and Migration Studies, 45(6), 975-993.

https://doi.org/10.1080/1369183X.2018.1440493

Portes, A., \& Rumbaut, R. G. (2006). Immigrant America: A portrait (3rd ed.). Berkeley: University of Califonia Press.

Portes, Alejandro, Escobar, C., \& Radford, A. W. (2007). Immigrant transnational organizations and development: A comparative study. International Migration Review, 41(1), 242-281. https://doi.org/10.1111/j.17477379.2007.00063.x

Portes, Alejandro, Haller, W. J., \& Guarnizo, L. E. (2002). Transnational entrepreneurs: An alternative form of immigrant economic adaptation. American Sociological Review, 2(67), 278-298.

Portes, Alejandro, \& Mozo, R. (1985). The political adaptation process of Cubans and other ethnic minorities in the United States: a preliminary analysis. International Migration Review, 19(1), 35-63. https://doi.org/10.2307/2545655

Portes, Alejandro, \& Rumbaut, R. G. (2014). Immigrant America: A portrait (4th ed.). Berkeley: Unversity of California Press. https://doi.org/.1037//00332909.I26.1.78

Portes, Alejandro, \& Zhou, M. (2012). Transnationalism and development: Mexican and Chinese immigrant organizations in the United States. Population and Development Review, 38(2), 191-220.

Pothmulla, L. (2017, May 9). Bandula to go to SC on Mahendran's citizenship. 
Daily Mirror. Retrieved from http://www.dailymirror.lk/article/Bandula-togo-to-SC-on-Mahendran-s-citizenship-128611.html

Price, C. A. (1999). Australian population: Ethnic origins. People and Place, 7(4), $12-16$.

Quinn, M., \& Devasagayam, R. A. J. (2005). Building brand community among ethnic diaspora in the USA: Strategic implications for marketers. Brand Management, 13(2), 101-114.

Rabionet, S. E. (2011). How I learned to design and conduct semi-structured interviews: An ongoing and continuous journey. The Qualitative Report, 16(2), 563-566. Retrieved from http://www.nova.edu/ssss/QR/QR162/rabionet.pdf

Ragazzi, F. (2014). A comparative analysis of diaspora policies. Political Geography, 41, 74-89. https://doi.org/10.1016/j.polgeo.2013.12.004

Raijman, R., Davidov, E., Schmidt, P., \& Hochman, O. (2008). What does a nation owe non-citizens? National attachments, perception of threat and attitudes towards granting citizenship rights in a comparative perspective. International Journal of Comparative Sociology, 49(2-3), 195-220. https://doi.org/10.1177/0020715208088912

Rajasingham, K. T. (2013). No more direct dual citizenship to Sri Lankans abroad. Retrieved May 23, 2018, from http://www.asiantribune.com/node/62252

Ramakrishnan, S. K., \& Espenshade, T. J. (2001). Immigrant incorporation and political participation in the United States. International Migration Review, 35(3), 870-909. https://doi.org/0 198-91 83/01/3503.0135

Rapley, T. (2011). Interviews. In C. Seale, G. Gobo, J. F. Gubrium, \& D. Silverman (Eds.), Qualitative Research Practice (pp. 16-34). London: Sage.

Rees, A. M. (2016). T.H.Marshall and the progress of citizenship. In M. Bulmer \& A. M. Rees (Eds.), Citizenship today: The contemporary relevance of 
T.H.Marshall (pp. 1-24). Routledge.

Reeves, P. (2013). The encyclopedia of the Sri Lankan diaspora. (P. Reeves, Ed.). Singapore: Editions Didier Millet.

Renshon, S. A. (2001). Dual citizenship and American national identity.

Washington, DC: Center for Immigration Studies.

Revi, B. (2014). T. H. Marshall and his critics: Reappraising 'social citizenship' in the twenty-first century. Citizenship Studies, 18(3-4), 452-464. https://doi.org/10.1080/13621025.2014.905285

Roche, M. (1987). Citizenship, social theory, and social change. Theory and Society, 16(3), 363-399.

Rodríguez, C. M. (2010). Noncitizen voting and the extraconstitutional construction of the polity. $I \bullet C O N, 8(1), 30-49$. https://doi.org/10.1093/icon/mop032

Ronkainen, J. K. (2011). Mononationals, hyphenationals, and shadow-nationals: multiple citizenship as practice. Citizenship Studies, 15(2), 247-263. https://doi.org/10.1080/13621025.2011.549723

Rosenstone, S. J., \& Hansen, M. (1993). Mobilization, participation and democracy in America. New York: MacMillan Publishing Company.

Roulston, K. (2010). Reflective interviewing: A guide to theory and practice. London: Sage.

Safran, W. (1991). Diasporas in Modern Societies: Myths of Homeland and Return. Diaspora: A Journal of Transnational Studies, 1(1), 83-99. https://doi.org/10.1353/dsp.1991.0004

Samaranayake, G. (1990). Political violence in the third world: A case study of Sri lanka, 1971-1987. University of St. Andrews, Scotland.

Sankaran, L. (2019). "Homeland" \& "hostland” identifications in the Sri Lankan Tamil diaspora (Working Papers in Urban Language and Literacies). 
Schacter, D., Gilbert, D., Wegner, D., \& Hood, B. M. (2012). Sensation and Perception. In Pshychology: European Edition. Palgrave Macmillan.

Schiller, N. G., Basch, L., \& Blanc-szanton, C. (1992). Transnationalism : A New Analytic Framework for Understanding Migration. Annals of the New York Academy of Sciences, 645(1), 1-24.

Scipioni, M. (2017). Failing forward in EU migration policy? EU integration after the 2015 asylum and migration crisis. Journal of European Public Policy, O(0), 1-19. https://doi.org/10.1080/13501763.2017.1325920

Sejersen, T. B. (2008). "I vow to thee my countries" - the expansion of dual citizenship in the 21 st century. International Migration Review, 42(3), 523549. https://doi.org/10.1111/j.1747-7379.2008.00136.x

Shachar, A. (2009). The birthright lottery: Citizenship and global inequality. Harvard University Press.

Sharma, S. L. (2004). Perspectives on Indians abroad. In N. Jayaram (Ed.), The Indian diaspora: Dynamics of migration (pp. 44-65). New Delhi: Sage.

Silva, A. (2017, May 17). Issues faced by expatriates who remain loyal to Sri Lanka without dual citizenship. Sunday Island. Retrieved from http://www.island.lk/index.php?page_cat=article-details\&page=articledetails\&code_title $=164656$

Silva, M. De. (2017). The care pentagon: Older adults within Sri Lankan Australian transnational families and their landscapes of care. Population, Space and Place, 23(8). https://doi.org/10.1002/psp.2061

Silverman, D. (Ed.). (2011). Qualitative research (3rd ed.). London: Sage.

Simon-Kumar, R. (2015). Neoliberalism and the new race politics of migration policy: changing profiles of the desirable migrant in New Zealand. Journal of Ethnic and Migration Studies, 41(7), 1172-1191. https://doi.org/10.1080/1369183X.2014.936838

Simonsen, K. B. (2016). How the host nation's boundary drawing affects 
immigrants' belonging. Journal of Ethnic and Migration Studies, 42(7), 1153-1176. https://doi.org/10.1080/1369183X.2016.1138854

Simonsen, K. B. (2017). Does citizenship always further immigrants' feeling of belonging to the host nation? A study of policies and public attitudes in 14 western democracies. Comparative Migration Studies, 5(1), 3. https://doi.org/10.1186/s40878-017-0050-6

Siriwardhana, C., \& Wickramage, K. (2014). Conflict, forced displacement and health in Sri Lanka: A review of the research landscape. Conflict and Health, 8(22), 1-9. https://doi.org/10.1186/1752-1505-8-22

Skulte-Ouaiss, J. (2013). Home is where the heart is; citizenship is where it is safe: Dual citizenship and Europe. Identities, 20(2), 133-148.

https://doi.org/10.1080/1070289X.2012.763166

Spiro, P. (2017). Multiple citizenship. In Ayelet Shachar, R. Bauböck, I. Bloemraad, \& M. Vink (Eds.), The Oxford Handbook of Citizenship. Oxford University Press.

Spoonley, P., \& Butcher, A. (2009). Reporting superdiversity. The mass media and immigration in New Zealand. Journal of Intercultural Studies, 30(4), 355-372. https://doi.org/10.1080/07256860903213638

Sriskandarajah, D. (2002). The migration-development nexus: Sri Lanka case study. International Migration, 40(5), 283-307. https://doi.org/10.1111/1468-2435.00220

Stasiulis, D. K. (1997). International migration, rights, and the decline of 'actually existing liberal democracy.' Journal of Ethnic and Migration Studies, 23(2), 197-214. https://doi.org/10.1080/1369183X.1997.9976586

Statistics New Zealand. (2010). New Zealand's International Migration Statistics: 1922-2009. Wellington.

Statistics New Zealand. (2013a). 2013 Census ethnic group profiles: Sri Lankan. Retrieved from http://archive.stats.govt.nz/Census/2013-census/profile-and- 
summary-reports/ethnic-profiles.aspx?url=/Census/2013-census/profile-andsummary-reports/ethnic-

profiles.aspx\&request_value $=24750 \&$ tabname $=$ Languagesspoken $\& \mathrm{p}=\mathrm{y} \&$ pri ntall=true

Statistics New Zealand. (2013b). 2013 census quickstats about culture and identity. 2013 Census. Retrieved from http://archive.stats.govt.nz/Census/2013-census/profile-and-summaryreports/quickstats-culture-identity/birthplace.aspx?url=/Census/2013census/profile-and-summary-reports/quickstats-cultureidentity/birthplace.aspx

Stein, C., \& Mankowski, E. (2004). Asking, witnessing, interpreting, knowing: Conducting qualitative research in community psychology. American Journal of Community Psychology, 33(1/2), 21-35.

Sunstein, B. S., \& Chiseri-Strater, E. (2012). FieldWorking: Reading and writing research (4th ed.). Boston: Bedford/St.Martin’s.

Swarbrick, N. (2005). Story: Sri Lankans. Retrieved from https://teara.govt.nz/en/sri-lankans

Taniguchi, K. (2017). Sri Lanka's labour market and human capital formation. In P.-C. Athukorala, E. Ginting, H. Hill, \& U. Kumar (Eds.), The Sri Lankan economy: charting a new course (pp. 268-278). Manila. https://doi.org/http://dx.doi.org/10.22617/TCS178786-2

Tennakoon, R. (2017, November). Geetha, Dual Citizens, Sri Lanka \& Australia. Colombo Telegraph. Retrieved from https://www.colombotelegraph.com/index.php/geetha-dual-citizens-srilanka-australia/

The World Bank. (2019). Overview: Economy. Retrieved June 11, 2019, from https://www.worldbank.org/en/country/srilanka/overview\#4

Tilly, C. (1995). Citizenship, identity and social history. Internation Review of Social History. https://doi.org/10.1017/S0020859000113586 
Tölölyan, K. (1996). Rethinking Diaspora (s): Stateless Power in the

Transnational Moment. Diaspora: A Journal of Transnational Studies, 5(1), 3-36. https://doi.org/10.1353/dsp.1996.0000

Toma, J. D. (2006). Approaching rigour in applied qualitative research. In R. C. Conrad, C.F.; Serlin (Ed.), The SAGE handbook for research in Education. https://doi.org/10.4135/9781412976039.n23

Tongco, M. D. C. (2007). Purposive sampling as a tool for informant selection. Ethnobotany Research \& Application, 5, 147-158. https://doi.org/10.17348/era.5.0.147-158

Topp, L., Barker, B., \& Degenhardt, L. (2004). The external validity of results derived from ecstasy users recruited using purposive sampling strategies. Drug and Alcohol Dependence, 73,33-40. https://doi.org/10.1016/j.drugalcdep.2003.09.001

Turner, B. S. (1993). Citizenship and social theory. London: Sage.

Turner, B. S. (1997). Citizenship studies: A general theory. Citizenship Studies, 1(1), 5-18. https://doi.org/10.1080/13621029708420644

Uhlaner, C. J., Cain, B. E., \& Kiewiet, D. R. (1989). Political participation of ethnic minorities in the 1980s. Political Behavior, 11(3), 195-231. https://doi.org/10.2307/2545797

Ukwatta, S. (2013). Sri Lanka, migration 1960s to present. The Encyclopedia of Global Human Migration.

United Nations Development Programme. (2016). Human Development Report 2016: Sri Lanka.

United Nations High Commissioner for Refugees. (2019). UN Conventions on Statelessness. Retrieved April 8, 2020, from https://www.unhcr.org/un conventions-on-statelessness.html

Varadarajan, L. (2014). The transnationalism of the embattled State. New Politican Science, 36(3), 366-386. 
https://doi.org/10.1080/07393148.2014.918718

Victoria State Government. (2018). Sri Lanka-born: Victorian Community

Profiles: 2016 Census. Retrieved from

https://multicultural.vic.gov.au/images/2016_Census/CommunityProfiles201

6/Sri-Lanka-Community-Profile-2016-Census.pdf

Walters, W. (2004). Secure borders, safe haven, domopolitics. Citizenship Studies, 8(3), 237-260. https://doi.org/10.1080/1362102042000256989

Wanasinghe-Pasqual, M., \& Jayawardena, P. (2017). Sri Lanka’s Illegal

Migration: detriment to development. In International Research Conference, Faculty of Arts. The University of Colombo.

Ward, C., \& Masgoret, A. M. (2008). Attitudes toward immigrants, immigration, and multiculturalism in New Zealand: A social psychological analysis.

International Migration Review, 42(1), 227-248.

https://doi.org/10.1111/j.1747-7379.2007.00119.x

Wayland, S. (2004). Ethnonationalist networks and transnational opportunities:

The Sri Lankan Tamil diaspora. Review of International Studies, 30(3), 405426. https://doi.org/10.1017/S0260210504006138

Weerasooria, W. S. (1988). Links between Sri Lanka and Australia: A book about Sri Lankans (Ceylonese) in Australia. Colombo: Government Printer.

White, R., \& Tadesse, B. (2007). Immigration policy, cultural pluralism and trade: evidence from the white Australia policy. Pacific Economic Review, 12(4), 489-509. https://doi.org/10.1111/j.1468-0106.2007.00368.x

Wijesinghe, S. (2017, May 9). Dual citizenship issue in Sri Lanka. Daily Mirror. Retrieved from http://www.dailymirror.lk/article/Dual-citizenship-issue-inSri-Lanka-128575.html

Yanasmayan, Z. (2015). Citizenship on paper or at heart? A closer look into the dual citizenship debate in Europe. Citizenship Studies, 19(6-7), 785-801. https://doi.org/10.1080/13621025.2015.1053793 
Yang, P. Q. (1994). Explaining immigrant naturalization. International Migration Review, 28(3), 449-477. https://doi.org/10.2307/2546816

Zapata-Barrero, R., Gabrielli, L., Elena, S., \& Jaulin, T. (2013). The political participation of immigrants in host countries: An interpretative framework from the perspective of orig in countries and societies.

Zappala, G., \& Castles, S. (1999). Citizenship and immigration in Australia. Georgetown Immigration Law Journal, 13(273), 273-316. https://doi.org/10.3868/s050-004-015-0003-8

Zhou, M., \& Liu, H. (2016). Homeland engagement and host-society integration: A comparative study of new Chinese immigrants in the United States and Singapore. International Journal of Comparative Sociology, 57(1-2), 30-52. https://doi.org/10.1177/0020715216637210

Zubrzycki, J. (1995). The evolution of the policy of multiculturalism in Australia 1968-1995. In Global Cultural Diversity Conference Proceedings. 


\section{Appendix A: List of participants}

\begin{tabular}{|c|c|c|c|c|c|c|}
\hline & $\begin{array}{c}\text { Name } \\
\text { (pseudonym), } \\
\text { age,gender, } \\
\text { ethnicity and } \\
\text { religion }\end{array}$ & $\begin{array}{c}\text { Date and } \\
\text { location of } \\
\text { the } \\
\text { interview }\end{array}$ & $\begin{array}{c}\text { Marital } \\
\text { status }\end{array}$ & Profession & $\begin{array}{l}\text { Host country } \\
\text { citizenship status }\end{array}$ & $\begin{array}{l}\text { Home country } \\
\text { citizenship status }\end{array}$ \\
\hline 1 & $\begin{array}{l}\text { Anura, } \\
31, \\
\text { Male, } \\
\text { Sinhalese, } \\
\text { Buddhist }\end{array}$ & $\begin{array}{l}20^{\text {th }} \text { January } \\
2019 \text {, } \\
\text { Melbourne }\end{array}$ & Married & $\begin{array}{l}\text { Was a manager } \\
\text { in Sri Lanka. } \\
\text { Now a } \\
\text { supervisor ata } \\
\text { cleaning } \\
\text { service. }\end{array}$ & $\begin{array}{l}\text { Arrived in Australia } \\
\text { in } 2017 \text { as the partner } \\
\text { of a student visa } \\
\text { holder. } \\
\text { Currently a } \\
\text { temporary resident, } \\
\text { expecting to obtain } \\
\text { citizenship in the } \\
\text { future. }\end{array}$ & $\begin{array}{l}\text { A Sri Lankan citizen. } \\
\text { Expecting to become } \\
\text { a dualcitizen oncehe } \\
\text { becomes an } \\
\text { Australian citizen. }\end{array}$ \\
\hline 2 & $\begin{array}{l}\text { Amal, } \\
33, \\
\text { Male, } \\
\text { Sinhalese, } \\
\text { Buddhist }\end{array}$ & $\begin{array}{l}18^{\text {th }} \text { January } \\
2019, \\
\text { Melbourne }\end{array}$ & $\begin{array}{l}\text { Married } \\
\text { with one } \\
\text { child }\end{array}$ & $\begin{array}{l}\text { Was a manager } \\
\text { in Sri Lanka. } \\
\text { Does not have a } \\
\text { permanent full- } \\
\text { time job in } \\
\text { Australia. Does } \\
\text { part time work. }\end{array}$ & $\begin{array}{l}\text { Arrived in Australia } \\
\text { in } 2015 \text { as a student. } \\
\text { Currently a } \\
\text { temporary resident, } \\
\text { expecting to obtain } \\
\text { citizenship in the } \\
\text { future }\end{array}$ & $\begin{array}{l}\text { A Sri Lankan citizen. } \\
\text { Expecting to become } \\
\text { a dualcitizen oncehe } \\
\text { becomes an } \\
\text { Australian citizen. }\end{array}$ \\
\hline 3 & $\begin{array}{l}\text { Charith, } \\
46, \\
\text { Male, } \\
\text { Sinhalese, } \\
\text { Buddhist }\end{array}$ & $\begin{array}{l}17^{\text {th }} \text { January } \\
2019, \\
\text { Melbourne }\end{array}$ & $\begin{array}{l}\text { Married } \\
\text { with two } \\
\text { children }\end{array}$ & $\begin{array}{l}\text { Was an } \\
\text { accountantin } \\
\text { Sri Lanka. } \\
\text { A financial } \\
\text { advisorin } \\
\text { Australia. Also } \\
\text { leads a Sri } \\
\text { Lankan dancing } \\
\text { academy. }\end{array}$ & $\begin{array}{l}\text { First arrived in New } \\
\text { Zea land a s a skilled } \\
\text { migrant in } 1999 . \\
\text { Becamea citizen in } \\
2008, \text { then left to } \\
\text { permanently settle in } \\
\text { Melbourne, Australia. } \\
\text { Does not intend to } \\
\text { became an Australian } \\
\text { citizen, instead will } \\
\text { continue to be a New } \\
\text { Zealand citizen. }\end{array}$ & $\begin{array}{l}\text { Not a Sri Lankan dual } \\
\text { citizen currently, but } \\
\text { wishes to obta in la ter. }\end{array}$ \\
\hline 4 & $\begin{array}{l}\text { Darshi, } \\
38, \\
\text { Female, } \\
\text { Sinhalese, } \\
\text { Buddhist }\end{array}$ & $\begin{array}{l}20^{\text {th }} \text { January, } \\
2019 \\
\text { Melbourne }\end{array}$ & $\begin{array}{l}\text { Married } \\
\text { with two } \\
\text { children }\end{array}$ & $\begin{array}{l}\text { Was a manager } \\
\text { and a lecturer in } \\
\text { Human } \\
\text { Resource } \\
\text { management in } \\
\text { Sri Lanka. } \\
\text { A corporate } \\
\text { officerin } \\
\text { Australia. }\end{array}$ & $\begin{array}{l}\text { Arrived in Australia } \\
\text { in } 2012 \text { as a skilled } \\
\text { migrant a nd as a } \\
\text { permanent resident. } \\
\text { Obtained Australian } \\
\text { citizenship in } 2017 .\end{array}$ & $\begin{array}{l}\text { Obtained dual } \\
\text { citizenship in } 2017 .\end{array}$ \\
\hline 5 & $\begin{array}{l}\text { Dinindu, } \\
45, \\
\text { Male, } \\
\text { Sinhalese, } \\
\text { Buddhist }\end{array}$ & $\begin{array}{l}19^{\text {th }} \text { January } \\
2019, \\
\text { Melbourne }\end{array}$ & $\begin{array}{l}\text { Married } \\
\text { with two } \\
\text { children }\end{array}$ & $\begin{array}{l}\text { Was a bankerin } \\
\text { England and } \\
\text { now a banker in } \\
\text { Australia }\end{array}$ & $\begin{array}{l}\text { First migra ted to } \\
\text { England in } 2003 \text { for } \\
\text { his higher studies. } \\
\text { From Engla nd, he } \\
\text { migrated to Australia } \\
\text { in } 2009 . \text { Obtained } \\
\text { permanent residency } \\
\text { in } 2011 \text { and } \\
\text { citizenship in } 2014 .\end{array}$ & $\begin{array}{l}\text { Not a Sri Lankan dual } \\
\text { citizen. }\end{array}$ \\
\hline 6 & $\begin{array}{l}\text { Nimal, } \\
50, \\
\text { Male, } \\
\text { Sinhalese, } \\
\text { Catholic } \\
\end{array}$ & $\begin{array}{l}19^{\text {th }} \text { January } \\
2019 \text {, } \\
\text { Melbourne }\end{array}$ & $\begin{array}{l}\text { Married } \\
\text { with two } \\
\text { children }\end{array}$ & $\begin{array}{l}\text { Was an artist } \\
\text { and a chef in Sri } \\
\text { Lanka and in } \\
\text { Australia. }\end{array}$ & $\begin{array}{l}\text { Arrived in Australia } \\
\text { a s a skilled migrant in } \\
2014 \text { with permanent } \\
\text { residency status. }\end{array}$ & $\begin{array}{l}\text { A Sri Lankan citizen. } \\
\text { Expecting to become } \\
\text { a dualcitizen oncehe } \\
\text { becomes an } \\
\text { Australian citizen. }\end{array}$ \\
\hline
\end{tabular}




\begin{tabular}{|c|c|c|c|c|c|c|}
\hline & & & & & $\begin{array}{l}\text { Expecting to obtain } \\
\text { citizenship in the } \\
\text { future. }\end{array}$ & \\
\hline 7 & $\begin{array}{l}\text { Padma, } \\
60, \\
\text { Female } \\
\text { Sinhalese, } \\
\text { Catholic }\end{array}$ & $\begin{array}{l}21^{\text {st }} \text { January } \\
2019 \\
\text { Melbourne }\end{array}$ & $\begin{array}{l}\text { Married } \\
\text { with two } \\
\text { children }\end{array}$ & $\begin{array}{l}\text { Was a teacher in } \\
\text { Sri Lanka and is } \\
\text { now a Professor } \\
\text { in a university } \\
\text { in Melbourne. }\end{array}$ & $\begin{array}{l}\text { Arrived in Australia } \\
\text { in } 1987 \text { on a } \\
\text { Commonwealth } \\
\text { scholarship. Obtained } \\
\text { permanent residency } \\
\text { in } 1996 \text { and } \\
\text { citizenship in } 2015 .\end{array}$ & $\begin{array}{l}\text { Not a Sri Lankan dual } \\
\text { citizen. }\end{array}$ \\
\hline 8 & $\begin{array}{l}\text { Rashmi, } \\
44, \\
\text { Female, } \\
\text { Sinhalese, } \\
\text { Buddhist }\end{array}$ & $\begin{array}{l}19^{\text {th }} \text { January } \\
2019 \\
\text { Melbourne }\end{array}$ & $\begin{array}{l}\text { Married } \\
\text { with two } \\
\text { children }\end{array}$ & $\begin{array}{l}\text { Worked in the } \\
\text { IT sector in Sri } \\
\text { Lanka. } \\
\text { Runs a business } \\
\text { in Austra lia. }\end{array}$ & $\begin{array}{l}\text { Arrived in Australia } \\
\text { in } 2014 \text { as the partner } \\
\text { of a skilled migrant. } \\
\text { Expecting to obtain } \\
\text { Australian citizen ship } \\
\text { in the future. }\end{array}$ & $\begin{array}{l}\text { A Sri Lankan citizen. } \\
\text { Expecting to obtain } \\
\text { dual citizen ship when } \\
\text { she obtains } \\
\text { Australian } \\
\text { citizenship. }\end{array}$ \\
\hline 9 & $\begin{array}{l}\text { Samanthi, } \\
38, \\
\text { Female, } \\
\text { Sinhalese, } \\
\text { Catholic }\end{array}$ & $\begin{array}{l}17^{\text {th }} \text { January } \\
2019 \\
\text { Melbourne }\end{array}$ & $\begin{array}{l}\text { Married } \\
\text { with two } \\
\text { children }\end{array}$ & $\begin{array}{l}\text { Was a business } \\
\text { administrator in } \\
\text { Sri Lanka. Now } \\
\text { runs her own } \\
\text { business in } \\
\text { Australia. }\end{array}$ & $\begin{array}{l}\text { Arrived in Australia } \\
\text { in } 2007 \text { as a student. } \\
\text { Obtained permanent } \\
\text { residency in } 2013 \text { and } \\
\text { citizenship in } 2017 .\end{array}$ & $\begin{array}{l}\text { Not a Sri Lankan dual } \\
\text { citizen. }\end{array}$ \\
\hline 10 & $\begin{array}{l}\text { Shehan, } \\
46, \\
\text { Male, } \\
\text { Sinhalese, } \\
\text { Buddhist }\end{array}$ & $\begin{array}{l}20^{\text {th }} \text { January } \\
2019 \\
\text { Melbourne }\end{array}$ & $\begin{array}{l}\text { Married } \\
\text { with two } \\
\text { children }\end{array}$ & $\begin{array}{l}\text { Was an } \\
\text { executive } \\
\text { manager in the } \\
\text { clothing } \\
\text { industry in Sri } \\
\text { Lanka. } \\
\text { A quality } \\
\text { assurance } \\
\text { manager in } \\
\text { Australia. Runs } \\
\text { his own } \\
\text { cleaning service } \\
\text { business. }\end{array}$ & $\begin{array}{l}\text { Arrived in Australia } \\
\text { in } 2007 \text { a s a student. } \\
\text { Obtained permanent } \\
\text { residency in } 2014 \text { and } \\
\text { Australian citizenship } \\
\text { in } 2017 \text {. }\end{array}$ & $\begin{array}{l}\text { Not a Sri Lankan dual } \\
\text { citizen. }\end{array}$ \\
\hline 11 & $\begin{array}{l}\text { Shivakumar, } \\
70, \\
\text { Male, } \\
\text { Tamil, Hindu }\end{array}$ & $\begin{array}{l}18^{\text {th }} \text { January } \\
2019 \\
\text { Melbourne }\end{array}$ & Married & $\begin{array}{l}\text { Engineer in Sri } \\
\text { Lanka and in } \\
\text { Australia, }\end{array}$ & $\begin{array}{l}\text { Arrived in Australia } \\
\text { in } 1988 \text { as a skilled } \\
\text { migrant with } \\
\text { permanent residency } \\
\text { status. Became a } \\
\text { citizen in } 1991 .\end{array}$ & $\begin{array}{l}\text { Not a Sri Lankan dual } \\
\text { citizen. }\end{array}$ \\
\hline 12 & $\begin{array}{l}\text { Udari, } \\
50, \\
\text { Female, } \\
\text { Sinhalese, } \\
\text { Catholic }\end{array}$ & $\begin{array}{l}24^{\text {th }} \text { January } \\
2019 \\
\text { Sydney }\end{array}$ & $\begin{array}{l}\text { Married } \\
\text { with one } \\
\text { child }\end{array}$ & $\begin{array}{l}\text { Lawyer in both } \\
\text { Sri Lanka and } \\
\text { Australia. }\end{array}$ & $\begin{array}{l}\text { Arrived in Australia } \\
\text { in } 1994 \text { as a skilled } \\
\text { migrant with } \\
\text { permanent residency } \\
\text { status. Obtained } \\
\text { Australian citizen ship } \\
\text { in } 2000 \text {. }\end{array}$ & $\begin{array}{l}\text { Obtained SriLa nkan } \\
\text { dualcitizenship in } \\
2009 .\end{array}$ \\
\hline 13 & $\begin{array}{l}\text { Aloka, } \\
30, \\
\text { Male, } \\
\text { Sinhalese, } \\
\text { Buddhist }\end{array}$ & $\begin{array}{l}25^{\text {th }} \text { January } \\
2019 \\
\text { Sydney }\end{array}$ & Married & $\begin{array}{l}\text { Was a student in } \\
\text { Sri Lanka. } \\
\text { Manager in a } \\
\text { private company } \\
\text { in Austra lia. }\end{array}$ & $\begin{array}{l}\text { Arrived in Australia } \\
\text { in } 2010 \text { as a student. } \\
\text { Currently, he is a } \\
\text { temporary resident. } \\
\text { He intend s to obtain } \\
\text { permanent residency } \\
\text { and Australian }\end{array}$ & $\begin{array}{l}\text { Currently a Sri } \\
\text { Lankan citizen. }\end{array}$ \\
\hline
\end{tabular}




\begin{tabular}{|c|c|c|c|c|c|c|}
\hline & & & & & $\begin{array}{l}\text { citizenship in the } \\
\text { future. }\end{array}$ & \\
\hline 14 & $\begin{array}{l}\text { Kaushi, } \\
46, \text { Female, } \\
\text { Sinhalese, } \\
\text { Buddhist }\end{array}$ & $\begin{array}{l}26^{\text {th }} \text { January } \\
2019, \\
\text { Sydney }\end{array}$ & $\begin{array}{l}\text { Married } \\
\text { with one } \\
\text { child }\end{array}$ & $\begin{array}{l}\text { Was a translator } \\
\text { and a nartist in } \\
\text { Sri Lanka. } \\
\text { Could not find a } \\
\text { suitable } \\
\text { permanent job } \\
\text { in Australia. }\end{array}$ & $\begin{array}{l}\text { Arrived in Australia } \\
\text { in } 2014 \text { as a skilled } \\
\text { migrant with } \\
\text { permanent residency. } \\
\text { Does not intend to } \\
\text { obtain Australian } \\
\text { citizenship. }\end{array}$ & $\begin{array}{l}\text { A Sri Lankancitizen } \\
\text { currently. She said } \\
\text { she will remain as a } \\
\text { Sri Lankan citizen. }\end{array}$ \\
\hline 15 & $\begin{array}{l}\text { Rasika, } \\
44, \\
\text { Male, } \\
\text { Sinhalese, } \\
\text { Buddhist }\end{array}$ & $\begin{array}{l}25^{\text {th }} \text { January } \\
2019, \\
\text { Sydney }\end{array}$ & $\begin{array}{l}\text { Married } \\
\text { with two } \\
\text { children }\end{array}$ & $\begin{array}{l}\text { Was a bankerin } \\
\text { Sri Lanka and } \\
\text { Dubai. } \\
\text { Works in a } \\
\text { private company } \\
\text { in Austra lia. }\end{array}$ & $\begin{array}{l}\text { Arrived in Australia } \\
\text { in } 2013 \text { as a student. } \\
\text { Obtained permanent } \\
\text { residency in } 2016 . \\
\text { Expecting to become } \\
\text { an Australian citizen. }\end{array}$ & $\begin{array}{l}\text { Currently a Sri } \\
\text { Lankan citizen. }\end{array}$ \\
\hline 16 & $\begin{array}{l}\text { Madavi, } \\
30, \\
\text { Female, } \\
\text { Sinhalese, } \\
\text { Buddhist }\end{array}$ & $\begin{array}{l}27^{\text {th }} \text { January } \\
2019, \\
\text { Sydney }\end{array}$ & Married & $\begin{array}{l}\text { Was a student in } \\
\text { Sri Lanka. } \\
\text { Works in a } \\
\text { private company } \\
\text { in Austra lia. }\end{array}$ & $\begin{array}{l}\text { Arrived in Australia } \\
\text { in } 2015 \text { as a student. } \\
\text { Expects to becomean } \\
\text { Australian permanent } \\
\text { resident and a citizen. }\end{array}$ & $\begin{array}{l}\text { Currently a Sri } \\
\text { Lankan citizen. She } \\
\text { intends to obtain dual } \\
\text { citizenship when she } \\
\text { becomes an } \\
\text { Australian citizen. }\end{array}$ \\
\hline 17 & $\begin{array}{l}\text { Gopal, } \\
56, \\
\text { Male, } \\
\text { Tamil, Hindu }\end{array}$ & $\begin{array}{l}28^{\text {th }} \text { January } \\
2019 \\
\text { Sydney }\end{array}$ & $\begin{array}{l}\text { Married } \\
\text { with one } \\
\text { child }\end{array}$ & $\begin{array}{l}\text { Was a media } \\
\text { broadcaster in } \\
\text { Sri Lanka and a } \\
\text { producer in } \\
\text { Australia. }\end{array}$ & $\begin{array}{l}\text { Arrived in Australia } \\
\text { in } 2013 \text { as the partner } \\
\text { of a skilled migrant } \\
\text { with perma nent } \\
\text { residency status. } \\
\text { Expecting to obtain } \\
\text { Australian citizen ship } \\
\text { in the future. }\end{array}$ & $\begin{array}{l}\text { A Sri Lankan citizen } \\
\text { currently. When he } \\
\text { obtains Australian } \\
\text { citizenship, he is } \\
\text { intending to obtain } \\
\text { Sri Lankan dual } \\
\text { citizenship. }\end{array}$ \\
\hline 18 & $\begin{array}{l}\text { Nethra, } \\
\text { 33, Female, } \\
\text { Tamil, Hindu }\end{array}$ & $\begin{array}{l}26^{\text {th }} \text { January } \\
2019, \\
\text { Sydney }\end{array}$ & $\begin{array}{l}\text { Not } \\
\text { married }\end{array}$ & $\begin{array}{l}\text { Was a student in } \\
\text { Sri Lanka. } \\
\text { Runs her own } \\
\text { business in } \\
\text { Australia. }\end{array}$ & $\begin{array}{l}\text { Arrived in Australia } \\
\text { in } 2011 \text { as a refugee. } \\
\text { Currently an } \\
\text { Australian citizen. }\end{array}$ & $\begin{array}{l}\text { Not a Sri Lankan } \\
\text { citizen and does not } \\
\text { intend to be a Sri } \\
\text { Lankan dual citizen. }\end{array}$ \\
\hline 19 & $\begin{array}{l}\text { Raj, } \\
\text { 34, } \\
\text { Male, } \\
\text { Tamil, Hindu }\end{array}$ & $\begin{array}{l}24^{\text {th }} \text { January } \\
2019, \\
\text { Sydney }\end{array}$ & Married & $\begin{array}{l}\text { Professional in } \\
\text { both in Sri } \\
\text { Lanka and in } \\
\text { Australia. }\end{array}$ & $\begin{array}{l}\text { Arrived in Australia } \\
\text { in } 2015 \text { as a skilled } \\
\text { migrant with } \\
\text { permanent residency } \\
\text { status. Expecting to } \\
\text { obta in Australian } \\
\text { citizenship in the } \\
\text { future. }\end{array}$ & $\begin{array}{l}\text { Currently a Sri } \\
\text { Lankan citizen. He } \\
\text { intends to obtain dual } \\
\text { citizenship when he } \\
\text { becomes an } \\
\text { Australian citizen. }\end{array}$ \\
\hline 20 & $\begin{array}{l}\text { Niru, } \\
53, \\
\text { Female, } \\
\text { Tamil, Hindu }\end{array}$ & $\begin{array}{l}24^{\text {th }} \text { January } \\
2019, \\
\text { Sydney }\end{array}$ & Married & $\begin{array}{l}\text { Was a teacher in } \\
\text { Sri Lanka and a } \\
\text { government } \\
\text { worker in } \\
\text { Australia. }\end{array}$ & $\begin{array}{l}\text { Arrived in Australia } \\
\text { in } 1995 \text { as a refugee. } \\
\text { Obtained permanent } \\
\text { residency in } 1997 \text { and } \\
\text { later, Austra lian } \\
\text { citizenship. }\end{array}$ & $\begin{array}{l}\text { Not a Sri Lankan dual } \\
\text { citizen but intends to } \\
\text { obta init. }\end{array}$ \\
\hline 21 & $\begin{array}{l}\text { Eranga, } \\
45, \\
\text { Male, } \\
\text { Sinhalese, } \\
\text { Buddhist }\end{array}$ & $\begin{array}{l}25^{\text {th }} \text { January } \\
2019, \\
\text { Sydney }\end{array}$ & $\begin{array}{l}\text { Married } \\
\text { with one } \\
\text { child }\end{array}$ & $\begin{array}{l}\text { Professionalin } \\
\text { both SriLanka } \\
\text { and Australia. }\end{array}$ & $\begin{array}{l}\text { Arrived in Australia } \\
\text { in } 2004 \text { as a skilled } \\
\text { migrant. He obtained } \\
\text { Australian citizen ship } \\
\text { in } 2010 \text {. }\end{array}$ & $\begin{array}{l}\text { Not a Sri Lankan dual } \\
\text { citizen. }\end{array}$ \\
\hline
\end{tabular}




\begin{tabular}{|c|c|c|c|c|c|c|}
\hline 22 & $\begin{array}{l}\text { Anton, } \\
80, \\
\text { Male, } \\
\text { Burgher, } \\
\text { Catholic }\end{array}$ & $\begin{array}{l}24^{\text {th }} \text { January } \\
2019, \\
\text { Sydney }\end{array}$ & $\begin{array}{l}\text { Married } \\
\text { with two } \\
\text { children }\end{array}$ & $\begin{array}{l}\text { Was a student in } \\
\text { Sri Lanka and } \\
\text { then was a } \\
\text { government } \\
\text { officer in } \\
\text { Australia. }\end{array}$ & $\begin{array}{l}\text { Arrived in Australia } \\
\text { in 1963, under the } \\
\text { White Austra lia } \\
\text { policy and became a } \\
\text { citizen in a few years. }\end{array}$ & $\begin{array}{l}\text { Not a Sri Lankan dual } \\
\text { citizen but expects to } \\
\text { obta in dual } \\
\text { citizenship. }\end{array}$ \\
\hline 22 & $\begin{array}{l}\text { Priyantha, } \\
57, \\
\text { Male, } \\
\text { Sinhalese, } \\
\text { Buddhist }\end{array}$ & $\begin{array}{l}27^{\text {th }} \text { January } \\
2019, \\
\text { Sydney }\end{array}$ & Married & $\begin{array}{l}\text { Was a journalist } \\
\text { in Sri Lanka and } \\
\text { now a } \\
\text { government } \\
\text { officialin } \\
\text { Australia. }\end{array}$ & $\begin{array}{l}\text { Arrived in Australia } \\
\text { a s a student in } 1989 . \\
\text { Obtained Australian } \\
\text { citizenship in } 2003 .\end{array}$ & $\begin{array}{l}\text { Obtained SriLankan } \\
\text { dualcitizenship in } \\
2005 .\end{array}$ \\
\hline 24 & $\begin{array}{l}\text { Pathum, } \\
45, \\
\text { Male, } \\
\text { Sinhalese, } \\
\text { Christian }\end{array}$ & $\begin{array}{l}12^{\text {th }} \\
\text { December } \\
2018, \\
\text { Auckland }\end{array}$ & $\begin{array}{l}\text { Married } \\
\text { with } \\
\text { three } \\
\text { children }\end{array}$ & $\begin{array}{l}\text { Was a senior } \\
\text { executive in the } \\
\text { garment } \\
\text { industry in Sri } \\
\text { Lanka. Works in } \\
\text { a shop in New } \\
\text { Zealand. }\end{array}$ & $\begin{array}{l}\text { Arrived in New } \\
\text { Zealand in } 2017 \text { as a } \\
\text { visitor and then } \\
\text { lodged a refugee } \\
\text { application. Heis } \\
\text { now waiting for the } \\
\text { refugee application to } \\
\text { be approved. He } \\
\text { expects to be a New } \\
\text { Zealand citizen. }\end{array}$ & $\begin{array}{l}\text { Currently a Sri } \\
\text { Lankan citizen. } \\
\text { Expecting to obtain } \\
\text { dualcitizenship when } \\
\text { he obtains the New } \\
\text { Zealand citizenship. }\end{array}$ \\
\hline 25 & $\begin{array}{l}\text { Sachini, } \\
\text { 32, Female, } \\
\text { Sinhalese, } \\
\text { Christian }\end{array}$ & $\begin{array}{l}13^{\text {th }} \\
\text { December } \\
2018, \\
\text { Auckland }\end{array}$ & $\begin{array}{l}\text { Married } \\
\text { with one } \\
\text { child }\end{array}$ & $\begin{array}{l}\text { Was a student in } \\
\text { Sri Lanka. Now, } \\
\text { works in a } \\
\text { company in } \\
\text { New Zea land. } \\
\text { Also, runs a } \\
\text { business in Sri } \\
\text { Lanka. }\end{array}$ & $\begin{array}{l}\text { Arrived in New } \\
\text { Zea land in } 2012 \text { as a } \\
\text { student. Currently a } \\
\text { New Zea land } \\
\text { permanent resident. } \\
\text { Expects to become a } \\
\text { citizen. }\end{array}$ & $\begin{array}{l}\text { A Sri Lankan citizen. } \\
\text { She expects to obtain } \\
\text { dual citizenship when } \\
\text { she becomes a New } \\
\text { Zealand citizen. }\end{array}$ \\
\hline 26 & $\begin{array}{l}\text { Kamal, } \\
33, \\
\text { Male, } \\
\text { Sinhalese, } \\
\text { Buddhist }\end{array}$ & $\begin{array}{l}14^{\text {th }} \\
\text { December } \\
2018 \\
\text { Auckland }\end{array}$ & Married & $\begin{array}{l}\text { Was a senior } \\
\text { executive in a } \\
\text { multinational } \\
\text { company in Sri } \\
\text { Lanka. Now, an } \\
\text { accountant } \\
\text { manager in } \\
\text { Auckland. } \\
\end{array}$ & $\begin{array}{l}\text { Arrived in New } \\
\text { Zea land in } 2015 \text { as a } \\
\text { skilled migrant with a } \\
\text { permanent residency } \\
\text { visa. Expecting to } \\
\text { become a New } \\
\text { Zea land citizen. }\end{array}$ & $\begin{array}{l}\text { A Sri Lankan citizen. } \\
\text { Expecting to obtain } \\
\text { dualcitizenship when } \\
\text { he obtains New } \\
\text { Zea land citizenship. }\end{array}$ \\
\hline 27 & $\begin{array}{l}\text { Jayasiri, } \\
68, \\
\text { Male, } \\
\text { Sinhala, } \\
\text { Christian }\end{array}$ & $\begin{array}{l}13^{\text {th }} \\
\text { December } \\
2018, \\
\text { Auckland }\end{array}$ & $\begin{array}{l}\text { Married } \\
\text { with two } \\
\text { children }\end{array}$ & $\begin{array}{l}\text { Was a teacher in } \\
\text { Sri Lanka. } \\
\text { Was a tutor in } \\
\text { New Zealand. }\end{array}$ & $\begin{array}{l}\text { Arrived in New } \\
\text { Zea land in } 1997 \text { as a } \\
\text { skill migra nt and } \\
\text { becamea New } \\
\text { Zea land citizen in } \\
2001 .\end{array}$ & $\begin{array}{l}\text { Obtained SriLankan } \\
\text { dual citizenship in } \\
2001 .\end{array}$ \\
\hline 28 & $\begin{array}{l}\text { Romesh, } \\
31, \\
\text { Male, } \\
\text { Sinhalese, } \\
\text { Christian }\end{array}$ & $\begin{array}{l}14^{\text {th }} \\
\text { December } \\
2018, \\
\text { Auckland }\end{array}$ & $\begin{array}{l}\text { Married } \\
\text { with one } \\
\text { child }\end{array}$ & $\begin{array}{l}\text { Was a } \\
\text { marketing } \\
\text { executive in Sri } \\
\text { Lanka. } \\
\text { Now, works in } \\
\text { the hotel field in } \\
\text { New Zealand }\end{array}$ & $\begin{array}{l}\text { Arrived in New } \\
\text { Zea land in } 2013 \text { as a } \\
\text { student. Currently } \\
\text { holds permanent } \\
\text { residency status and } \\
\text { is expecting to } \\
\text { become a New } \\
\text { Zealand citizen soon. }\end{array}$ & $\begin{array}{l}\text { Currently a Sri } \\
\text { Lankan citizen. }\end{array}$ \\
\hline 29 & $\begin{array}{l}\text { Praveena, } \\
\text { 29, Female, } \\
\text { Sinhalese, } \\
\text { Buddhist } \\
\end{array}$ & $\begin{array}{l}13^{\text {th }} \\
\text { December } \\
2018, \\
\text { Auckland }\end{array}$ & $\begin{array}{l}\text { Not } \\
\text { married }\end{array}$ & $\begin{array}{l}\text { Was a student in } \\
\text { Sri Lanka. }\end{array}$ & $\begin{array}{l}\text { Arrived in New } \\
\text { Zea land in } 2014 \text { and } \\
\text { currently a permanent } \\
\text { resident. }\end{array}$ & $\begin{array}{l}\text { A Sri Lankan citizen. } \\
\text { She intends to obtain } \\
\text { dualcitizenship when }\end{array}$ \\
\hline
\end{tabular}




\begin{tabular}{|c|c|c|c|c|c|c|}
\hline & & & & $\begin{array}{l}\text { Works in a } \\
\text { company in } \\
\text { New Zea land. }\end{array}$ & & $\begin{array}{l}\text { she becomes a New } \\
\text { Zea land citizen. }\end{array}$ \\
\hline 30 & $\begin{array}{l}\text { Saranya, } \\
\text { 50, Female, } \\
\text { Tamil, Hindu }\end{array}$ & $\begin{array}{l}15^{\text {th }} \\
\text { December } \\
2018, \\
\text { Auckland }\end{array}$ & $\begin{array}{l}\text { Married } \\
\text { with two } \\
\text { children }\end{array}$ & $\begin{array}{l}\text { Didn't work in } \\
\text { Sri Lanka (was } \\
\text { a house wife). } \\
\text { Now, works in a } \\
\text { shop in New } \\
\text { Zea land. }\end{array}$ & $\begin{array}{l}\text { Arrived in New } \\
\text { Zealand in } 2008 \text { and } \\
\text { claimed refugee } \\
\text { status. She became a } \\
\text { permanent resident in } \\
\text { New Zea land in } 2013 \\
\text { and a citizen in } 2015 .\end{array}$ & $\begin{array}{l}\text { Not a Sri Lankan } \\
\text { citizen. She expects } \\
\text { to become a Sri } \\
\text { Lankan dual citizen. }\end{array}$ \\
\hline 31 & $\begin{array}{l}\text { Dulanka, } \\
26, \\
\text { Male, } \\
\text { Sinhalese, } \\
\text { Buddhist }\end{array}$ & $\begin{array}{l}13^{\text {th }} \\
\text { December } \\
2018 \\
\text { Auckland }\end{array}$ & $\begin{array}{l}\text { Not } \\
\text { married }\end{array}$ & $\begin{array}{l}\text { Was a student in } \\
\text { Sri Lanka and } \\
\text { now, works as a } \\
\text { supervisor in a } \\
\text { supermarket } \\
\text { chain in New } \\
\text { Zealand. }\end{array}$ & $\begin{array}{l}\text { Arrived in New } \\
\text { Zea land in } 2015 \text { as a } \\
\text { student. Since his } \\
\text { mother got New } \\
\text { Zea land citizenship, } \\
\text { she a ssisted Dulanka } \\
\text { to become a } \\
\text { permanent resident. } \\
\text { He is expecting to } \\
\text { become a New } \\
\text { Zea land citizen. }\end{array}$ & $\begin{array}{l}\text { A Sri Lankan citizen. } \\
\text { Expecting to obtain } \\
\text { dual citizenship when } \\
\text { he obtains New } \\
\text { Zea land citizenship. }\end{array}$ \\
\hline 32 & $\begin{array}{l}\text { Saman, } \\
29, \\
\text { Male, } \\
\text { Sinhalese, } \\
\text { Buddhist }\end{array}$ & $\begin{array}{l}13^{\text {th }} \\
\text { December } \\
2018 \\
\text { Auckland }\end{array}$ & $\begin{array}{l}\text { Not } \\
\text { married }\end{array}$ & $\begin{array}{l}\text { Was a student in } \\
\text { Sri Lanka. } \\
\text { Works in a } \\
\text { company in } \\
\text { New Zea land. }\end{array}$ & $\begin{array}{l}\text { Arrived in New } \\
\text { Zea land in } 2010 \text { a nd } \\
\text { currently a pemanent } \\
\text { resident. Expects to } \\
\text { become a New } \\
\text { Zea land citizen. }\end{array}$ & A Sri Lankan citizen. \\
\hline 33 & $\begin{array}{l}\text { Nipun, } \\
42, \\
\text { Male, } \\
\text { Sinhalese, } \\
\text { Buddhist }\end{array}$ & $\begin{array}{l}16^{\text {th }} \\
\text { December } \\
2018, \\
\text { Auckland }\end{array}$ & $\begin{array}{l}\text { Married } \\
\text { with one } \\
\text { child }\end{array}$ & $\begin{array}{l}\text { Was a junior } \\
\text { executive in Sri } \\
\text { Lanka. } \\
\text { Currently an IT } \\
\text { manager in New } \\
\text { Zea land. }\end{array}$ & $\begin{array}{l}\text { Arrived in New } \\
\text { Zea land in } 2012 \text { as a } \\
\text { student. Obtained } \\
\text { permanent residency } \\
\text { status in } 2015 \text { and } \\
\text { citizenship in } 2018 .\end{array}$ & $\begin{array}{l}\text { Does not want to } \\
\text { retain Sri La nkan } \\
\text { dual citizen ship. }\end{array}$ \\
\hline 34 & $\begin{array}{l}\text { Wimal, } \\
46, \\
\text { Male, } \\
\text { Sinhalese, } \\
\text { Buddhist }\end{array}$ & $\begin{array}{l}16^{\text {th }} \\
\text { December } \\
2018, \\
\text { Auckland }\end{array}$ & $\begin{array}{l}\text { Married } \\
\text { with two } \\
\text { children }\end{array}$ & $\begin{array}{l}\text { Was an a ssistant } \\
\text { ex ecutive in Sri } \\
\text { Lanka. } \\
\text { Owns a car sale } \\
\text { in New Zea land. }\end{array}$ & $\begin{array}{l}\text { Arrived in New } \\
\text { Zea land a s a student } \\
\text { in } 2011 . \text { Now a New } \\
\text { Zea land citizen. }\end{array}$ & $\begin{array}{l}\text { Does not want to } \\
\text { retain the SriLa nkan } \\
\text { dualcitizenship. }\end{array}$ \\
\hline 35 & $\begin{array}{l}\text { Nimesha, } \\
28, \\
\text { Female, } \\
\text { Sinhalese, } \\
\text { Buddhist }\end{array}$ & $\begin{array}{l}17^{\text {th }} \\
\text { December } \\
2018 . \\
\text { Auckland }\end{array}$ & Married & $\begin{array}{l}\text { Was a model in } \\
\text { Sri Lanka. } \\
\text { Does some odd } \\
\text { jobs in New } \\
\text { Zealand. }\end{array}$ & $\begin{array}{l}\text { Arrived in New } \\
\text { Zea land in } 2018 \text { on a } \\
\text { visitor's visa to join } \\
\text { her husband. She } \\
\text { intends to obtain New } \\
\text { Zea land citizenship. }\end{array}$ & $\begin{array}{l}\text { A Sri Lankan citizen. } \\
\text { Expecting to obtain } \\
\text { dual citizenship when } \\
\text { she obtains New } \\
\text { Zea land citizenship. }\end{array}$ \\
\hline 36 & $\begin{array}{l}\text { Rajika, } \\
31, \\
\text { Male, } \\
\text { Sinhalese, } \\
\text { Buddhist }\end{array}$ & $\begin{array}{l}18^{\text {th }} \\
\text { December } \\
2018, \\
\text { Auckland }\end{array}$ & $\begin{array}{l}\text { Married } \\
\text { and have } \\
\text { a child }\end{array}$ & $\begin{array}{l}\text { Was a student in } \\
\text { Sri Lanka. } \\
\text { Works in the } \\
\text { hotelfield in } \\
\text { New Zealand. }\end{array}$ & $\begin{array}{l}\text { Arrived in New } \\
\text { Zea land in } 2009 . \\
\text { Obtained permanent } \\
\text { residency status in } \\
2011 \text { and citizenship } \\
\text { in } 2013 \text {. }\end{array}$ & $\begin{array}{l}\text { A Sri Lankan dual } \\
\text { citizen. }\end{array}$ \\
\hline 37 & $\begin{array}{l}\text { Krishani, } \\
32, \\
\text { Female, } \\
\text { Sinhalese, } \\
\text { Buddhist }\end{array}$ & $\begin{array}{l}16^{\text {th }} \\
\text { December } \\
2018, \\
\text { Auckland }\end{array}$ & Married & $\begin{array}{l}\text { Was a manager } \\
\text { in Sri Lanka. } \\
\text { A studentin } \\
\text { New Zealand. }\end{array}$ & $\begin{array}{l}\text { Arrived in New } \\
\text { Zea land in } 2017 \text { as a } \\
\text { student. Expects to } \\
\text { obtain permanent } \\
\text { residency status and }\end{array}$ & A Sri Lankan citizen. \\
\hline
\end{tabular}




\begin{tabular}{|c|c|c|c|c|c|c|}
\hline & & & & & $\begin{array}{l}\text { citizenship in New } \\
\text { Zealand. }\end{array}$ & \\
\hline 38 & $\begin{array}{l}\text { Tharaka, } \\
45, \\
\text { Male, } \\
\text { Sinhalese, } \\
\text { Buddhist }\end{array}$ & $\begin{array}{l}18^{\text {th }} \\
\text { December } \\
2018, \\
\text { Auckland }\end{array}$ & $\begin{array}{l}\text { Married } \\
\text { with } \\
\text { three } \\
\text { children }\end{array}$ & $\begin{array}{l}\text { Was a personal } \\
\text { security officer } \\
\text { for a minister in } \\
\text { Sri Lanka. Does } \\
\text { some odd jobs } \\
\text { in New Zealand }\end{array}$ & $\begin{array}{l}\text { Arrived in New } \\
\text { Zea land in } 2016 \text { as a } \\
\text { visitor and claimed } \\
\text { refugee status. } \\
\text { Currently he is } \\
\text { waiting for his } \\
\text { refugee application to } \\
\text { be approved. He } \\
\text { intends to obtain } \\
\text { permanent residency } \\
\text { sta tus and citizenship } \\
\text { in New Zea land in } \\
\text { the future. }\end{array}$ & A Sri Lankan citizen. \\
\hline 39 & $\begin{array}{l}\text { Nilmini, } \\
55, \\
\text { Female, } \\
\text { Sinhalese, } \\
\text { Buddhist }\end{array}$ & $\begin{array}{l}09^{\text {th }} \text { October } \\
2018 \text {, } \\
\text { Wellington }\end{array}$ & $\begin{array}{l}\text { Married } \\
\text { with two } \\
\text { children }\end{array}$ & $\begin{array}{l}\text { Worked at a } \\
\text { private company } \\
\text { in Sri Lanka. } \\
\text { Works a a } \\
\text { government } \\
\text { officialin New } \\
\text { Zealand. }\end{array}$ & $\begin{array}{l}\text { Arrived in New } \\
\text { Zealand in } 1995 \text { and } \\
\text { currently a New } \\
\text { Zealand citizen. }\end{array}$ & $\begin{array}{l}\text { Not a Sri Lankan dual } \\
\text { citizen but intends to } \\
\text { obta in dual } \\
\text { citizenship }\end{array}$ \\
\hline 40 & $\begin{array}{l}\text { Viru, } \\
48, \\
\text { Male, } \\
\text { Tamil, } \\
\text { Hindu }\end{array}$ & $\begin{array}{l}10^{\text {th }} \text { October } \\
2018, \\
\text { Wellington }\end{array}$ & $\begin{array}{l}\text { Married } \\
\text { with two } \\
\text { children }\end{array}$ & $\begin{array}{l}\text { Worked as an } \\
\text { account in Sri } \\
\text { Lanka and now } \\
\text { in New Zealand. }\end{array}$ & $\begin{array}{l}\text { Arrived in New } \\
\text { Zea land in } 2001 \text { as a } \\
\text { student a nd became a } \\
\text { citizen in } 2008 \text {. }\end{array}$ & $\begin{array}{l}\text { Not a Sri Lankan dual } \\
\text { citizen but intends to } \\
\text { obta in dual } \\
\text { citizenship }\end{array}$ \\
\hline 41 & $\begin{array}{l}\text { Anusha, } \\
45, \\
\text { Female, } \\
\text { Sinhalese, } \\
\text { Buddhist }\end{array}$ & $\begin{array}{l}11^{\text {th }} \text { October } \\
2018, \\
\text { Wellington }\end{array}$ & $\begin{array}{l}\text { Married } \\
\text { with one } \\
\text { child }\end{array}$ & $\begin{array}{l}\text { Professional in } \\
\text { both SriLanka } \\
\text { and New } \\
\text { Zealand. }\end{array}$ & $\begin{array}{l}\text { Arrived in New } \\
\text { Zealand in } 2002 \text { as a } \\
\text { skilled migrant. } \\
\text { Obtained New } \\
\text { Zea land citizenship in } \\
2009 .\end{array}$ & $\begin{array}{l}\text { A Sri Lankan dual } \\
\text { citizen. }\end{array}$ \\
\hline 42 & $\begin{array}{l}\text { Kithsiri, } \\
\text { 55, } \\
\text { Male, } \\
\text { Sinhalese, } \\
\text { Buddhist }\end{array}$ & $\begin{array}{l}23^{\text {rd }} \text { October } \\
2018, \\
\text { Wellington }\end{array}$ & $\begin{array}{l}\text { Married } \\
\text { with two } \\
\text { children }\end{array}$ & $\begin{array}{l}\text { Professional in } \\
\text { both Sri Lanka } \\
\text { and New } \\
\text { Zealand. }\end{array}$ & $\begin{array}{l}\text { Arrived in New } \\
\text { Zealand in } 1998 \text { as a } \\
\text { skilled migrant. Now } \\
\text { a New Zealand } \\
\text { citizen. }\end{array}$ & $\begin{array}{l}\text { Not a Sri Lankan dual } \\
\text { citizen. }\end{array}$ \\
\hline 43 & $\begin{array}{l}\text { Sarath, } \\
\text { 58, } \\
\text { Male, } \\
\text { Sinhalese, } \\
\text { Buddhist }\end{array}$ & $\begin{array}{l}08^{\text {th }} \\
\text { January } \\
2019, \\
\text { Wellington }\end{array}$ & $\begin{array}{l}\text { Married } \\
\text { with two } \\
\text { children }\end{array}$ & $\begin{array}{l}\text { Professional in } \\
\text { both Sri Lanka } \\
\text { and New } \\
\text { Zealand. }\end{array}$ & $\begin{array}{l}\text { Arrived in New } \\
\text { Zealand in } 1987 \text { as a } \\
\text { skilled migrant. He } \\
\text { obtained permanent } \\
\text { residency status in } \\
1989 \text { and citizenship } \\
\text { in } 1999 .\end{array}$ & $\begin{array}{l}\text { Not a Sri Lankan dual } \\
\text { citizen. }\end{array}$ \\
\hline 44 & $\begin{array}{l}\text { Malathi, } \\
40, \\
\text { Female, } \\
\text { Sinhalese, } \\
\text { Buddhist }\end{array}$ & $\begin{array}{l}07^{\text {th }} \text { October } \\
2018, \\
\text { Wellington }\end{array}$ & $\begin{array}{l}\text { Not } \\
\text { married }\end{array}$ & $\begin{array}{l}\text { Was a } \\
\text { government } \\
\text { officer in Sri } \\
\text { Lanka. } \\
\text { Works at a } \\
\text { private company } \\
\text { and a s music } \\
\text { teacher in New } \\
\text { Zea land. }\end{array}$ & $\begin{array}{l}\text { Arrived in New } \\
\text { Zea land in } 2014 \text { as a } \\
\text { student. She is } \\
\text { expecting to become } \\
\text { a permanent resident } \\
\text { and then a citizen in } \\
\text { New Zea land. }\end{array}$ & $\begin{array}{l}\text { She is currently a Sri } \\
\text { Lankan citizen. } \\
\text { Expecting to obtain } \\
\text { Sri Lankan dual } \\
\text { citizenship when she } \\
\text { obta ins New Zea land } \\
\text { citizenship. }\end{array}$ \\
\hline
\end{tabular}




\begin{tabular}{|c|c|c|c|c|c|c|}
\hline 45 & $\begin{array}{l}\text { Supun, } \\
33, \\
\text { Male, } \\
\text { Sinhalese, } \\
\text { Buddhist }\end{array}$ & $\begin{array}{l}04^{\text {th }} \\
\text { November } \\
2018, \\
\text { Wellington }\end{array}$ & Married & $\begin{array}{l}\text { A professional } \\
\text { in both Sri } \\
\text { Lanka and New } \\
\text { Zealand. }\end{array}$ & $\begin{array}{l}\text { Arrived in New } \\
\text { Zea land in } 2014 \text { as a } \\
\text { student a nd currently } \\
\text { a New Zea land } \\
\text { permanent resident. } \\
\text { Expecting to be a } \\
\text { New Zea land citizen. }\end{array}$ & $\begin{array}{l}\text { Currently a Sri } \\
\text { Lankan citizen. } \\
\text { Expecting to obtain } \\
\text { Sri Lankan dual } \\
\text { citizenship when he } \\
\text { obta ins NewZealand } \\
\text { citizenship. }\end{array}$ \\
\hline 46 & $\begin{array}{l}\text { Dinesh, } \\
50, \\
\text { Male, } \\
\text { Sinhalese, } \\
\text { Buddhist }\end{array}$ & $\begin{array}{l}20^{\text {th }} \text { October } \\
2018, \\
\text { Wellington }\end{array}$ & $\begin{array}{l}\text { Married } \\
\text { with } \\
\text { three } \\
\text { children }\end{array}$ & $\begin{array}{l}\text { Chef in Sri } \\
\text { Lanka and New } \\
\text { Zealand. }\end{array}$ & $\begin{array}{l}\text { Arrived in New } \\
\text { Zealand in } 2010 \text { as a } \\
\text { skilled migrant. He } \\
\text { obtained New } \\
\text { Zea land citizen ship in } \\
2017 .\end{array}$ & $\begin{array}{l}\text { Not a Sri Lankan dual } \\
\text { citizen but expects to } \\
\text { obta in dual } \\
\text { citizenship. }\end{array}$ \\
\hline 47 & $\begin{array}{l}\text { Priyadarshani, } \\
42, \\
\text { Female, } \\
\text { Sinhala, } \\
\text { Buddhist }\end{array}$ & $\begin{array}{l}03^{\text {rd }} \text { October } \\
2018, \\
\text { Wellington }\end{array}$ & Married & $\begin{array}{l}\text { General } \\
\text { Manager in the } \\
\text { IT field in Sri } \\
\text { Lanka. } \\
\text { IT professional } \\
\text { in New Zealand. }\end{array}$ & $\begin{array}{l}\text { Arrived in New } \\
\text { Zea land in } 2011 \text { as a } \\
\text { visitor, found a job } \\
\text { and shifted from } \\
\text { visitor to a work visa. } \\
\text { She is currently a } \\
\text { New Zealand } \\
\text { permanent resident. } \\
\text { She does not intend } \\
\text { to become a New } \\
\text { Zea land citizen. }\end{array}$ & $\begin{array}{l}\text { A Sri Lankan citizen. } \\
\text { She does not want to } \\
\text { lose it. }\end{array}$ \\
\hline 48 & $\begin{array}{l}\text { Thiru, } \\
50, \\
\text { Male, } \\
\text { Tamil, Hindu }\end{array}$ & $\begin{array}{l}25^{\text {th }} \text { October } \\
2018, \\
\text { Wellington }\end{array}$ & $\begin{array}{l}\text { Married } \\
\text { with } \\
\text { three } \\
\text { children }\end{array}$ & $\begin{array}{l}\text { Worked as a } \\
\text { driver in Sri } \\
\text { Lanka. } \\
\text { Works in a } \\
\text { supermarket in } \\
\text { New Zea land. }\end{array}$ & $\begin{array}{l}\text { Arrived in New } \\
\text { Zea land in } 2012 \text {, after } \\
\text { his refugee } \\
\text { a pplication was } \\
\text { accepted by the } \\
\text { government. } \\
\text { Currently a New } \\
\text { Zealand citizen. }\end{array}$ & $\begin{array}{l}\text { Not a Sri Lankan dual } \\
\text { citizen. }\end{array}$ \\
\hline 49 & $\begin{array}{l}\text { Shiva, } \\
70, \\
\text { Male } \\
\text { Tamil, } \\
\text { Hindu }\end{array}$ & $\begin{array}{l}04^{\text {th }} \text { October } \\
2018, \\
\text { Wellington }\end{array}$ & $\begin{array}{l}\text { Married } \\
\text { with two } \\
\text { children }\end{array}$ & $\begin{array}{l}\text { Was an } \\
\text { Engineer in Sri } \\
\text { Lanka. He could } \\
\text { not find a job } \\
\text { that matches his } \\
\text { qualifications in } \\
\text { New Zealand. } \\
\text { So, he worked } \\
\text { in Singapore for } \\
\text { more than ten } \\
\text { years, while his } \\
\text { family lived in } \\
\text { New Zealand. }\end{array}$ & $\begin{array}{l}\text { Arrived in New } \\
\text { Zea land in } 1993 \text { as a } \\
\text { skill migra nt. He } \\
\text { obta ined New } \\
\text { Zea land citizenship in } \\
2015 \text {. }\end{array}$ & $\begin{array}{l}\text { Currently is not a Sri } \\
\text { Lankan citizen, but } \\
\text { intends to obtain dual } \\
\text { citizenship. }\end{array}$ \\
\hline
\end{tabular}




\section{Appendix B: Participant information sheet}

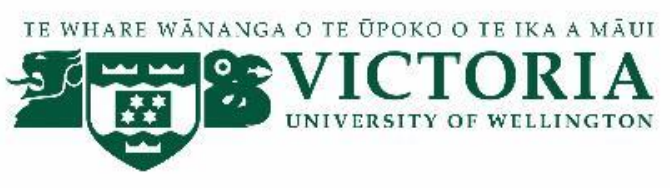

\section{Where to Belong and Why?: Sri Lankan immigrants'views of Sri Lankan, New Zealand and Australian citizenship}

\section{INFORMATION SHEET FOR PARTICIPANTS IN INTERVIEWS}

You are invited to take part in this research. Please read this information before deciding whether or not to take part. If you decide to participate, thank you. If you decide not to participate, thank you for considering this request.

\section{Who am I?}

My name is Pavithra Jayawardena and I am a doctoral student in the political science programme at Victoria University of Wellington. This research project is work towards my $\mathrm{PhD}$ thesis.

\section{What is the aim of the project?}

This project explores migrants' views about citizenship. In particular, this project attempts to find the factors that affect migrants' views about citizenship in their home country and their host country. As the case, Sri Lankan immigrants in New Zealand and Australia are studied.

This research has been approved by the Victoria University of Wellington Human Ethics Committee [Reference number: 26461].

\section{How can you help?}

You have been invited to participate because you are a Sri Lankan immigrant and a permanent resident or a citizen in New Zealand or Australia. If you agree to take part, I will interview you in either Auckland, Wellington, Melbourne or Sydney. The location of the interview will be a calm and a quiet place such as a café, restaurant, park or any private space such as your home, at your convenience. I will ask you questions about how you view citizenship in Sri Lanka and in New Zealand or Australia and about the factors that have influenced your view. The interview will take 20 to 30 minutes. I will audio record the interview with your permission and write it up later. The interviews will take place between 01st November, 2018 to $31^{\text {st }}$ March, 2019. You can choose to not answer 
any question or stop the interview at any time, without giving a reason. You can withdraw from the study by contacting me at any time before $31^{\text {st }}$ October, 2018. If you withdraw, the information you provided will be destroyed or returned to you.

\section{What will happen to the information you give?}

This research is confidential. This means that the researchers named below will be aware of your identity but the research data will be combined and your identity will not be revealed in any reports, presentations, or public documentation.

Only my supervisors (primary supervisor-Dr. Kate McMillan, secondary supervisor-Dr. Ayca Arkilic) and I will read the notes or transcript of the interview. The interview transcript, summaries and any recordings will be kept securely and destroyed on $30^{\text {th }}$ September, 2021.

\section{What will the project produce?}

The information from my research will be used in my $\mathrm{PhD}$ thesis, academic publications and conference presentations.

\section{If you accept this invitation, what are your rights as a research participant?}

You do not have to accept this invitation if you don't want to. If you do decide to participate, you have the right to:

- $\quad$ choose not to answer any question;

- $\quad$ ask for the recorder to be turned off at any time during the interview;

- $\quad$ withdraw from the study before $31^{\text {st }}$ October, 2018;

- $\quad$ ask any questions about the study at any time;

- $\quad$ receive a copy of your interview transcript;

- be able to read any reports of this research by emailing the researcher to request a copy.

If you have any questions or problems, who can you contact?

If you have any questions, either now or in the future, please feel free to contact either me or my supervisor:

\section{Student:}

Name: Pavithra Jayawardena

University email address:

Pavithra.Jayawardena@vuw.ac.nz

\section{Human Ethics Committee information}

If you have any concerns about the ethical conduct of the research you may contact the

Victoria University HEC Convenor: Dr Judith Loveridge. Contact details indicated in the original thesis are redacted in this version.
Supervisor:

Name: Dr. Kate McMillan

Role: Primary supervisor

School: History, Philosophy, Political

Science and International Relations

Contact details indicated in the original thesis are redacted in this version. 


\section{Appendix C: Participant consent form}

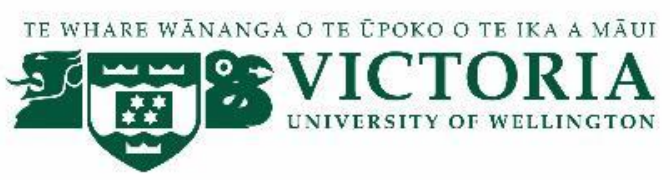

\section{Where to Belong and Why?: Sri Lankan immigrants'views of Sri Lankan, New Zealand and Australian citizenship}

\section{CONSENT TO INTERVIEW}

This consent form will be held for 5 years.

Researcher: Pavithra Jayawardena, School of History, Philosophy, Political Science and International Relations, Victoria University of Wellington.

- I have read the Information Sheet and the project has been explained to me. My questions have been answered to my satisfaction. I understand that I can ask further questions at any time.

- I agree to take part in an audio recorded interview.

I understand that:

- I may withdraw from this study at any point before $31^{\text {st }}$ October, 2018, and any information that I have provided will be returned to me or destroyed.

- The identifiable information I have provided will be destroyed on $31^{\text {st }}$ March,2020.

- Any information I provide will be kept confidential to the researcher and the supervisors.

- $\quad$ I understand that the results will be used for a $\mathrm{PhD}$ thesis, for academic publications and for conference presentations.

- My name will not be used in reports, nor will any information that would identify me.

- I will have the opportunity to receive and comment on the transcription of the interview.

- I would like to receive a copy of the final report and have added my email address below.

Signature of participant:

Name of participant:

Date:

Contact details: 


\section{Appendix D: Sample interview questions}

1. What does it mean to be an Australian or a New Zealand citizen? Do you feel you are a part of Australian or New Zealand society now? Do you think you are loyal to your host country?

2. What factors motivated your decision of becoming a New Zealand or an Australian citizen? Socio-economic, political and cultural reasons? To get the passport? To get voting rights? To get job opportunities? What do you know about your rights and duties as an Australian or a New Zealand citizen?

3. Do you vote in your host society? If yes, why? If no, why?

4. For participants from Australia: What do you think about the Australian citizenship test?

5. For participants from New Zealand: Do you think, New Zealand too should introduce a citizenship test similarly to Australia?

6. What does it mean to be a Sri Lankan dual citizen? Are you a Sri Lankan citizen? What do you know about your rights and duties as a Sri Lankan dual citizen?

7. What factors motivated your decisions of becoming or not becoming a Sri Lankan dual citizen? Socio-economic, political and cultural reasons? To visit your family in Sri Lanka? To own or maintain your property? Any other reason?

8. Are you engaged in Sri Lankan events in New Zealand? If yes, why? If no, why? What do you think about Sri Lankan emigrant groups in your host country?

9. Do you think Sri Lankan government should let Sri Lankan dual citizens vote in national elections? If yes, why? If no, why?

10. How far you are updated about what is happening in your home and host country? Do you keep contact with your home country? What mediums your use? How often? 